\title{
Secondary metabolite biosynthesis during vegetative incompatibility in Cryphonectria parasitica, causal agent of the American chestnut blight
}

\author{
by
}

Thomas Witte

\begin{abstract}
A thesis submitted to the Faculty of Graduate and Postdoctoral Affairs in partial fulfillment of the requirements for the degree of

Master of Science

in

Biology
\end{abstract}

Carleton University

Ottawa, Ontario

(C) 2019, Thomas Witte 


\section{ABSTRACT}

Vegetative Incompatibility (VI) can occur when filamentous fungi fuse during the asexual (mitotic) growth phase. In Cryphonectria parasitica, VI is modulated by six vic loci; hyphal fusion between strains that differ at one or more vic loci results in cell death. VI is considered an immune-like response that restricts heterokaryon formation and transmission of deleterious cytoplasmic elements through unknown mechanisms. A transcriptomic analysis of vic3associated incompatibility identified a set of differentially expressed genes within biosynthetic gene clusters (BGCs). Using UPLC-HRMS, we detected significant shifts in secondary metabolite production during vic3 incompatibility. Among these metabolites, HPLC purification and NMR structure elucidation revealed that a new variant of calbistrin is linked to VIupregulated BGCs, as is a farnesyl-S-oxide analog resembling mating pheromones. Similarly, detection of putative lysophosphatidylcholines and other modified lipids implicates membrane alteration during VI. Together, these findings suggest VI involves synthesis of novel secondary metabolites and complex membrane-associated signaling. 


\section{ACKNOWLEDGEMENTS}

Personal Acknowledgements: The biggest THANK YOU goes to Alison Slater, who listened to many long-winded explanations of nonself recognition systems in fungi and, importantly, remained my partner afterwards.

This type of project is multidisciplinary and involves many people whose contributions range from technical advice to idea sounding. I humbly thank Anne Hermans, Amanda Sproule, Dr. Keith Seifert, Emma Micalizzi, Shravan Raghu, Chanchal Yadav, Dr. Barbara Blackwell and Dr. Linda Harris.

Many heartfelt thanks go to Dr. Myron Smith and Dr. David Overy for always having their doors open, and for their deep insight into life, writing and the pursuit of science.

And lastly to my unendingly supportive parents Veronica Scott and Michael Jansson, to my late grandma Trinita Scott, and to my dad, Jim Witte, I say thank you for life! 


\section{Author contributions:}

Amanda Sproule ran all metabolomics samples on the UPLC-HRMS at AAFC, Ottawa, ON.

Sam Shields ran NMR experiments on calbistrin P on the Bruker $500 \mathrm{MHz}$ spectrometer at the AAFC, Ottawa, ON and guided interpretation of spectra.

Dr. Chris Boddy, Michael Darnowski and Graham Heberlig ran NMR experiments on calbistrin $\mathrm{O}$ and the farnesyl S-oxide (3) on a Bruker 600MHz NMR spectrometer at the University of Ottawa, and solved the structure of the farnesyl S-oxide.

Anatoly Belov assisted with interpretation of transcriptomic data derived from his doctoral thesis ( $\mathrm{PhD})$. 


\section{TABLE OF CONTENTS}

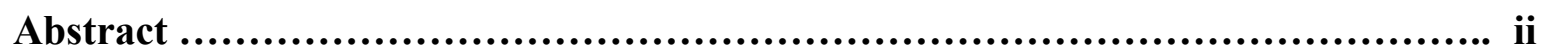

Acknowledgements ................................................................. iii

Author Contributions.................................................................. iv

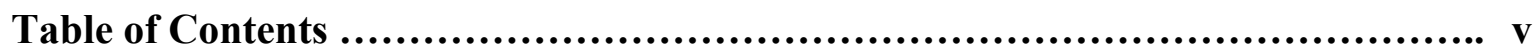

List of Tables ..................................................................... vii

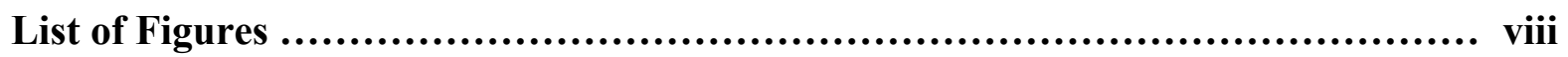

List of Appendices ..................................................................... ix

Chapter 1: Introduction ............................................................... 1

Chapter 2: Materials and Methods ................................................... 7

$2.1 \quad$ Strain Selection.......................................................... 7

$2.2 \quad$ Experimental Design................................................ 7

2.3 Extraction and UPLC-HRMS Analysis................................ 8

$2.4 \quad$ Data Processing ........................................................ 9

2.5 Signal Annotations and Structure Prediction.......................... 11

2.6 Compound Purification................................................ 11

2.7 NMR and Structure Elucidation..................................... 12

$2.8 \quad$ Biosynthetic Gene Cluster Prediction............................... 12

$2.9 \quad$ Biological Assays...................................................... 13

Chapter 3: Results and Discussion................................................. 14

3.1 Metabolomic Analyses............................................... 14

3.1.1 Results of Statistical Analyses................................... 14

3.1.2 Timing of Feature Detection.................................... 15

3.2 Secondary Metabolite Biosynthetic Gene Clusters Associated with vic3 VI...................................................... 15

3.3 Metabolite Annotation............................................ 17

3.4 Calbistrins and Calbistrin Precursors................................... 22

3.4.1 Calbistrin Isolation and Structure Elucidation .................. 22

3.4.2 Upregulation of BGC With Homology to Known Calbistrin / Decumbenone BGC in Penicillium decumbens.................. 25

3.4.3 Calbistrin is Structurally Similar to Statins and May Help Regulate Fungal Growth and Lipoprotein Signaling........... $\quad 26$

3.5 Farnesyl S-Oxide Analogs.......................................... 32

3.5.1 Identification of Two Farnesyl S-Oxide Analogs................ 32 
3.5.2 Farnesyl S-Oxide as a Byproduct of Mating Pheromone Processing During VI .................................. 32

3.6 Lysophosphatidylcholines and Lipid Disaccharides.................. 37

3.6.1 Detection of Putative Lysophosphatidylcholines Suggests

Membrane Lipid Modification During VI................... 37

3.6.2 Predicted Lipid Disaccharides Peak on Day Six After Co-Inoculation............................................. 38

$3.7 \quad$ Curvupallide................................................ 40

3.7.1 A Putative BGC with Similarity to Curvupallide is Upregulated During VI............................................. 40

3.7.2 Curvupallide Cluster Accessory Genes Bear Resemblance to Other Genes Implicated in VI............................. 42

3.8 Skyrins and Other Bisanthraquinones............................. 44

3.8.1 Skyrins and Rugulosins are Potent Bioactive Molecules Produced by $C$. parasitica.................................... 44

3.8.2 Two Predicted BGCs Show Homology to Emodin / Skyrin BGC In A. nidulans ........................................... 46

Chapter 4: Conclusions 


\section{List of Tables}

Table 1. Summary of characterized vegetative incompatibility genes............... 5

Table 2. Summary of predicted biosynthetic gene cluster diversity in C. parasitica EP155 genome compared to biosynthetic genes found to be differentially

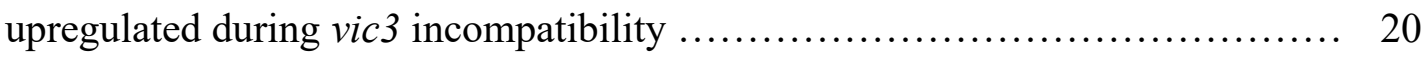

Table 3. Putative proteins within predicted calbistrin gene cluster in $C$. parasitica....... 28

Table 4. Putative proteins within predicted curvupallide gene cluster in C. parasitica.... 43

Table 5. Experimentally detected (putative) bisanthraquinone retention times, $\mathrm{m} / \mathrm{z}$ and UV absorbance maxima.................................................. 45

Table 6. Putative proteins within two putative biosynthetic gene clusters surrounding PKS1 and PKS10 in C. parasitica showing blastp homology to monodictyphenone cluster from $A$. nidulans ................................................... 47 


\section{List of Figures}

Figure 1. Principal component analysis (PCA) of agar sample data............... 16

Figure 2. Principal component analysis (PCA) of mycelium sample data ........... 17

Figure 3. Significant features in pairwise comparisons between vic3 incompatible strains ('VI') and monocultures EP155 ('E') and P74-3('P')................. 18

Figure 4. Heatmap visualization of representatives from correlated signal groups significant to VI along full time course (days 2 to 8 )...................... 19

Figure 5. Structures of VI-associated compounds ............................ 21

Figure 6. A: Calbistrin P COSY correlations (bold lines) and HMBC correlations (arrows)

B: NOESY correlations (arrows) for calbistrin P decalin moiety............. 23

Figure 7. A: Gene synteny of putative decumbenone gene clusters in C. parasitica and P. decumbens. B: Differential gene expression from vic3 VI transcriptomes...... 27

Figure 8. Farnesyl S-oxide (3) COSY (bold lines) and HMBC correlations (arrows).... 33

Figure 9. A: Gene cluster synteny analysis between a VI-associated cluster in C. parasitica and the curvupallide biosynthesis cluster described from ascomycete Curvullaria pallescens. B: Differential expression of genes in the putative curvupallide BGC.. 41

Figure 10. Experimentally derived UV chromophore of putative skyrin, corresponding to variable RT5.6_539.08933 ........................................ 46 


\section{List of Appendices}

Appendix A: Time course visualizations............................ 52

Appendix B: NMR tables....................................... 54

Appendix C: $\mathrm{MS}^{2}$ fragmentation patterns............................... 56

Appendix D: Multivariate analyses................................ 58

Appendix E: NMR data.......................................... 60

Subappendix E.1: Calbistrin P Data.............................. 60

Subappendix E.2: Calbistrin O Data............................ 64

Subappendix E.3: Farnesyl S-Oxide Data........................ 67

Appendix F: R code used for Pearson correlation analysis................ 71 


\subsection{INTRODUCTION}

Recognition of non-self at a cellular level is an essential function of all living organisms and shapes the concept of the immune system (Medzhitov et al., 2002). Among filamentous ascomycete fungi, the concept of 'self' is nuanced by their ability to anastomose or fuse cells, a process which is developmentally regulated during 'vegetative' growth (Simonin et al., 2012), and which can permit the formation of genetic chimeras or heterokaryons (Maheshwari, 2005; Roper et al., 2013). Restriction of genetic chimerism is in part controlled through diverse vegetative incompatibility (VI) systems which have evolved in these fungi to function as 'nonself' or 'modified self' sensors, restricting the fusion of genetically distinct colonies (S J Saupe, 2000). VI protects not just fungal genetic identity or 'self', but restricts the spread of deleterious genetic elements such as parasitic nuclei (Debets et al., 1998), plasmids (Debets et al., 1994), transposons and viruses that can be transmitted by cell fusion (Nuss, 2005). Studies of VI hold great potential to inform and inspire tools which may be used to control future blight outbreaks (Stauder et al., 2019). For example, efforts to use virus based biocontrols to inhibit Cryphonectria parasitica, an aggressive ascomycete plant pathogen responsible for the destruction of the American chestnut tree (Kuhlman, 1978), were limited in part due to VI processes blocking transmission of the virus (Anagnostakis, 1986; Cortesi et al., 1998). At a more fundamental level, conspecific nonself recognition in fungi shows many similarities to innate immunity and could represent an exaptation of immune functions common to all eukaryotes (Paoletti and Saupe 2009).

What is known about VI? The morphological changes and genetics underpinning this type of non-self recognition have been extensively studied in three species of ascomycete fungi: Cryphonectria parasitica, Podospora anserina and Neurospora crassa (where it is known as 
heterokaryon incompatibility or HI). Incompatibility systems in these species consist of between 6-11 vic (or het) loci, each comprised of diverse, tightly linked, highly polymorphic genes, some with structural similarities to innate immunity-associated genes (Paoletti et al., 2009; Smith et al., 2013). Often, vic loci will include a filamentous fungal-specific cell death-inducing domain called a HET domain (Kaneko et al., 2006), whose mechanism of action remains unknown (Paoletti et al., 2007; Smith et al., 2000). Polymorphisms at any one or more vic loci will induce an as-yet poorly understood chain of events culminating in the rapid initiation of a form of programmed cell death (PCD) among heterokaryotic fused cells (Glass et al., 2000; Saupe, 2000), and the interacting mycelia will often proceed to form a distinctive 'barrage' zone demarcating colony boundaries (Micali et al., 2003). Symptoms of VI-associated PCD consist of rapid cytosolic granularization, vacuolization and compartmentalization, all suggestive of fungal apoptosis (Biella et al., 2002). Barraging cultures generally exhibit variable morphological changes in hyphal abundance and branching patterns at interacting zones, as well as the production of pigments and conidia-bearing structures.

While classical genetics and morphological studies have laid the groundwork for understanding the genetic triggers, evolutionary patterns and symptoms of VI, modern 'omics' technologies provide unprecedented potential to look into the cellular processes and molecular interactions driving conspecific nonself recognition. For example, when a strain of $N$. crassa bearing a thermo-sensitive het-c/pin-c incompatibility was triggered to undergo heterokaryon incompatibility (HI), transcriptomic analysis revealed up-regulation of gene groups related to signal transduction and cellular communication, such as lysophosphatidylinositol, $\mathrm{Ca}+$ and cAMP-signal associated genes, as well as oxidative stress response genes related to ROS generation and scavenging (Hutchison et al., 2009). Gene expression during activation of a 
similarly thermosensitive het- $R$ / het- $V$ incompatibility locus in $P$. anserina suggested extensive transcriptomic remodeling during HI. Upregulated gene groups were associated with STANDclass proteins involved in pathogen detection with central roles in innate immunity (Leipe et al., 2004), as well as hydrolytic proteins and secondary metabolite biosynthesis-associated genes (Bidard et al., 2013; Lamacchia et al., 2016). Genes down-regulated during incompatibility significantly overlapped in both $N$. crassa and P. anserina systems, involving cellular growthrelated processes such as ribosome biogenesis, DNA replication and mitochondrial function, whereas up-regulated genes among the two systems tended to be species-specific and suggestive of stress-response and signal propagation.

The study of secondary metabolites associated with VI in C. parasitica is complicated by the lack a thermosensitive 'switch' to activate heterokaryotic incompatibility processes and monitor their immediate effects. Instead, C. parasitica VI is studied by co-inoculating strains in close proximity and observing broader trends over a longer time scale. This method may more closely approximate VI phenotypes in nature, because VI and barrage formation ultimately involve the simultaneous interaction of hyphae detecting non-self without cell fusion, of incompatible cells anastomosing and undergoing PCD, and of global, colony-level changes in metabolic states and phenotypes. Methodological differences notwithstanding, a recent transcriptomic analysis of VI between co-inoculated strains of $C$. parasitica which are polymorphic at the vic3 locus supports many of the proposed patterns in heterokaryon incompatibility-associated differential expression discussed above (Belov, 2018). The vic3 locus encodes two genes: one with unknown function, and another with homology to Lifeguard1, whose product is a transmembrane protein shown to inhibit Fas-mediated apoptotic signals and is conserved among many species of animal (Somia et al., 1999)(Table 1). It is unclear how these genes function to activate VI-associated PCD and 
barrage. Gene expression profiles from day 3 after co-inoculation suggested significant upregulation of genes associated with mating-type pheromone and secondary metabolite production, cellular detoxification, reactive oxygen species generation, and apoptosis. The vic3 locus is unlike many others in that it lacks predicted proteins with HET domains, however transcriptomic data showed unlinked HET domain genes were among differentially expressed genes during vic3 VI, including genes associated with vicl incompatibility.

In this C. parasitica system, differentially expressed genes associated with biosynthesis formed a category which included numerous predicted polyketide synthases (PKS), non-ribosomal peptide synthases (NRPS) and terpene synthases as well as cytochrome P450s and other 'tailoring enzymes' predicted to modify the structure of secondary metabolites (Table 1). PKSs and NRPSs are large modular multienzymes which construct diverse scaffolds of small molecules either via iterative polymerization of CoA acyl monomers, or by assembly line peptide condensation (respectively)(Walsh, 2004). These types of enzymes may also be hybridized to link polyketide products with peptides (PKS-NRPS). All produce molecular 'scaffolds' which are often further processed at specific sites by enzymes such as oxidoreductases or transferases which are coregulated during activation of the biosynthetic gene cluster (BGC) surrounding the core synthase. Tight association of biosynthetic genes enables the production of molecules optimized for specific bioactivity in response to cell signals, and allows for the possible coregulation of relevant transport and defense genes. The potential for diverse types of small molecule bioactivity (from cytotoxicity to signal propagation) is enormous and has traditionally been the subject of intense pharmaceutical exploration. In the case of $C$. parasitica, the association of BGC activation with VI opens the possibility of linking biological context to small molecule detection. 
Table 1. Summary of characterized vegetative incompatibility genes

\begin{tabular}{|c|c|c|c|}
\hline Species/Loci & Gene & Conserved Domains & Reference \\
\hline \multicolumn{4}{|c|}{ C. parasitica (six incompatibility loci identified) } \\
\hline \multirow[t]{4}{*}{ vic1 } & vic1a & HET & Zhang et al., 2014 \\
\hline & vic1b-2 & DUF1909 & Zhang et al., 2014 \\
\hline & vic1c-1 & TY1/Copia-like LTR retrotransposon & Zhang et al., 2014 \\
\hline & vic1d-1 & HET & Zhang et al., 2014 \\
\hline \multirow[t]{2}{*}{ vic2 } & vic2-1 & $\begin{array}{l}\text { Patatin-like phospholipase (PLP), P-loop } \\
\text { NTPase, TPR repeat X2 }\end{array}$ & Choi et al., 2012 \\
\hline & $\operatorname{vic} 2 a$ & SNARE sec9 like, Alanine zipper & Choi et al., 2012 \\
\hline \multirow[t]{2}{*}{ vic3 } & vic3a & Unknown protein & Zhang et al., 2014 \\
\hline & $\operatorname{vic} 3 b$ & glutamate receptor-associated, Lifeguard1-like & Zhang et al., 2014 \\
\hline \multirow[t]{2}{*}{ vic4 } & vic4-1 & Protein kinase C-like & Choi et al., 2012 \\
\hline & vic4-2 & $\mathrm{NACHT}+\mathrm{WD} 40$ & Choi et al., 2012 \\
\hline \multirow[t]{2}{*}{ vic6 } & vic6 & HET & Choi et al., 2012 \\
\hline & pix6 & DUF1040 & Choi et al., 2012 \\
\hline vic7 & vic7 & HET & Choi et al., 2012 \\
\hline \multicolumn{4}{|c|}{ P. anserina (nine incompatibility loci identified) } \\
\hline het-s & het-s & Prion protein & Balguerie et al., 2003 \\
\hline het-C & het- $C$ & Glycolipid transfer protein & Saupe et al., 1994 \\
\hline het- $E$ & het-E & $\mathrm{HET}+\mathrm{NACHT}+\mathrm{WD} 40$ & Saupe et al., 1994 \\
\hline het- $D$ & het- $D$ & $\mathrm{HET}+\mathrm{NACHT}+\mathrm{WD} 40$ & Espagne et al., 2002 \\
\hline het- $R$ & het- $R$ & $\mathrm{HET}+\mathrm{NACHT}+\mathrm{WD} 40$ & Chevanne et al., 2009 \\
\hline het-V & het-V & Uncharacterized & Chevanne et al., 2009 \\
\hline \multirow[t]{3}{*}{ het-Z } & plp-1 & plp,NBD,TPR & Heller et al., 2018 \\
\hline & $p / p-2$ & plp,TPR & Heller et al., 2018 \\
\hline & sec9-like & SNARE & Heller et al., 2018 \\
\hline \multicolumn{4}{|c|}{ N. crassa (11 incompatibility loci identified) } \\
\hline \multirow[t]{3}{*}{ mat } & mat-A1 & alpha domain & Glass et al., 1990 \\
\hline & mat-a1 & HMG box & Philley and Staben, 1994 \\
\hline & tol & HET & Shiu and Glass, 1999 \\
\hline \multirow[t]{2}{*}{ het-c } & het-c & Glycine-rich signal + incomp domain & $\begin{array}{l}\text { Sven J. Saupe et al., } \\
1996\end{array}$ \\
\hline & pin-c & HET & Kaneko et al., 2006 \\
\hline \multirow[t]{2}{*}{ het- 6} & het- 6 & HET & Smith et al. 2000 \\
\hline & $u n-24$ & RNRL + incomp domain & $\begin{array}{l}\text { Lafontaine and Smith } \\
2012\end{array}$ \\
\hline \multirow[t]{3}{*}{ GRD } & $p / p-1$ & PLP, NBD, TPR & Heller et al., 2018 \\
\hline & plp-2 & PLP, TPR & Heller et al., 2018 \\
\hline & $\sec 9$ & SNARE & Heller et al., 2018 \\
\hline
\end{tabular}

Using ultra-high pressure liquid chromatography (UPLC) coupled to high-resolution mass spectrometry (HRMS), the research in this thesis carries out an untargeted metabolomic 
investigation of the hypothesis that vic $3 \mathrm{VI}$ in C. parasitica leads to novel secondary metabolite production. Where possible, NMR structural elucidation and database-driven comparison of tandem MSMS spectra to online spectral libraries are used to annotate signals significant to VI metabolomes. Annotations are compared to predicted BGCs and other genes found to be upregulated in the previous transcriptomic study. Together, these findings suggest a complex response to VI involving both mycelium-associated and secreted small molecules with potential roles in membrane signaling, and lays groundwork for future studies of VI effectors which may act to coordinate or execute conspecific non-self recognition in C. parasitica. 


\subsection{MATERIALS AND METHODS}

\subsection{Strain Selection}

C. parasitica strain "EP155" is a standard laboratory strain and has a fully sequenced genome available at the Joint Genome Institute at http://genome.jgi.doe.gov/Crypa2/ Crypa2.home.html. The second strain, "P74-3", was selected because it differs from EP155 at the vic3 locus but is identical at all other vic loci. It should also be noted that EP155 and P74-3 come from distinct genetic backgrounds (Biella et al., 2002). EP155 carries the vic3-1 haplotype and P74-3 carries the vic3-2 haplotype. Polymorphism at the vic3 locus is known to elicit a strong incompatibility reaction but the exact mechanism of cell signaling during vic3 incompatibility remains unknown (Biella et al., 2002; Zhang et al., 2014). Both strains are of the same mating type (mat-2) and were sourced from the collection of Dr. Myron Smith (Carleton University). The transcriptomes of both strains in monoculture, as well as in a co-cultured mix, have been described in a recent study (Belov, 2018).

\subsection{Experimental Design}

Both strains were grown separately in $12 \mathrm{ml}$ liquid suspensions of $2 \%$ potato dextrose broth (PDB, BD Difco Brand, NJ, USA) for 7 days at $30^{\circ} \mathrm{C}$ in the dark. They were then diluted with fresh 2\% PDB and blended in a Waring commercial blender at high speed for two 1-minute intervals separated by a 30-second pause. The resulting cell slurries (the "monoculture" treatments) had approximately 2000 CFUs per ml, determined by serial dilution on PDA. Equal portions of the resulting cell suspensions were mixed together in a 1:1 ratio to create the "VI" incompatibility treatment. This approach was taken to maximize contact between the two strains and thus amplify any chemical signal which might occur due to incompatibility reactions. 
Next, $100 \mu 1$ (200CFU) of inoculum from the three treatments (EP155, P74-3, and "VI") was spread onto sterile semi-permeable plastic membranes overlaid on $30 \mathrm{ml}$ of $2 \%$ potato dextrose agar (PDA, BD Difco brand, NJ, USA). The two monocultures were plated separately as controls against which the VI treatment could be compared. Cultures were incubated in the dark at $30^{\circ} \mathrm{C}$ until harvested for extractions. Mycelium and the agar underneath the semi-permeable membrane were harvested as separate samples from each plate, placed into glass scintillation vials, and frozen at $-20^{\circ} \mathrm{C}$ until extractions were performed one week later. Mycelium wet weight was measured before freezing to create a growth curve of the incompatible cultures such that any subsequent scale-ups for compound purification could be harvested at the appropriate time postinoculation. Media controls (PDA with sterile membrane overlaid) were included and were sampled on day 5 of the experiment. All treatments and controls were performed in six replicates.

\subsection{Extraction and UPLC-HRMS Analysis}

Each sample was extracted with $10 \mathrm{ml}$ of ethyl acetate for $1.5 \mathrm{~h}$, gently shaking at $150 \mathrm{rpm}$. Supernatants were carefully collected and transferred to fresh pre-weighed scintillation vials, which were dried under vacuum. Extracts were reconstituted in $\mathrm{MeOH}$ to a concentration of 500 $\mu \mathrm{g} / \mathrm{ml}$ and centrifuged prior to UPLC-HRMS analysis on a Thermo Ultimate 3000 UPLC coupled to a Thermo LTQ Orbitrap XL high resolution mass spectrometer. Chromatography was performed on a Phenomenex $\mathrm{C}_{18}$ Kinetex column $(50 \mathrm{~mm}$ x $2.1 \mathrm{~mm}$ ID, $1.7 \mu \mathrm{m})$ with a flow rate of $0.35 \mathrm{ml} / \mathrm{min}$, running a gradient of $\mathrm{H} 2 \mathrm{O}(+0.1 \%$ formic acid $)$ and $\mathrm{ACN}(+0.1 \%$ formic acid): starting at $5 \% \mathrm{ACN}$ increasing to $95 \% \mathrm{ACN}$ by 4.5 mins and held at $95 \% \mathrm{ACN}$ until 8.0 mins until returning to $5 \% \mathrm{ACN}$ by 9 mins and holding to allow the column to equilibrate to starting conditions by 10 mins. The HRMS was operated in $\mathrm{ESI}^{+}$mode (with a $m / z 100-2000 \mathrm{~m} / \mathrm{z}$ 
range) using the following parameters: sheath gas (40), auxiliary gas (5), sweep gas (2), spray voltage $(4.2 \mathrm{kV})$, capillary temperature $\left(320^{\circ} \mathrm{C}\right)$, capillary voltage $(35 \mathrm{~V})$, and tube lens $(100 \mathrm{~V})$.

All extractions were processed in sequential order in March 2018. MS ${ }^{\mathrm{n}}$ fragmentation was performed in high resolution on select $\mathrm{m} / \mathrm{z}$ in subsequent experiments using CID with collision energy set to $35 \mathrm{eV}$.

\subsection{Data Processing}

Data preprocessing was carried out using MZMine v2.29 (Cell Unit, Okinawa Institute of Science and Technology (OIST), Onna, Okinawa, Japan). Raw data files included MeOH blanks run after every sixth sample, and all were carefully examined to determine a minimum noise level threshold for data analysis. The Full Width at Half Maximum (FWHM) algorithm was used for mass detection with a noise cut-off level of $\left(5.0 E^{5}\right)$. UPLC-HRMS data were then deconvoluted with a chromatographic threshold of $35 \%$, a search minimum of $0.05 \mathrm{~min}$ in the retention time (RT) range, a minimum relative height of $35.0 \%$, and a minimum ratio of peak top/edge of 1.2. These settings were determined by examination of their effects on previewed ion chromatographs within MZMine. The data was then cleared of isotopes, aligned, and converted into a data matrix of discriminate variables (a combination of RT and $\mathrm{m} / \mathrm{z}$ ) based on peak area measurements. Peaks were aligned using the Join Alignment function (with a $m / z$ tolerance of $5.0 \mathrm{ppm}$ and a RT tolerance of 0.1 min with a 2:1 weight for $\mathrm{m} / \mathrm{z}$ vs. RT). Gaps in the data set where variables fell below the noise limit detection threshold were backfilled using a gap-filling algorithm (using a $\mathrm{m} / \mathrm{z}$ tolerance of $5 \mathrm{ppm}$ and RT tolerance of $0.05 \mathrm{~min}$ ). Peak area values were normalized to the total ion current for each sample.

The resulting data matrix of metabolomic features was exported from MZMine and visualized in Microsoft Excel. Signals consistent to methanol blanks, media blanks and reserpine 
standards were removed. Statistical analysis was then performed in the ' $R$ ' environment, first using the freely available packages 'muma' (Metabolomics Univariate and Multivariate Analysis, Gaude et al. 2013), 'MetaboAnalyst' as accessed using the online portal at http://www.metaboanalyst.ca (Xia et al., 2016) and further visualized using ggplot2 package. For all multivariate analyses, data was scaled using the 'pareto' method of data scaling, wherein the square root of the standard deviation is used as the scaling factor, and then centered by the mean for each variable. Univariate analysis was performed using 'muma', which employs ShapiroWilk's test for normality on each variable to determine whether parametric (Welsh's T-test) or non-parametric tests (Wilcoxon-Mann Whitney) are appropriate before determining fold changes and $p$-values in pairwise comparisons between treatments. Comparisons of the VI treatment and each monoculture were performed separately. Variables were kept in the analysis if both $p$ values from the two comparisons were $<0.05$, and if the $\log 2$ fold changes were $>1$ or $<1$ consistently for both comparisons. The above analysis included data from all days of the time course. Once a list of significant variables was determined, univariate analysis was employed once more to identify whether each variable was significantly more or less abundant in either agar ('A') or mycelium ('Myc') samples from the VI cultures ( $p$-value threshold $=0.05$ ).

A correlation analysis reduced the dimensions of the data set via an in-house $\mathrm{R}$ script which groups features likely to be fragments or adducts of a single parent ion - signals which are informative for annotation but are considered 'noise' when estimating signal diversity. After close examination of spectral signatures and peak shapes, features were grouped if their Pearson correlation coefficients were above a threshold of 0.85 , and if they eluted from the column within 0.05 minutes of each other. The correlated groups were then named by the feature with the highest averaged intensity in the data set, or by examination of the group constituents to 
determine the most likely $[\mathrm{M}+\mathrm{H}]+$ or $[\mathrm{M}+\mathrm{Na}]+$ ion by mathematical relationships. This method is imperfect as it assumes there are no variables which elute at the same time and exhibit the same detection pattern among all observations. However, it is highly informative in separating coeluting signals which do not exhibit the same observed pattern among samples, and in reducing the number of features included in subsequent analyses.

\subsection{Signal Annotation and Structure Prediction}

Exact masses of protonated or sodiated ions $(<5 \mathrm{ppm})$ and their isotope patterns were analyzed using MassWorks (Cerno Bioscience) to predict chemical formulas. $\mathrm{MS}^{2}$ fragmentation patterns were compared to in silico predictions of freely available online chemical databases such as Pubchem, Chemspider, UDP, UNDP and MassBank using free tools MSFINDER (Lai et al., 2018) and CSI Finger-ID (Dührkop et al., 2019). Many signals found to be significant to the VI treatment were not satisfactorily annotated using these methods and major signals were structurally elucidated using NMR.

\subsection{Compound Purification}

Two rounds of VI culture extractions were performed to isolate suitable quantities of target compounds for NMR analysis and bioassays. In the first round, 200 plates of incompatible cultures were inoculated on PDA using the same methodology described above, and the mycelia were harvested at the equivalent of day 5 of the metabolomics experiment. In the second round of bulk extractions, 400 plates of incompatible cultures were harvested at the equivalent of day 6 , targeting compounds significant to VI from both agar and mycelium samples.

Scaled up extractions were performed by immersing pooled samples for two hours in $4 \mathrm{~L}$ of ethyl acetate, and the process was then repeated for a second extraction and pooled with the first. Bulk agar and mycelium extractions were then analyzed using UPLC-HRMS to assess the 
presence of targeted signals, and then fractionated by preparatory HPLC using a Kinetex C-18 reverse phase column running a gradient of water/ACN. Gradients began with 1 min of 5\% $\mathrm{ACN}$, ramping up to $100 \% \mathrm{ACN}$ over $10 \mathrm{~min}$, and held at $100 \% \mathrm{ACN}$ for a final $4.5 \mathrm{mins}$, with flow rate set to $20 \mathrm{~mL} / \mathrm{min}$. This protocol yielded approximately 50 fractions per bulk extract, which were then dried, weighed, analyzed again via UPLC-HRMS, and if necessary, subjected to further purification steps using solid phase extraction in silica flash columns using orthogonal solvent systems. Compounds $\mathbf{1}$ and $\mathbf{3}$ eluted in fractions 37 and 33 of the second scale-up agar extractions, respectively. Compound 2 eluted in fraction 34 of the mycelium from the first scaled up experiment. Compound $\mathbf{3}$ co-eluted with other signals, and further separation was achieved using a flash column loaded with silica gel running an isocratic gradient of $20 \%$ hexane in ethyl acetate, in which compound $\mathbf{3}$ was the last to elute.

\subsection{NMR and Structural Elucidation}

1D and 2D spectra for calbistrin P, including H, C, COSY, NOESY, HSQC, DEPT and $\mathrm{HMBC}$, were recorded on a Bruker $500 \mathrm{MHz}$ spectrometer with standard pulse sequences at Agriculture and AgriFood Canada in Ottawa. NMR spectra for all other compounds were recorded on a Bruker $600 \mathrm{MHz}$ spectrometer at the University of Ottawa. Signals were referenced to the deuterated solvent, $\mathrm{CD}_{3} \mathrm{OD}$. NMR data was processed in Topspin 4.0.6 (Bruker). NMR tables are in Appendix B (Tables S1 and S2). NMR data screenshots are in Appendix E.

\subsection{Biosynthetic Gene Cluster (BGC) Prediction}

The genome assembly of strain EP155 used in this study unfortunately suffers from lengthy gene annotation naming conventions and is not uploaded to Genbank, however, it is freely available at the JGI website at (https://mycocosm.jgi.doe.gov/Crypa2/Crypa2.home.html). Genes discussed in this study will instead be referred to by their simpler putative protein IDs 
which consist of a string of 6-8 numbers. The genome of strain EP155 was scanned for predicted fungal BGCs using the freely available online program "antiSMASH” in January 2019 (Blin et al., 2019). Genes found to be differentially expressed in vic3 VI transcriptomes (Belov, 2018) were then compared with the predicted BGCs where possible or examined manually using the JGI online genome browser.

\subsection{Biological Assays}

Assays were performed using 96-well microtiter plates to determine whether purified compounds inhibited the germination and growth of conidia from EP155. Each well was filled with $200 \mu$ of PDB mixed with 100 CFU of conidia from frozen stocks, and to each was added extract or compound such that the final well concentration was $1 \%$ DMSO. Purified compounds were tested in two-fold dilution series, from $100 \mu \mathrm{g} / \mathrm{ml}$ to $0.11 \mu \mathrm{g} / \mathrm{ml}$. Hygromycin B was used as a positive antifungal control. Negative controls were conidial suspensions in PDB containing 1\% DMSO. Blanks were PDB without conidia added. Conidia were incubated in darkness for 48 hours at $30^{\circ} \mathrm{C}$. Visualization was performed via the addition of $18 \mu 1$ of rezasurin stain (PrestoBlue, Thermofisher, CA) to each well, followed by incubation for 1 hour. Rezasurin is reduced in the mitochondria of viable cells, changing colour from a dark blue (oxidized) form to a red, fluorescent form (reduced). Fluorescence was measured at 590nm. 


\subsection{RESULTS AND DISCUSSION}

\subsection{Metabolomics Analyses}

\subsubsection{Results of Statistical Analyses}

General trends in data variation were modeled using a principal component analysis (PCA) of data from agar (Fig. 1) and mycelium samples (Fig. 2) across all days. VI samples from both agar and mycelia show clear separation from monocultures along the y-axis or second principal component (PC2), explaining approximately $18 \%$ of the total variance. $\mathrm{PC} 1$ models approximately $42 \%$ and $53 \%$ of variance in agar and mycelium sample data, respectively, and correlates with the time course: plates harvested sooner after inoculation cluster along the negative $\mathrm{x}$-axis, progressing to plates sampled later towards the positive $\mathrm{x}$-axis.

Among all treatments and multivariate analyses, samples from days 2 and 3 are clustered very closely. Explained variance in PC2 separates monocultures from incompatible ones beginning on day 4 , increasing approximately linearly over time. This data supports the transcriptomic analysis of VI in Cp, which suggested secondary metabolite-related chemical profiles should begin to change in VI interactions on or after day 3 from co-inoculation, the optimal day at which transcripts were harvested (Belov, 2018).

A list of 107 statistically significant features was generated via univariate analysis of fold changes and $p$-values in pairwise comparisons of agar and mycelium data summed together for each replicate (Appendix A, Fig. S1), and then reduced to a 'shortlist' of 32 representative features after likely adducts and associated fragments were removed via correlation analysis (Fig. 3). All p-values and fold changes described above were concatenated into a table to expedite the comparison of different variables. Among the 32 metabolomic features included in this list, 26 were detected at significantly higher levels in VI samples, and six were associated 
with monocultures. Among those detected from the VI samples, approximately half were associated with mycelium and half with agar. Annotation of the six signals significantly underrepresented in VI samples (shaded variables in Fig. 4) was inconclusive using MSFINDER and CSI Finger-ID, and as scale ups of the monocultures were beyond the scope of this study, they remain as potential targets for future investigations.

\subsubsection{Timing of Feature Detection}

Time-course trends were visualized using a heatmap of scaled and centered data, with variables' Euclidean distance values hierarchically clustered using Ward linkage criterion in MetaboAnalyst (Fig. 4)(Xia et al., 2016). The results showed a clear succession of feature detection, with some features 'peaking' earlier and others increasing linearly over time. Additionally, graphs visualizing non-scaled, normalized peak area signature over time for individual variables were generated in R (important variables included in Appendix A, Fig. S2).

\subsection{Secondary Metabolite Biosynthetic Gene Clusters Associated with vic3 VI}

AntiSMASH predicted a total of 46 biosynthetic gene clusters (BGCs) in the EP155 genome. The largest group of putative BGCs were classified as type 1 PKS-associated clusters. Close examination of the previously acquired transcriptomic data showed 17 core scaffold-type biosynthetic genes, including PKSes, NRPSes and terpene synthases were upregulated during VI. Of these, seven clusters had at least five genes (including the core synthase) differentially upregulated during vic3 VI (Table 2), suggesting upregulation of the entire cluster. This level of BGC upregulation agrees with the transcriptomic analysis of heterokaryon incompatibility in $P$. anserina, in which 21/35 predicted BGCs had more than three genes upregulated (Lamacchia et al., 2016). 

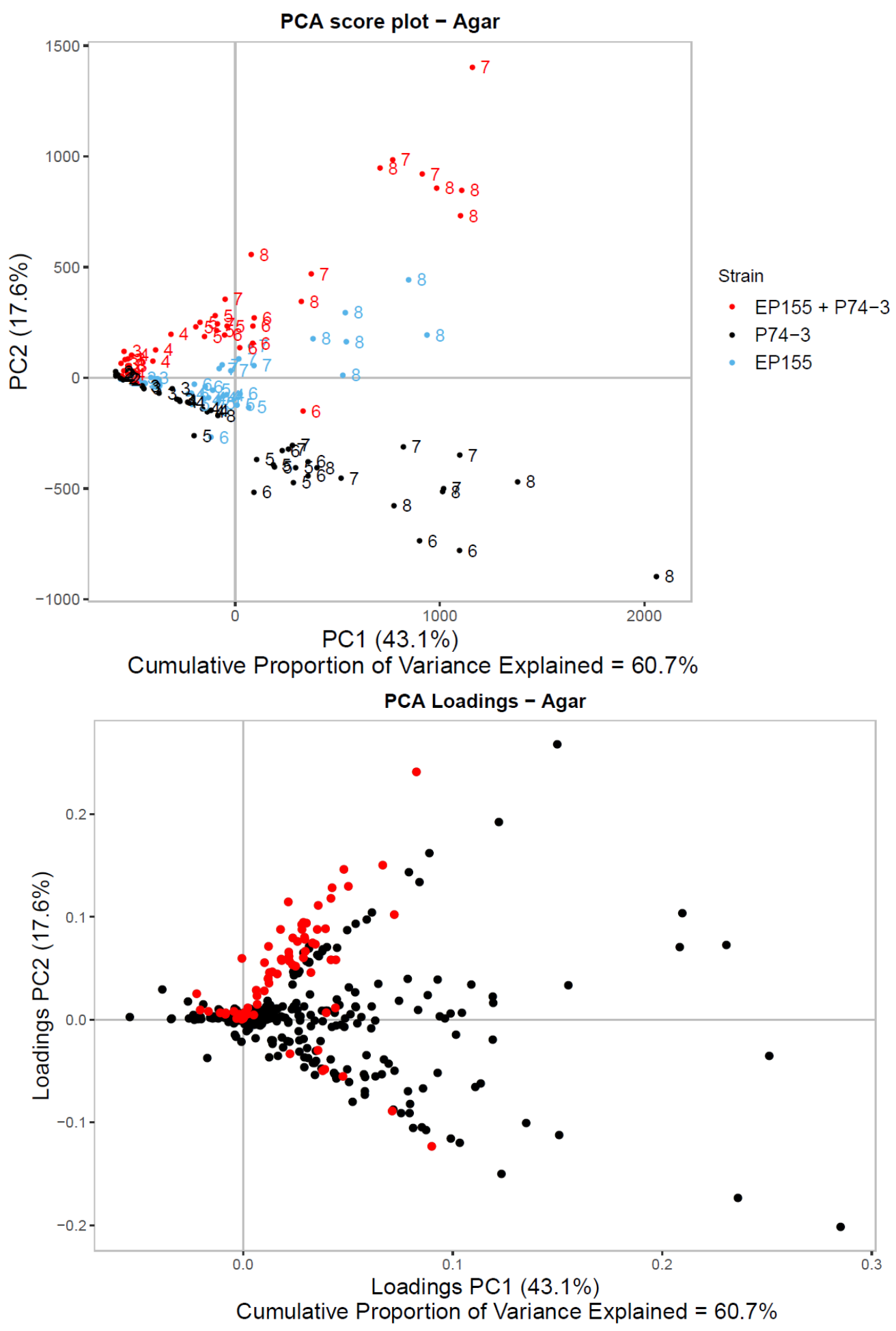

Figure 1. Principal component analysis (PCA) of agar sample data. Score plot and loadings are for PC1 vs. PC2. Dots on score plot represent samples, and adjacent numbers indicate day on which sample was harvested after inoculation. Dots on loadings plot represent variables, with red dots representing variables deemed significantly significant to VI samples compared to both monocultures (averaged $p$-values and fold changes from both comparisons), thresholds $=p$-value $<0.05$ and LFC $>1$ or $<-1$. All data scaled using pareto method. For loadings plots with feature labels attached to significant variables, see Appendix D, Fig. S7. 

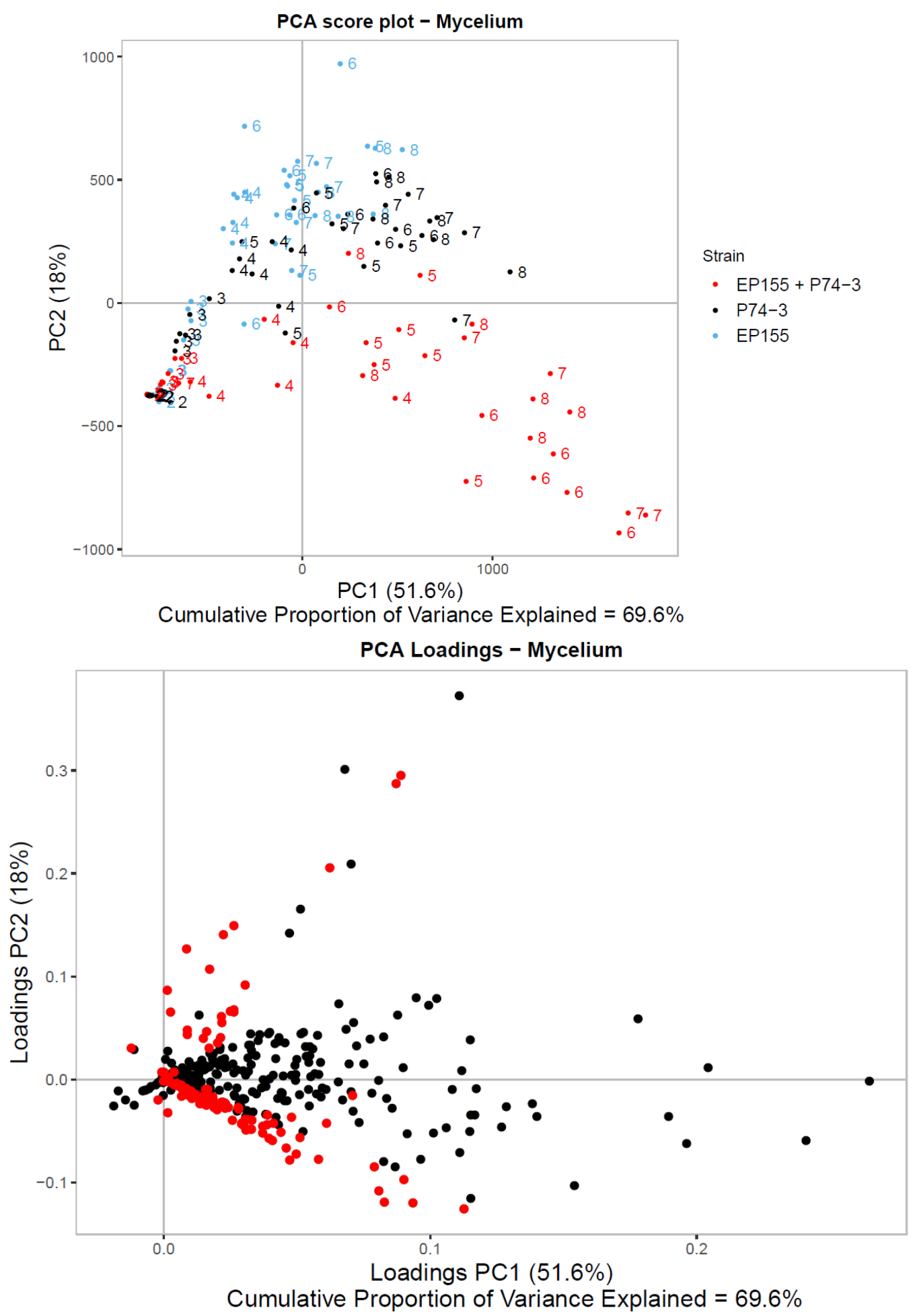

Figure 2. Principal component analysis (PCA) of mycelium sample data. Score plot and loadings are for PC1 vs. PC2. Dots on score plot represent samples, and adjacent numbers indicate day on which sample was harvested after inoculation. Dots on loadings plot represent variables, with red dots representing variables deemed significantly significant to VI samples compared to both monocultures (averaged $p$-values and fold changes from both comparisons), thresholds $=p$-value $<0.05$ and LFC $>1$ or $<-1$. All data scaled using pareto method. For loadings plots with feature labels attached to significant variables, see Appendix D, Fig. S7. 


\begin{tabular}{|c|c|c|c|c|c|}
\hline \multirow{3}{*}{\begin{tabular}{|l} 
Feature \\
(RT_m/z)
\end{tabular}} & \multicolumn{4}{|c|}{ VI vs Monoculture (E or $\mathrm{P}$ ) } & \multirow{3}{*}{$\begin{array}{c}\text { VI only } \\
\text { Fold Change (Log2) } \\
\text { A vs Myc } \\
\end{array}$} \\
\hline & \multicolumn{2}{|c|}{ P-Value } & \multicolumn{2}{|c|}{ Fold Change (Log2) } & \\
\hline & VI vs $P$ & VI vs $\mathrm{E}$ & VI vs $P$ & VI vs $\mathrm{E}$ & \\
\hline RT2.17_301.08944 & 0.00559 & 0.000381 & -1.32 & -1.79 & -8.29 \\
\hline RT2.61_331.0998 & 0.000789 & 0.000134 & -1.72 & -2.59 & -41.42 \\
\hline RT2.96_331.09969 & 0.00152 & 0.000451 & -1.25 & -1.74 & -9.60 \\
\hline RT3.23_301.08949 & 3.87E-05 & $9.32 \mathrm{E}-06$ & -2.13 & -2.97 & -7.62 \\
\hline RT3.86_321.16718 & 1.53E-09 & $1.52 \mathrm{E}-07$ & 3.89 & 3.03 & 3.69 \\
\hline RT3.89_249.07632 & 0.00965 & 0.00801 & -1.11 & -1.94 & 4.42 \\
\hline RT3.94_305.17284 & 0.000133 & 0.001714 & 1.34 & 1.01 & 4.41 \\
\hline RT4.28_690.30377 & $6.73 \mathrm{E}-09$ & 4.77E-10 & 44.40 & 44.66 & 5.13 \\
\hline RT4.39_341.08135 & 1.15E-06 & 3.74E-07 & 11.55 & 43.47 & 4.53 \\
\hline RT4.49_383.18661 & 1.19E-08 & $1.38 \mathrm{E}-07$ & 10.59 & 9.66 & 4.80 \\
\hline RT4.51_207.06534 & 3.43E-09 & 6.01E-07 & -2.95 & -1.97 & 3.38 \\
\hline RT4.51_545.27217 & $5.04 \mathrm{E}-10$ & 3.93E-14 & 3.49 & 4.33 & -2.89 \\
\hline RT4.58_559.25306 & $2.40 \mathrm{E}-04$ & 5.17E-04 & 2.95 & 2.83 & 1.51 \\
\hline RT4.61_353.17633 & $1.51 \mathrm{E}-09$ & $6.79 \mathrm{E}-10$ & 10.35 & 10.24 & 4.24 \\
\hline RT4.63_724.33339 & 1.27E-04 & $9.74 \mathrm{E}-04$ & 2.53 & 1.75 & 5.21 \\
\hline RT4.66_543.25681 & $1.06 \mathrm{E}-05$ & 8.27E-06 & 2.72 & 2.83 & $-0.34 *$ \\
\hline RT4.7_515.26127 & 0.000375 & 0.00466 & 3.38 & 2.34 & 3.33 \\
\hline RT4.78_407.24152 & $6.81 \mathrm{E}-20$ & $1.13 \mathrm{E}-14$ & 5.46 & 4.43 & 1.71 \\
\hline RT4.83_543.25664 & $7.72 \mathrm{E}-06$ & 1.09E-05 & 3.02 & 3.04 & $-0.17^{*}$ \\
\hline RT4.84_680.34291 & 0.00182 & 8.94E-05 & 2.14 & 2.73 & 3.54 \\
\hline RT4.97_540.29262 & 0.000375 & 4.95E-07 & 5.36 & 5.20 & 6.29 \\
\hline RT5.00_518.32441 & 0.00356 & 2.38E-09 & 1.18 & 3.18 & -4.99 \\
\hline RT5.04_747.44405 & 8.38E-05 & 2.87E-11 & 3.49 & 6.92 & -5.67 \\
\hline RT5.17_147.11688 & 4.67E-04 & 0.04002 & 2.50 & 1.08 & 3.84 \\
\hline RT5.2_520.34112 & 0.00238 & $3.74 \mathrm{E}-07$ & 1.64 & 3.07 & -5.61 \\
\hline RT5.46_522.35676 & 0.00981 & 4.08E-04 & 1.74 & 2.33 & -4.46 \\
\hline RT5.69_445.25614 & $1.80 \mathrm{E}-04$ & 0.00367 & 4.98 & 2.95 & $0.84^{*}$ \\
\hline RT5.92_689.41139 & 7.95E-06 & $6.42 \mathrm{E}-08$ & 5.65 & 7.50 & -6.62 \\
\hline RT6.04_703.42587 & 3.27E-05 & 3.42E-09 & 3.92 & 6.21 & -4.63 \\
\hline RT6.16_717.44299 & 0.00208 & 3.45E-04 & 4.81 & 6.52 & -6.11 \\
\hline RT6.18_1017.60327 & 0.00303 & 0.00571 & 1.97 & 1.88 & -6.14 \\
\hline RT7.64_309.20604 & 0.0142 & 0.00466 & 3.58 & 3.87 & -5.07 \\
\hline
\end{tabular}

Figure 3. Significant features in pairwise comparisons between vic3 incompatible strains ('VI') and monocultures EP155 ('E') and P74-3('P'). Feature nomenclature combines the retention time (after "RT"), followed by the exact mass/charge ratio (after the underscore), accurate to $<5 \mathrm{ppm}$. $P$-values and $\log 2$ fold changes from pairwise comparisons are listed for summed agar + mycelium data set, where negative values associate feature detection with monocultures and positive values associate features with VI samples. The last column represents pairwise comparisons of variable intensity of agar ('A') versus mycelium ('Myc') samples, data from the VI samples only. Negative values in the final column indicate association with mycelium (blue) and positive values indicate association with agar (yellow). Asterisks denote lack of statistical significance ( $p$-values $>0.05$ ). All values are calculated independently of the time course and better represent an average of all data. 


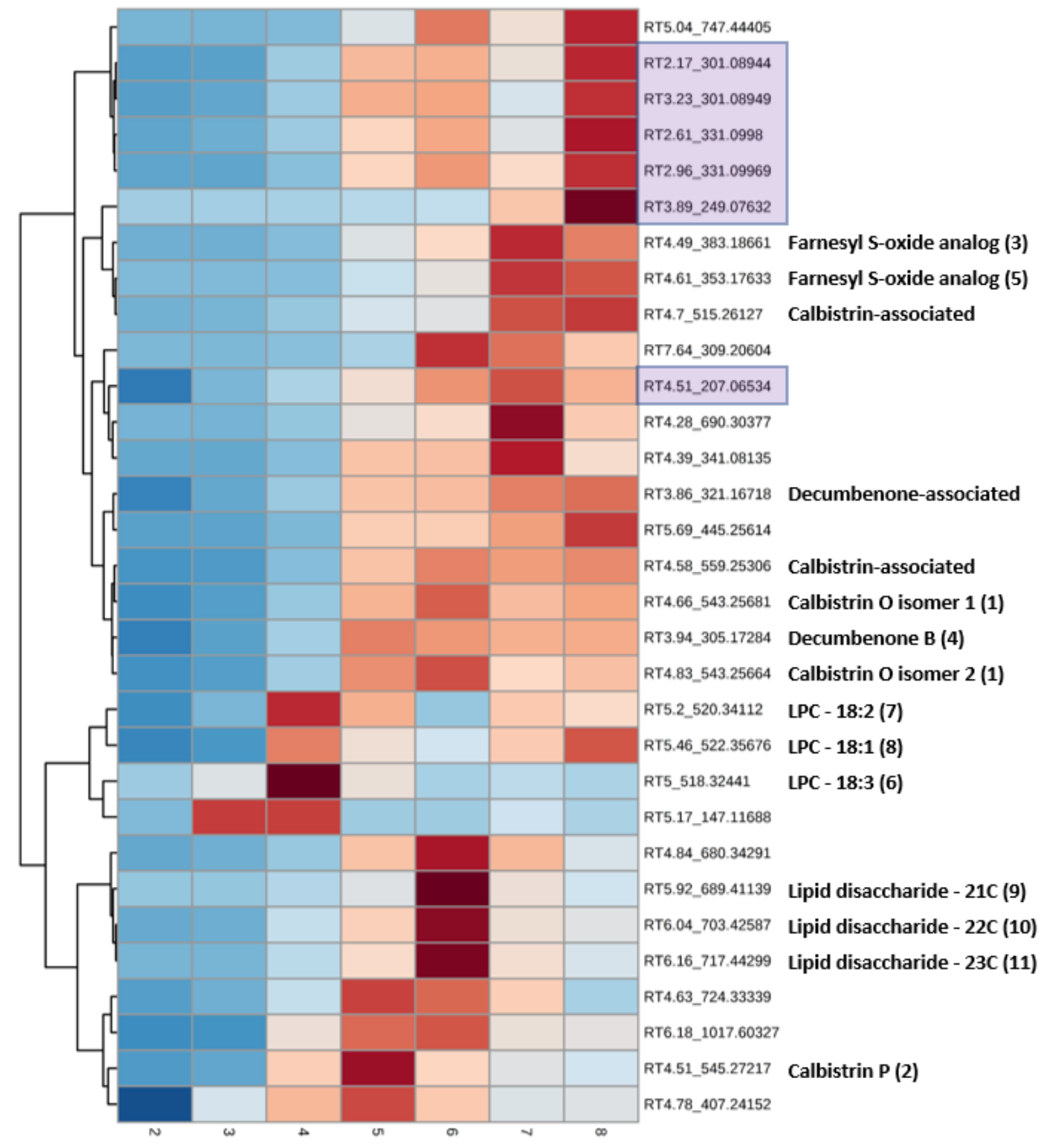

Day (averaged, $n=6$ )

Annotation

Figure 4. Heatmap visualization of signature abundances over time. Variables are representatives from correlated signal groups significant to VI. Data is from the summation of agar and mycelium samples, 'pareto' scaled and clustered using the Ward algorithm (rows). Samples are averaged by day ( $\mathrm{n}=6$, columns). Red colours indicate higher normalized, scaled peak area values. Heatmap created using MetaboAnalyst (Xia et al., 2016). Calbistrin O, calbistrin P and the farnesyl S-oxide analog (3) were derived via NMR structure elucidation, all other annotations are from $\mathrm{MS}^{\mathrm{n}}$ fragment pattern analysis. Shaded feature names were significantly abundant in monocultures compared to VI, whereas all other features were significantly more abundant in VI samples. 
Table 2. Summary of predicted biosynthetic gene cluster diversity in C. parasitica EP155 genome compared to biosynthetic genes found to be differentially upregulated during vic 3 incompatibility. Core synthase genes are indicators of predicted cluster type. T1PKS = Type 1 polyketide synthase, NRPS $=$ Non-ribosomal peptide synthase.

\begin{tabular}{lccc}
\hline Cluster type & $\begin{array}{c}\text { Total antiSMASH } \\
\text { BGC predictions }\end{array}$ & $\begin{array}{c}\text { \# of BGCs with core } \\
\text { synthase upregulated } \\
\text { during VI }\end{array}$ & $\begin{array}{c}\text { \# of BGCs with }>\text { 5 genes } \\
\text { upregulated during VI } \\
\text { (including synthase) }\end{array}$ \\
\hline T1PKS & 15 & 9 & 4 \\
T1PKS-NRPS & 5 & 3 & 2 \\
T1PKS-Terpene & 2 & & 1 \\
T3PKS & 1 & 1 & \\
Indole & 2 & 4 & \\
Terpene & 8 & & \\
Lantipeptide-T1PKS & 1 & & \\
NRPS & 4 & & \\
Other & 7 & 17 & \\
Phosphonate & 1 & & \\
\hline Total & 46 & & \\
\hline
\end{tabular}

\subsection{Metabolite annotation}

Analysis of the VI-associated signals and their fragment patterns allowed for the prediction of many "families" of pseudo-molecular ions, of which we were able to annotate the most abundant five (Fig. 5). Two groups of signals bore resemblance to the calbistrin family of molecules, were structurally elucidated using NMR and are here named calbistrins P (1) and O (2). A farnesyl-s-oxide analog (3) was also elucidated using NMR. Database comparison of $\mathrm{MS}^{2}$ fragmentation patterns supported the above structures via annotation of signals associated with decumbenone B (4) and a truncated analog (5) of the farnesyl-s-oxide (3). $\mathrm{MS}^{2}$ fragmentation pattern analysis enabled the annotation of lysophosphatidylcholines (LPCs) with 1, 2 and 3 unsaturations at unknown locations on an 18C chain (6-8) and lipid disaccharides with $\mathrm{MS}^{2}$ signatures approximating those of known sophorolipids: two hexose moieties attached (in series) to a saturated fatty acid chain with 21, 22 and 23 carbons (9-11)(Fig. 5B). All other significant 
signals were not successfully dereplicated using existing databases of $\mathrm{MS}^{2}$ spectra and unfortunately were produced in insufficient quantities for NMR structure elucidation. Additionally, BGC synteny analysis comparing BGCs differentially expressed during vic3 VI to online databases of known fungal BGCs predicted the production of curvupallide-like molecules, such as curvupallide A (12).

A
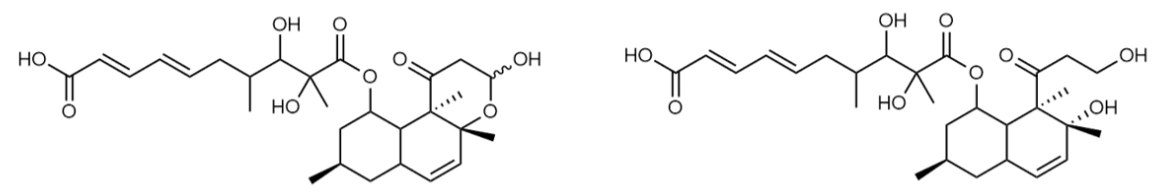

(1) Calbistrin $\mathrm{O}$

(2) Calbistrin P<smiles>CC(=CCCC(O)C(O)CCC(C)C)CCS(=O)CC(O)C(=O)O</smiles>

(3) Farnesyl S-oxide analog

B<smiles>CC1CC(O)C2C(C=CC(C)(C)C2C(=O)CCO)C1</smiles><smiles>CC(=CCS(=O)CC(=O)O)CCC=C(C)C(O)CCC(C)C</smiles>

(4) Decumbenone B

(5) Farnesyl S-oxide analog 2<smiles>[R]C(=O)OCC(O)COP(=O)([O-])OC[N+](C)(C)C</smiles><smiles>[R]CCO</smiles>

(6) $\mathrm{LPC}(18: 3) \mathrm{R}=\mathrm{C}_{17} \mathrm{H}_{29}$

(7) $\mathrm{LPC}(18: 2) \mathrm{R}=\mathrm{C}_{17} \mathrm{H}_{31}$

(8) $\mathrm{LPC}(18: 1) \mathrm{R}=\mathrm{C}_{17} \mathrm{H}_{33}$

Lysophosphatidylcholines

(9) $\mathrm{R}=\mathrm{C}_{21} \mathrm{H}_{41} \mathrm{O}_{2}$

(10) $\mathrm{R}=\mathrm{C}_{22} \mathrm{H}_{43} \mathrm{O}_{2}$

(11) $\mathrm{R}=\mathrm{C}_{23} \mathrm{H}_{45} \mathrm{O}_{2}$

Lipid disaccharides

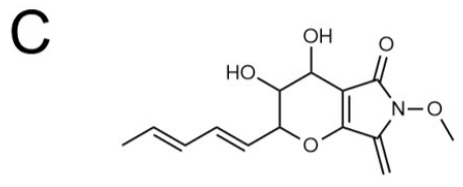

(12) Curvupallide A

Figure 5. Structures of VI-associated compounds. A: new structures elucidated using NMR in this study. $\mathbf{B}$ : putative structures predicted via $\mathrm{MS}^{\mathrm{n}}$ spectral analysis. C: Curvupallide A is annotated here based on upregulation of a biosynthetic gene cluster with homology to known curvupallide cluster during VI, however curvupallide Aassociated MS signals were not significantly associated with VI metabolomes. 


\subsection{CALBISTRINS AND CALBISTRIN PRECURSORS}

\subsubsection{Calbistrin Isolation and Structure Elucidation}

Compound 2 was obtained as a yellow oil after preparative HPLC fractionation of mycelial extracts from both scale-ups, with an observed $m / z$ of $[\mathrm{M}+\mathrm{Na}]+=545.27217$ and UV absorbance spectra at 220 and 260. Attempts to dereplicate $\mathrm{MS}^{2}$ spectra were unsuccessful using MSFINDER and CSI-FingerID. Isotopic signatures from HRMS data suggested the molecular formula $\mathrm{C} 28 \mathrm{H} 42 \mathrm{O} 9$, and extensive NMR spectral analysis revealed a new structure related to the known compound class "calbistrin" designated here as calbistrin P (Fig. 6). Calbistrins consist of a decalin moiety linked via ester to a linear unsaturated dioic acid. The decalin moiety in compound 2 matched reported C-NMR, H-NMR and NOESY correlations of decumbenone B (Fujii et al., 2002). NOESY experiments were uninformative in deciphering the stereochemistry of carbons 2', 3' and 4' of the linear chain. MSMS fragmentation patterns of compound 2 support the proposed structure, showing abundant peaks corresponding to exact masses of predicted decalin and dioic acid fragments which are the most likely products of fragmentation along either side of the ester bond (Appendix C, Fig. S3). HRMS data showed the presence of abundant sodiated adduct and protonated water-loss peaks with notable absence of a protonated base molecule peak, a pattern which matches signatures from known calbistrins (Brill et al., 1993; Grijseels et al., 2018).

Compound 1 was obtained as a yellow oil from fractionation of agar extracts from the second scale-up, and was obtained as a mix of two peaks both showing observed $m / \mathrm{z}[\mathrm{M}+\mathrm{Na}]+$ $=543.25681$ (retention times were 4.66 and $4.83 \mathrm{~min}$ ), calculated formula $=\mathrm{C} 28 \mathrm{H} 40 \mathrm{O} 9$. Efforts

to separate the two putative compounds were unsuccessful. Both showed UV absorbance at 215 and $265 \mathrm{~nm}$, and similar fragmentation patterns (same $\mathrm{m} / \mathrm{z}$ but different relative intensities patterns)(Figure S3). NMR spectra were complex due to the mixing of the two compounds, 
however close comparison to NMR spectra of compound $\mathbf{2}$ and published data from calbistrin A (Brill et al., 1993) supports the presence of a cyclized hemiacetal similar to that of calbistrin A (Appendix B, Table S1). NMR spectral analysis supports the presence of the two distinct compound signatures due to diastereoisomerism formed by the closing of the diol in compound 2 to form the cyclic hemiacetal in compound $\mathbf{1}$. Compound $\mathbf{1}$ is here tentatively named calbistrin O, without specification for stereochemistry in the cyclized hemiacetal. Bioassays showed no inhibition of germination or growth of EP155 conidia when inoculated at 500CFU/ml in PDB containing up to $100 \mu \mathrm{g} / \mathrm{ml}$ of compound 2 .

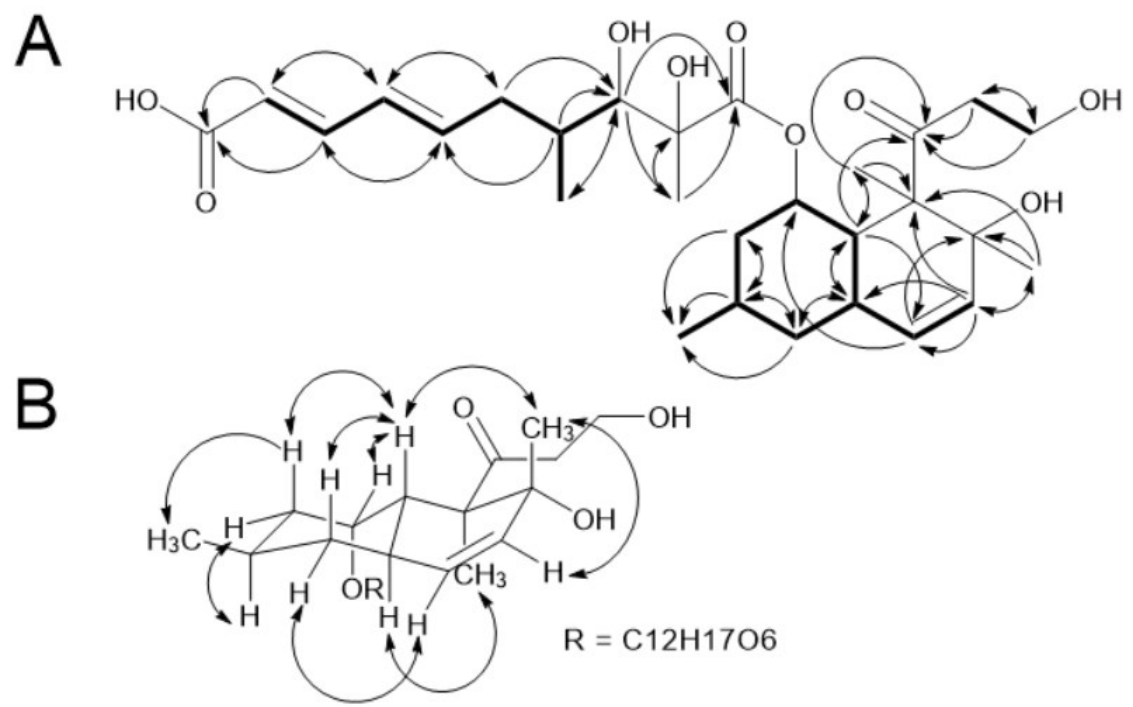

Figure 6. A: Calbistrin P COSY correlations (bold lines) and HMBC correlations (arrows) B: NOESY correlations (arrows) for calbistrin P decalin moiety

Closer examination of the metabolomes suggested there were two more calbistrin-like signals significantly more abundanct in VI cultures. The first had an exact mass difference relative to calbistrin P corresponding to a loss of CH2O $\left(\mathrm{RT} \_m / z=4.7 \_515.26127, \Delta m / z=\right.$ 30.0109 , mass of $\mathrm{CH} 2 \mathrm{O}=30.0105)$. The second had an exact mass difference of one oxygen relative to calbistrin $\mathrm{O}\left(\mathrm{RT} \_m / \mathrm{z}=4.58 \_559.25306, \Delta m / z=15.99625\right)$. $\mathrm{MS}^{2}$ spectra of the first 
showed identical putative dioic acid fragment-associated spectra $(<5 \mathrm{ppm})$ indicating the mass difference was in the decalin moiety (Appendix C, Fig. S3). The second was difficult to isolate for $\mathrm{MS}^{2}$ due to coelution with a compound of similar $\mathrm{m} / \mathrm{z}$ (likely rugulosin, observed $\mathrm{m} / \mathrm{z}=$ 559.12, discussed in section 3.9). The abundance of these signals was very low and attempts to isolate either of them were not feasible.

Time course analyses suggested calbistrin P began to accumulate by day 3 after coinoculation and peaked around days $4 / 5$, where other calbistrin-associated signals increased approximately linearly beginning on day 3 (Fig. 4). All calbistrin-associated signals were significantly more abundant in VI cultures ( $\mathrm{p}$-values $<0.05$ ), but varied in their signal localizations: calbistrin $\mathrm{P}$ was associated with the mycelium, whereas the loss of $\mathrm{CH} 2 \mathrm{O}$ variant was associated with agar samples, and there was no significant difference in detection of calbistrin $\mathrm{O}$ in either agar or mycelium (Fig 3). This suggests calbistrin $\mathrm{P}$ is produced earlier than other variants, is transformed or degraded over time and is associated with the mycelium, whereas others accumulate linearly over time in the agar medium.

Following this discovery, signals with the exact $\mathrm{m} / \mathrm{z}$ of the decalin moieties of the calbistrins were identified, matching the $\mathrm{m} / \mathrm{z}$ of decumbenones B and C, eluting at 3.94 and 3.86 minutes and associated with VI agar (Fujii et al., 2002; Zhuravleva et al., 2012). Decumbenone B-associated signals share $\mathrm{MS}^{2}$ fragmentation spectra with calbistrin $\mathrm{P}$, whereas decumbenone C-associated signals only shared modest fragment spectra with calbistrin O (Appendix C, Fig. S3). This suggests the decumbenone C-associated signal is likely an oxidized form of decumbenone B, however the structure of the oxidized form is unclear. Given the many sites of possible oxidation in decumbenone, the annotation of decumbenone $\mathrm{C}$ is uncertain. Decumbenone B-associated signals were also detected at relatively abundant levels in the 
monocultures (Appendix A, Fig. S2a), suggesting structural modifications to decumbenones including the addition of dioic acids or oxidation are associated with barraging cultures and possibly represent a functionalization of decumbenone.

\subsubsection{Upregulation of BGC With Homology to Known Calbistrin / Decumbenone Gene Cluster in}

\section{Penicillium decumbens}

Recently a BGC responsible for the production and secretion of decumbenones and calbistrins in Penicillium decumbens was published (Grijseels et al., 2018). A genetic knockout of PdecPKS10 (CalA) in P. decumbens strain IBT11843 arrested the production of both decumbenone, calbistrin and the linear dioic acid associated with detected calbistrins A-D. Additional knockouts showed an adjacent transport gene (CalB) was required to export calbistrins from the cell, and a transcription factor $(\mathrm{CalC})$ was associated with cluster expression. Transcriptomic comparisons of IBT11843 grown on permissive and restrictive media supported the involvement of an additional 10 adjacent genes in this gene cluster, bringing the total number of genes associated with calbistrin production in P. decumbens to 13 .

When blasted against the C. parasitica EP155 genome, 12 out of the 13 calbistrinassociated genes have homologs with ID matches $>50 \%$ (Table 3), all of which are upregulated in the VI transcriptomes, and 10 of the 12 are in one predicted BGC (Fig. 7B). Following the format of Grijseels et al. 2018, a synteny map comparing the upregulated genes in C. parasitica to the $P$. decumbens decumbenone BGC shows a high level of homology and remarkable gene "rearrangement" (Fig. 7A).

Three genes present in the $P$. decumbens cluster are missing from the proposed cluster in C. parasitica: PdecCalI, a dehydrogenase; PdecCalJ, an acyltransferase; and PdecCalL, a 
cytochrome $\mathrm{P} 450$. PdecCalJ is hypothesized to function as an acyltransferase connecting the two moieties of calbistrin A and is very likely crucial to the production of calbistrin, functionally similar to acyltransferase LovD, which attaches the decalin and diketide moieties of the related molecule 'lovastatin' (Kennedy et al., 1999), discussed below. When PdecCalJ was blasted against the EP155 genome, protein $C p 346253$ was the top hit with a 54\% ID match over $92 \%$ of the compared region (blastp comparison, E-value $=4.77 \times 10 \mathrm{E}-157$ ). $C p 346253$ is significantly upregulated in VI transcriptomes $(\mathrm{LFC}=3.42, p$-value $<0.05)$ and its genomic context places it outside all antiSMASH-predicted BGCs (3.6m bp from putative decumbenone cluster), flanked by genes downregulated during VI. A similar scenario describes $C$. parasitica's closest homolog to PdecCalL, one of three cytochrome P450s associated with calbistrin biosynthesis: Cp 274617 has very high homology to $P d e c$ CalL ( $>80 \%$ at aa level) and is significantly upregulated in VI transcriptomes $(\mathrm{LFC}=6.30)$.

Two predicted genes associated with the C. parasitica calbistrin BGC are not homologous to any genes in the $P$. decumbens BGC: $\mathrm{CpCalO}$ is a cytochrome $\mathrm{P} 450$, and $C p C a l N$ is an unusual hybrid methyl-transferase keto-reductase. While further studies are needed to characterize the function of $C p C a l N$, the predicted domains suggest contribution to the creation or modification of the dioic acid moiety during calbistrin production.

\subsubsection{Calbistrin is Structurally Similar to Statins and May Help Regulate Fungal Growth and}

\section{Lipoprotein Signaling}

This study brings the total number of known calbistrin variants to twenty-two, including those described from Penicillium decumbens, P. striatisporum, Aspergillus versicolor, A.

aculeatus (Hewage et al., 2014; Horn et al., 1993; Jackson et al., 1993; Stewart et al., 2005), and at least one unidentified species from class Dothideomycetes (González-Menéndez et al., 2018; 
Wijesekera et al., 2017). These species are currently placed among three classes of ascomycetes:

Eurotiomycetes, Sordariomycetes, and Dothideomycetes, suggesting either a high level of conservation for this class of secondary metabolite, extensive horizontal transfer, or convergent evolution. Among the Sordariomycetes (of which Cryphonectria is classified), Grijseels et al. (2018) identify BGCs from two species of Colletotrichum which bear all predicted calbistrin biosynthetic genes with the exclusion of the putative acyltransferase CalJ.

A

C. parasitica

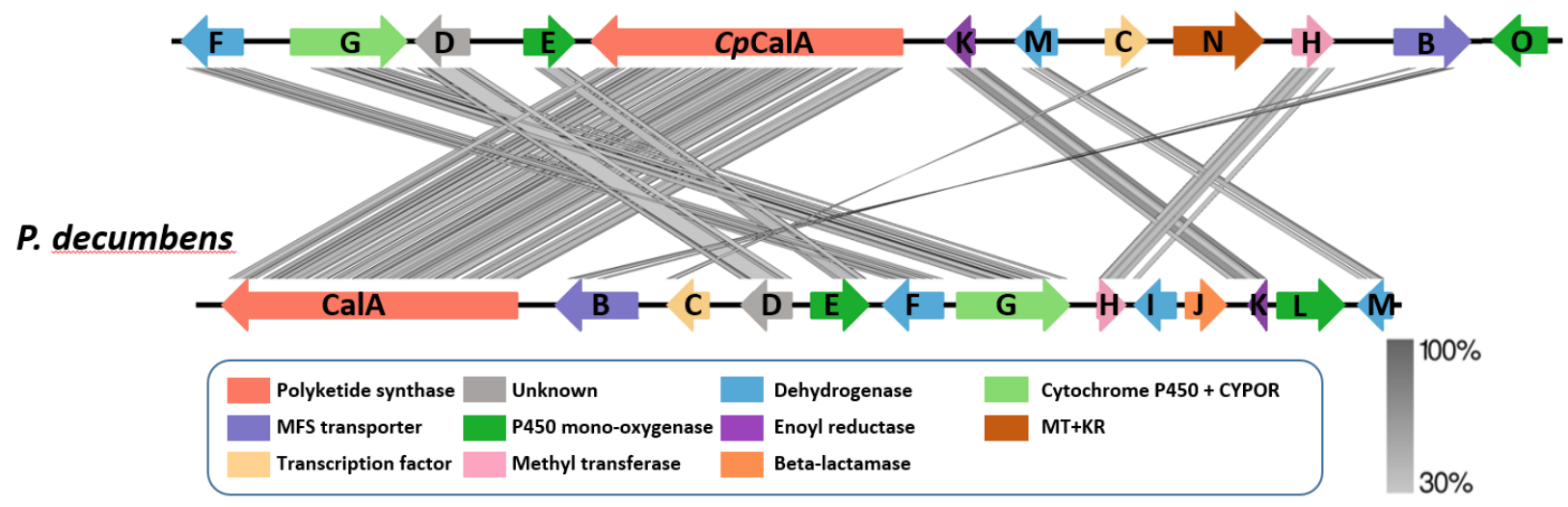

B

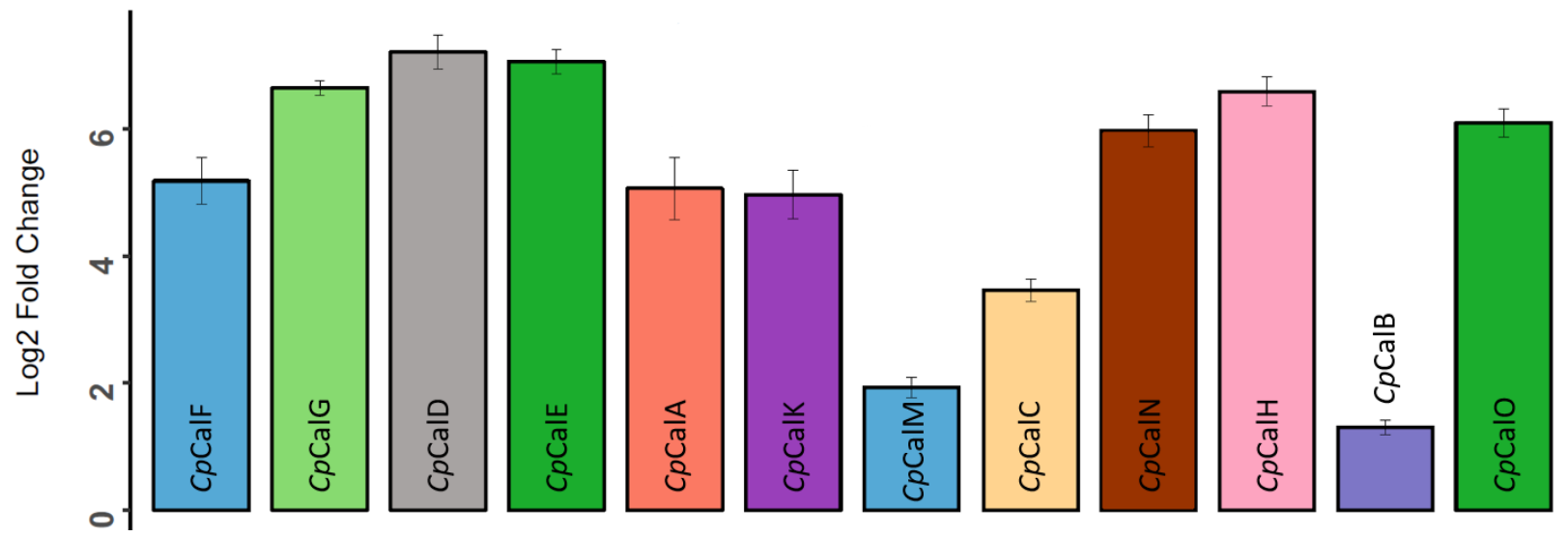

Figure 7. A: Gene synteny of putative decumbenone gene clusters in C. parasitica and P. decumbens. Figure made using EasyFig (Sullivan et al., 2011). B: Differential gene expression from vic3 VI transcriptomes. 
Table 3. Putative proteins within predicted calbistrin gene cluster in C. parasitica

\begin{tabular}{|c|c|c|c|c|c|c|c|}
\hline Name & $\begin{array}{l}C p \text { protein } \\
\text { ID }\end{array}$ & $\begin{array}{l}\text { Size } \\
\text { (aa) }\end{array}$ & $\begin{array}{l}\text { BLASTp } \\
\text { Pdec }\end{array}$ & $\begin{array}{l}\text { ID } \\
\%\end{array}$ & $\begin{array}{l}\text { BLASTp } \\
\text { Aver }\end{array}$ & ID\% & Conserved domains \\
\hline CpCalA & 256096 & 2843 & OQD73955.1 & 69.4 & OJJ08178.1 & 68.8 & PKS \\
\hline CpCalB & 257204 & 537 & OQD73972.1 & 58.6 & OJJ08177.1 & 56.8 & $\begin{array}{l}\text { Drug resistance transporter, MFS } \\
\text { pump }\end{array}$ \\
\hline CpCalC & 105776 & 431 & OQD73953.1 & 45 & OJJ08176.1 & 46.8 & $\begin{array}{l}\text { GAL4-like ZN(II)Cys6 DNA- } \\
\text { binding domain }\end{array}$ \\
\hline CpCalD & 289501 & 493 & OQD73799.1 & 60.1 & OJJ08174.1 & 60.2 & Transferase \\
\hline CpCalE & 355864 & 374 & OQD73977.1 & 64.2 & OJJ08173.1 & 64.2 & Cytochrome p450 \\
\hline CpCalG & 345802 & 1070 & NA & NA & OJJ08171.1 & 65.6 & $\begin{array}{c}\text { Cytochrome P450, CYPOR } \\
\text { bifunctional }\end{array}$ \\
\hline $\mathrm{CpCalH}$ & 67772 & 360 & OQD73938.1 & 62.6 & OJJ08170.1 & 60.3 & SAM dependent methyltransferase \\
\hline NA & $346253^{*}$ & 400 & PdecCalJ & 58.6 & OJJ08168.1 & 54 & Beta-lactamase \\
\hline CpCalK & 321882 & 163 & OQD73827.1 & 69.6 & OJJ08167.1 & 70.4 & Enoyl-reductase-like \\
\hline NA & $274617^{*}$ & 452 & OQD73856.1 & 80.3 & OJJ08166.1 & 81.8 & Cytochrome p450 \\
\hline CpCalM & 355867 & 298 & PdecCalM & 70.6 & OJJ08165.1 & 70.6 & $\begin{array}{l}\text { Short-chain dehydrogenase/ } \\
\text { oxidoreductase }\end{array}$ \\
\hline CpCalN & 67771 & 859 & NA & NA & NA & NA & $\begin{array}{l}\text { SAM dependent methyltransferase, } \\
\text { KR, (short-chain dehydrogenase) }\end{array}$ \\
\hline CpCalO & 88222 & 509 & NA & 28.6 & NA & NA & Cytochrome p450 \\
\hline
\end{tabular}

* = C. parasitica genes with best homology to calbistrin-associated genes in decumbenone gene cluster from $P$. decumbens but not found in genetic vicinity of putative $C$. parasitica decumbenone gene cluster. These genes are significantly upregulated in VI transcriptomes.

The absence of the CalJ homolog $C p 346253$ from the putative calbistrin cluster in $C$. parasitica suggests the addition of the dioic acid could be decoupled from decumbenone biosynthesis if genetic regulation is independent. A similar separation exists in C. tofieldiae as well (Grijseels et al., 2018). This hypothesis is somewhat supported by univariate analysis of vic3 VI metabolomes which showed decumbenone B-associated signals were significant to the VI treatment on day 5 only (Appendix A, Fig. S2a)(averaged $p$-value $=0.00158)$. The VIassociated abundance of decumbenone B-associated signals on day 5 correlates with a significant increase in detection of calbistrin $\mathrm{P}$ on day 5. This pattern contrasts with detection of calbistrinrelated signals and the putative oxidized decumbenone signals, which were significant on all but day 2 (p-values $<0.01)$. It is therefore possible that decumbenone B-associated signals are constitutively produced in growth conditions used in this experiment, whereas modifications 
including addition of dioic acid and oxidation (creating the oxidized decumbenone signal) are associated with VI.

MS signals associated with a freely occurring dioic acid corresponding to that of calbistrins $\mathrm{P}$ and $\mathrm{O}$ were not detected in this study, in contrast to studies of calbistrin A from $P$. decumbens (Grijseels et al., 2018). Grijseels et al. were unable to determine the source of the dioic acid, presumed to be a PKS product, but found that knockouts of the core PKS eliminated dioic acid-associated signals. A study of calbistrins produced by $P$. striatisporum also did not detect $m / z$ corresponding to the dioic acids associated with their respective calbistrin variants, however a truncated dioic acid analog was discovered and named striatisporin A (Stewart et al., 2005). While no dioic acid analog signals were characterized in the present study, the calbistrin $P$ dioic acid fragment $\mathrm{m} / \mathrm{z}$ was detected as a neutral loss in $\mathrm{MS}^{2}$ spectra from another VI-significant feature, RT4.84_680.34291 (Fig. 3), which not sufficiently abundant for purification. This could indicate the functionalization of other molecules via the addition of the dioic acid. A similar attachment of calbistrin A and aculene A was detected via $\mathrm{MS}^{2}$ fragmentation of an uncharacterized pseudomolecular ion subsequently named "acucalbistrin" in a study of natural products producted by Aspergillus aculeatus, providing some precedence for PKS product modularity (Petersen et al., 2014). This suggests multi-PKS modular construction may be happening frequently in these systems, and if so, putative transferases such as CalJ might be important factors in their construction.

The association of calbistrin production with VI in C. parasitica contrasts with patterns of increased calbistrin production in other fungi, which have been linked to changes in media components such as the inclusion of yeast extract or autolysate (Grijseels et al., 2018; Petersen et al., 2014), potato and malt extracts from diverse sources (Hewage et al., 2014), or absorptive 
resins (González-Menéndez et al., 2018). Consistent triggers for calbistrin production across taxa are unclear, suggesting a broad function or multiplicity of functions for filamentous ascomycetes.

The question of function leads to inevitable comparisons of calbistrins to structurally similar statin-class drugs such as compactin or lovastatin, which are also abundantly (but not exclusively) found in filamentous ascomycetes, have a decalin scaffold, and linear chain attachment via aliphatic ester bond at same position as in calbistrins (Gunde-Cimerman et al., 1995). Mevastatin was the first statin characterized, produced by Penicillium citrinum (Akira Endo et al., 1976). Since then many more variants have emerged, such as the much-studied lovastatin from Monascus ruber and Aspergillus terreus (Alberts et al., 1980; Akira Endo, 1979). Statins are renowned for their ability to competitively inhibit HMG CoA reductase (A. Endo, 1988), a highly conserved rate-limiting enzyme in the mevalonate pathway. The mevalonate pathway is essential to eukaryotic life and is regulated by complex mechanisms, as it produces versatile isoprenoid subunits incorporated into key molecules such as sterols and farnesylated proteins involved in cell signaling (Goldstein et al., 1990). Thanks to statins' remarkable inhibition, lipid production is slowed, requiring some mammalian cells to upregulate outermembrane low-density lipoprotein (LDL) receptors, thereby endocytosing LDL and reducing detectable blood cholesterol levels. Calbistrins were proposed to inhibit sterol production (Patent No. CA2063230A1, 1992), however published results confirming this are lacking. Notably, lovastatin's ability to mimic HMG-CoA relies on the metabolysis of a $\beta$-hydroxylactone ring to a $\beta$-hydroxy acid from the decalin moiety, enabling it to fit into the active site of HMG-CoA reductase. Calbistrins do not possess this structure, but they do have analogous open and closed hemiacetal ring forms, immediately adjacent to the decalin. It is unclear what affect, if any, this difference would have on calbistrin's association with HMG-CoA reductases. 
Whether HMG-CoA inhibitors such as statins are produced by filamentous fungi primarily for regulation of their own mevalonate pathways or whether they are produced as an antibiotic secretion interfering with the growth of competitors, as originally predicted (Akira Endo, 2008), remains unclear. Perhaps both answers are true. Analogs of lovastatin have been shown to inhibit the growth of yeasts (Lorenz et al., 1990; Macreadie et al., 2006), as have calbistrins A and B (Jackson et al., 1993). Calbistrins have not yet been shown to inhibit the growth of filamentous fungi, however. In microtiter bioassays against EP155 conidia, calbistrin $\mathrm{P}$ had no inhibitive effect at concentrations up to $100 \mathrm{ug} / \mathrm{ml}$. Calbistrin $\mathrm{P}$ is thus either not an inhibitor of filamentous fungal growth, not an active form of the molecule, or exogenous applications are not effective. Alternatively, healthy cells may be immune to such inhibitors, where compromised cells such as those undergoing VI are vulnerable - or, calbistrin could act as an adjuvant in combination with other bioactive molecules. Additionally, calbistrin P is likely a degraded or metabolized form of another calbistrin: calbistrin A's rapid degradation into deformylcalbistrin A (difference $=$ loss of $\mathrm{CH} 20$ ) and other, less bioactive products in the presence of alkaline conditions and /or light was demonstrated shortly after calbistrins' discovery (Horn et al., 1993). One of the many calbistrin and decumbenone-related signals in the present time course study of VI reactions shows a mass difference equal to - $\mathrm{CH} 2 \mathrm{O}$, lending support for the theory of calbistrin P's degradation into other forms, potentially including deformylcalbistrin forms. Rapid degradation of calbistrins under natural conditions may strengthen the case for their involvement either as a signal molecule, or as a short-acting growth inhibitor with localized effects.

\subsection{FARNESYL S-OXIDE ANALOGS}

3.5.1 Identification of Two Farnesyl-S-Oxide Analogs 
Compound $\mathbf{3}$ was obtained as a brown, greasy solid, $[\mathrm{M}+\mathrm{Na}]+m / z=383.18661$, UV absorbance spectra $(u=200)$. Analysis of NMR data from H-NMR, C-NMR, HSQC and HMBC indicated the presence of a modified farnesyl group, bonded via a sulfoxide to a hydroxylated, three-carbon carboxylic acid chain (Fig. 8, NMR table in Appendix B, Table S2). The sodiated adduct corresponding to compound 3 (RT4.49_383.18661) appeared to increase linearly over time in the VI agar samples (Appendix A, Fig. S2c). Bioassays showed no inhibition of germination or growth of EP155 conidia when inoculated at 500CFU/ml in PDB containing up to $100 \mu \mathrm{g} / \mathrm{ml}$ of compound $\mathbf{3}$.

Closer examination of the MS spectra revealed the presence of a related signal, eluting slightly later at $4.66 \mathrm{~min}$, significantly detected in VI cultures with $m / z=353.17633([\mathrm{M}+\mathrm{Na}]+)$. The sodiated $\mathrm{m} / \mathrm{z}$ of this signal showed a mass difference of 30.01028 when compared to the sodiated signal of compound $\mathbf{3}$, matching the exact mass of $\mathrm{CH} 2 \mathrm{O}$ (30.01001). This compound was not produced in enough abundance for purification, however its $\mathrm{MS}^{2}$ fragment spectral pattern matched that of compound $\mathbf{3}$, with $\mathrm{CH} 2 \mathrm{O}$-associated mass differences occurring among carboxylic acid moiety-associated fragments (see Appendix C, Fig. S4 for fragment spectral predictions). Based on the MSMS fragmentation data, compound $\mathbf{5}$ is predicted as a likely structure, although no NMR experiments have yet been performed to support this further.

\subsubsection{Farnesyl s-oxide (2) as a Byproduct of Mating Pheromone Processing During VI}

Two non-exclusive hypotheses predict the association of compound $\mathbf{3}$ with cell signaling. First, it is likely the product of mating pheromone metabolism. Second, the structure of this molecule and its detection in the media suggests it could directly affect neighbouring cells, in a manner similar the structurally simpler compound farnesol (Hornby et al., 2001; Semighini et al., 2006). 


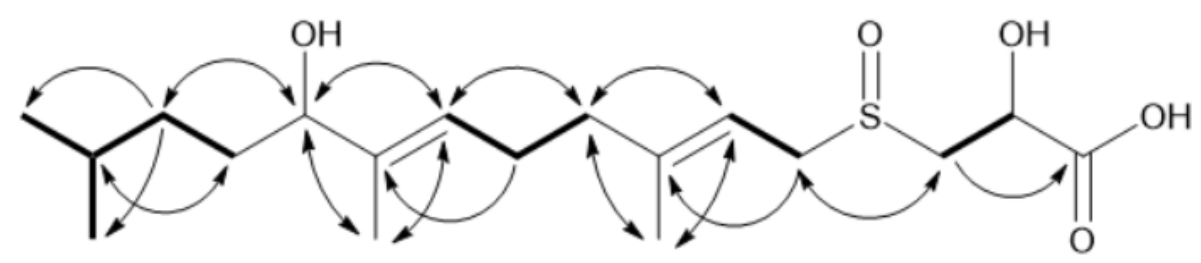

Figure 8. Farnesyl S-oxide (3) COSY (bold lines) and HMBC (arrows) correlations.

The first hypothesis is supported by compound 3's structural similarity to farnesyl-scysteine, which likely results from metabolism of $C$. parasitica type 'a' mating pheromones. $C$. parasitica mating pheromones show homology to Saccharomyces cerevisiae mating pheromones, of which there are two types, 'a' and $\alpha$. The type 'a' pheromone exhibits a conserved ' $\mathrm{CAAX}$ ' motif at the c-terminal of the protein, where $\mathrm{C}$ is a cysteine targeted for farnesylation by a farnesyltransferase, $\mathrm{A}$ is any aliphatic amino acid, and $\mathrm{X}$ is of a diverse selection of amino acids (Schafer et al., 1992). Type 'a' pheromones undergo multiple posttranslational modifications, including cysteine farnesylation, removal of the -AAX peptides, and carboxymethylation, allowing the pheromone to target mating-type G-protein-coupled receptors (GPCRs) in nearby cell membranes (Xue et al., 2008). Activation of fungal mating-type GPCRs produces a complex transcriptomic response arresting normal cell cycles and induces sexual differentiation in S. cerevisiae (Bardwell et al., 1994), as well as chemotropic growth of "female" trichogyne structure towards "male" conidia in N. crassa (Bistis, 1981, 1983).

In C. parasitica, type 'a' pheromone genes are slightly different from canonical type 'a' pheromones in that there are two copies: $m f 2-1$ and $m f 2-2$, which are not thought to encode different finished products due to identical amino acid sequences in the processed, 'final' pheromone form (Zhang et al., 1998). Both $m f 2-1$ and $m f 2-2$ were significantly differentially expressed during VI between mat-2 strains incompatible at vic1, vic2, vic3, vic6 and vic7 loci $(\mathrm{LFC}=13.31$ and 9.55 for $m f 2-1$ and $m f 2-2$ respectively during vic3 $\mathrm{VI}, \mathrm{p}$-values $<0.05)($ Belov, 
2018). Additionally, an upregulated predicted farnesyltransferase $(C p 266015, \mathrm{LFC}=2.09, \mathrm{p}$ value $<0.05$ ) is relevant to pheromone post-translational processing during vic3 incompatibility. Aside from mating pheromones, there are no other obvious DE genes that encode predicted proteins with the CAAX motif in VI transcriptomes, although it is possible that signals from compound 3 could originate from other digested lipoproteins not differentially regulated during VI.

Initiation of the sexual cycle during the interaction of EP155 and P74-3 is unlikely given they are of the same mating type, mat-2. Type 'a' pheromonal upregulation or perception in $C$. parasitica may therefore serve diverse functions apart from initiating sexual differentiation. This is not a novel assertion: a null mutant of $m f 2 / 2$ was not just female-sterile but also produced significantly less pycnidia (asexual spore-bearing structures) and conidia, approximating the effects of hypoviral infection (L. Zhang et al., 1993), and suggesting multiple downstream effects of pheromone receptor function. Pheromone type ' $a$ ' farnesylation, interaction with GPCRs and protein proteolysis by the target cells are generally conserved mechanisms among ascomycetes and basidiomycetes during mating, however phenotypes of pheromone knockout strains are often diverse and unpredictable among species (reviewed in (Jones et al., 2011; Kothe, 2008)), again suggesting a multiplicity of functions during mating pheromone perception.

The second hypothesis, suggesting that secretion of compound $\mathbf{3}$ acts directly on interacting strains, is informed by the related but simpler compound farnesol, which has been experimentally shown to cause apoptosis, mitochondria-associated ROS production and heterotrimeric G-protein signal induction in filamentous ascomycete Aspergillus nidulans (Semighini et al., 2006), as well as a morphological changes associated with farnesol-based quorum sensing in Saccharomyces pombe, among others (reviewed in (Polke et al., 2018)). 
Additionally, if compound $\mathbf{3}$ (or modified mating type 'a' pheromone) inhibits growth-related pathways similar to those enacted during chemotropic sexual differentiation, then this inhibition may itself be 'chemotropic', enabling the creation of the 'zone of barrage' between barraging incompatible cultures.

Compound 3's lack of bioactivity against EP155 conidia does little to support the second hypothesis, although it is possible that a compound gradient would be needed for chemotropism. Until more is known on the effects of this compound over a range of microbial species, it remains unclear whether compound $\mathbf{3}$ has any active purpose or is merely an artifact of pheromone processing.

Structurally, compound $\mathbf{3}$ differs from the farnesyl-S-cysteine portion of an ' $\mathrm{a}$ ' pheromone in a few ways: it shows the presence of the s-oxide, the lack of a carboxymethyl, the oxidized distal end of the farnesyl, and the replacement of an amine with a hydroxyl. The origins of the s-oxide bond are unclear, however it is unlikely it was introduced spontaneously by extract processing as this would have produced multiple distinct chromatographic peaks due to stereoisomerism surrounding the sulfur atom. It is similarly unlikely for reactive oxygen species (ROS), experimentally verified to be produced during vic3 VI (Belov, 2018), to be spontaneously oxidizing the sulfur bond as has been demonstrated in other s-cysteine analogs exposed to hydrogen peroxide (Colín-González et al., 2012). This leaves the possibility of enzymatic sulfoxidation during VI, which is mildly supported by transcriptomic upregulation of $C p 337118$, found in an upregulated terpene biosynthesis cluster and predicted to encode a flavin-containing mono-oxygenase $(\mathrm{FMO})(\mathrm{LFC}=3.03$, $p$-value $<0.05)$ with modest homology to known S-oxide forming FMOs in humans (compared to protein FMO5, \% ID = 35.2, \% Coverage $=39.5$, Evalue $=3.77$ E-21) (Ripp et al., 1997). The S-oxide form of pheromone 'a' has been previously 
documented in ascomycete and basidiomycete yeasts, where it typically appears in very low concentrations alongside non-sulfoxygenated pheromones (Miyakawa et al., 1982; Stotzler et al., 1976). In Rhodosporium toruloides, a basidiomycete yeast, Miyakawa et al. (1982) observed that presence of the sulfoxide bond inhibited sexual differentiation, in contrast to the presence of non sulfoxygenated pheromones. Support for sulfoxidated pheromones inhibiting mating type differentiation is sparse in the literature, however it is reasonable to suggest stress-response pathways involving ROS production could thus act to neutralize potential GPCR activation by lipoproteins. More support is needed to develop this hypothesis.

Additional differences between the farnesyl S-oxide analogs described here and farnesylS-cysteine may offer clues to altered interactions in C. parasitica. Hydroxylation of the distal end of the farnesyl moiety could alter the dynamics of pheromone-membrane interactions, reducing the permeability of this lipopeptide and affecting its function. The lack of c-terminal methylation in compound $\mathbf{3}$ is interesting because methylation at the c-terminal is considered important for functionality of $S$. cerevisiae mating type 'a' pheromones, and because the closest C. parasitica homolog to STE14, a carboxymethylase involved in type-a pheromone carboxymethylation in S. cerevisiae, is upregulated in VI transcriptomes (putative protein = Cp222606)(Hrycyna et al., 1991; Sapperstein et al., 1994). Lack of carboxymethylation may indicate alteration of the classic pheromone processing pathway, or some unknown mechanism of pro-pheromone methylation inhibition. Finally, the substitution of the cysteine amine with a hydroxyl group is perhaps not unusual: this process likely begins with a transamination reaction catalyzed by the pyridoxal phosphate (PLP) of an aminotransferase. From there, compound 3 could be produced via reduction of the resulting alpha keto acid via any of numerous redox 
pathways, or compound 5 could result from by thiamine pyrophosphate (TPP) or vitamin B1associated metabolism, a common process in all living cells.

\subsection{LYSOPHOSPHATIDYLCHOLINES AND LIPID DISACCHARIDES}

\subsubsection{Detection of Putative Lysophosphatidylcholines Suggests Membrane Lipid Modification}

\section{During VI}

Three significant VI mycelium-associated signals with $\mathrm{m} / \mathrm{z} 518.32441,520.34112$ and 522.35676 eluted at discrete times (Fig. 3) and were characterized as the protonated adducts of a family of compounds with chemical formulas $\mathrm{C} 26 \mathrm{H} 52 \mathrm{NO} 7 \mathrm{P}, \mathrm{C} 26 \mathrm{H} 50 \mathrm{NO} 7 \mathrm{P}$ and $\mathrm{C} 26 \mathrm{H} 48 \mathrm{NO} 7 \mathrm{P}$ (6-8). In all cases, $\mathrm{MS}^{2}$ fragmentation patterns revealed the presence of a fragment $\mathrm{m} / \mathrm{z}$ corresponding to the exact mass of the protonated phosphatidylcholine head group fragment (predicted $m / z=184.07332$ ) (Appendix C, Fig. S5). Further spectral analysis suggested the parent compounds are lysophosphatidylcholines (LPCs) 18:1, 18:2 and 18:3, corresponding to between one and three unsaturations in an $18 \mathrm{C}$ fatty acid chain. The exact location of the diene bonds is uncertain as these signals were not purified and submitted to NMR analysis due to insufficient production.

Little is known about the role of LPCs in filamentous fungi, aside from a study of LPC association with nutrient transfer between plants and symbiotic mycorrhizal fungi (Drissner et al., 2007), making it impossible to hypothesize their precise function during VI. LPCs are commonly found in eukaryotic cells and are metabolic products of phosphatidylcholine hydrolysis, a reaction often catalyzed by phospholipase A2 (PLA2) enzymes (Van Den Bosch, 1980). In plants, LPC production has been associated with wound response and defense (Narvaez-Vasquez et al., 1999; Viehweger et al., 2002). Among mammals, LPCs were the first molecular signals associated with phagocytic attraction to apoptosing cells, and were produced 
via calcium-independent iPLA2 enzymes activated by pro-apoptotic protein caspase- 3 during apoptosis (Lauber et al., 2003). LPCs have the potential to be pore-opening molecules when asymmetrically abundant in membranes (Kumamoto, 2008), and show activity as membranealtering "signal regulators" of proton-sensing GPCRs (L. Wang et al., 2005). This could be of interest to vic3 incompatibility because patatin-like phospholipase (PLP) is a calciumindependent PLA2 predicted to be involved with numerous vic and het loci, and one of the BGCs upregulated during vic3 VI bears a gene with predicted PLP domain (curvupallide BGC, discussed below in section 3.7).

\subsubsection{Predicted Lipid Disaccharides Peak on Day Six After Co-inoculation}

Three significant mycelium-associated signals with $\mathrm{m} / \mathrm{z} 689.41139,703.42587$ and 717.44299 (all $[\mathrm{M}+\mathrm{Na}]+$, eluting at 5.92, 6.03 and 6.16 minutes, respectively) were detected with isotope patterns and exact masses within 5ppm of the sodiated adducts of $\mathrm{C} 33 \mathrm{H} 62 \mathrm{O} 13$, C34H64O13 and C35H66O13, each predicted to have 2 double bond equivalents (9-11). All shared similar in-source fragmentation patterns. Unfortunately, compound production was insufficient for isolation. Compound 9 was detected in the least abundance and no further analyses were done on this signal. However, MSMS fragmentations patterns of compounds $\mathbf{1 0}$ and 11 revealed sequential neutral losses of the mass equivalent of two hexose moieties, leaving putative saturated 22 and 23C fatty acids. Detection of all three features peaked on day 6 after co-inoculation, and was sharply reduced thereafter, suggesting a possible role as signal or intermediary molecule. MSMS fragmentation analysis from MSFINDER and CSI-Finger ID predicted the known molecule "13-sophorosyloxydocosanoic acid" as the only database match to compound $\mathbf{1 0}$. 
While the structure of this molecule cannot be deduced at this time since no NMR experiments were possible, spectral evidence suggests this is not exactly the predicted sophorolipid. 13-sophorosyloxydocosanoic acid is a very-long chain sophorolipid with di- and mono-acetylated variants described from the basidiomycete yeast Candida bogoriensis, now known as Rhodotorula bogoriensis, in 1968 (Tulloch et al., 1968). Later, a shorter-chain, lactonized from was described from the ascomycete yeast Starmerella bombicola, previously Candida bombicola (Spencer et al., 1970). The MS data described here do not support lactone or acetylated forms of this putative molecule. Additionally, the presence of 21- and 23-carbon fatty acid chains are unlikely to take a linear form in fungi, suggesting the presence of methylation along a shorter chain, which disagrees with the predicted compound.

Furthermore, genomic and transcriptomic evidence do not support predicted biosynthesis of sophorolipids. The gene cluster predicted to encode a shorter chain analog of this in $S$. bombicola includes two glucosyltransferases, a fatty acid hydroxylase, a transporter, an acetyltransferase, and a putative alcohol dehydrogenase (Van Bogaert et al., 2013). The $C p$ genome does not exhibit such a cluster, which might have suggested dedicated production of sophorolipids: blast results show varying levels of ID matches from genes scattered over the $C$. parasitica genome, none of which were upregulated in the transcriptomes (data not shown). However, the transcriptomic analysis may not be helpful since this data was from day 3 after coinoculation, whereas the metabolomic signals of glycosylated lipids appear sharply on day 6 and decline immediately after (Fig 4). It is reasonable to suggest then the simple annotation of a disaccharide attached to an unsaturated lipid. Further analysis is necessary to expand on this annotation, however given their strong association with VI mycelium samples as well as 
predicted unsaturated long-chain carbon content, it is likely they are modified membrane constituents.

\subsection{CURVUPALLIDE}

\subsubsection{A Putative BGC with Similarity to Curvupallide is Upregulated During VI}

Closer inspection of putative biosynthetic gene clusters differentially upregulated in the VI transcriptomes revealed the presence of a 14-gene cluster on scaffold 4 with homology to the curvupallide biosynthetic gene cluster described from ascomycete plant pathogen Curvularia pallescens, anamorph of Cochliobolus pallescens (Fig. 9) (Abraham et al., 1995; Yokoyama et al., 2017). These homologs have between 60-80\% ID match at the amino acid level, with two exceptions: $c p a D$, a transcription factor (53.4\%); and $c p a H$, a protein of unknown function (46.7\%) (Table 4). Genes present in the C. pallescens cluster with no homolog in the $C$.

parasitica cluster include one transcription factor, cpaN2; one MFS transporter, cpaN1; and one heterokaryon incompatibility (HET) domain-containing protein, cpaM. The upregulated $C$. parasitica cluster also contains genes not present in the $C$. pallescens cluster: $C p 252545$ has a domain predicted to function as an alpha-beta hydrolase fold (e-value for domain ID = 2.58e-21); and $C p 76171$ is a putative protein with a patatin-like phospholipase (PLP) domain at the Nterminal and a tetracopeptide repeat (TPR) domain at the C-terminal. That nearly all relevant genes appear conserved between these species strongly suggests that curvupallides or similar molecules are produced during VI in C. parasitica.

HRMS signals corresponding to exact $\mathrm{m} / \mathrm{z}$ of curvupallides A (12) and B (predicted $\mathrm{m} / \mathrm{z}=$ 280.11798 for protonated molecule) are present in at least four distinct peaks sharing similar predicted in-source fragmentation patterns to curvupallides, however none were consistently statistically significant to the VI treatment when compared to monocultures, nor were they 
detected in abundance (data not shown). It is unclear whether these signals represent curvupallides.

\section{A}

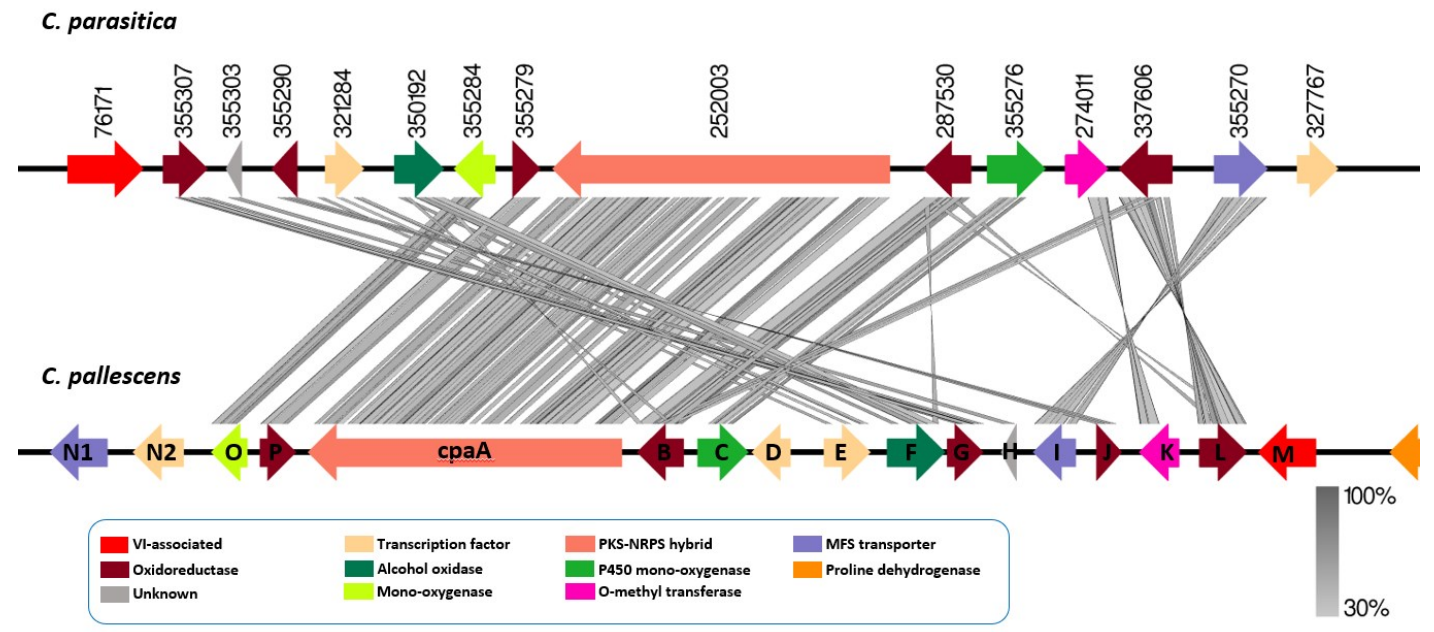

B

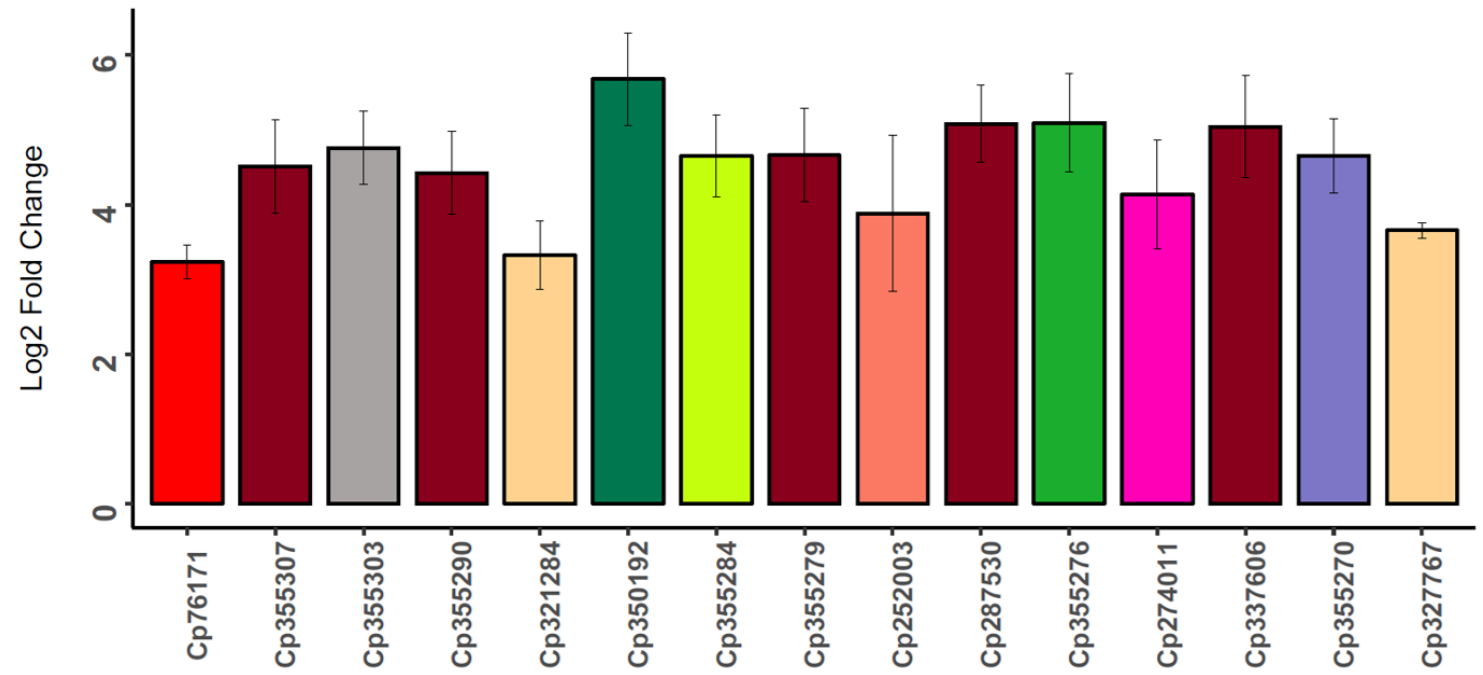

Fig 9. A: Gene cluster synteny analysis between a VI-associated cluster in C. parasitica and the curvupallide biosynthesis cluster described from ascomycete Curvullaria pallescens. Lines connecting predicted genes represent tblastn scores. Genes with multiple connections are all predicted to contain conserved FAD-binding domains. Figure made using EasyFig (Sullivan et al., 2011) B: Differential expression of genes in the putative curvupallide gene cluster which includes Cp76171, a gene with structural similarity to known genes involved in VI in all ascomycetes studied to date. 


\subsubsection{Curvupallide Cluster Accessory Genes Bear Resemblance to Other Genes Implicated in VI}

Surprisingly, the putative $C$. parasitica curvupallide cluster lacks a homolog for $C$.

pallescens' cpaM, which encodes a HET domain, since HET domain expression (and activation) induces PCD and genes containing a HET domain are commonly found in vic loci (Smith et al., 2013). However, $C p 76171$ shows homology to $p l p-2$, which encodes another protein associated with VI processes in all three ascomycetes studied so far, including "germling regulated death" (GRD) in N. crassa, vic2 associated PCD in C. parasitica, and heterokaryon incompatibility associated with the het-z locus in P. anserina (Choi et al., 2012; Heller et al., 2018). PLP-2 consists of a patatin-like phospholipase (PLP) attached to a series of tetracopeptide repeats (TPR).

GRD in $N$. crassa describes the death of anastomosing conidia from incompatible haplotypes. During GRD, PLP-2 oligomerizes with PLP-1 to form a complex with unknown function but which is critical to GRD. PLP-1 is structurally similar to PLP-2 but has a nucleotide binding domain (NBD) between the PLP and TPR domains, which likely enables PLP-1 to function as a molecular "switch" due to conformational changes associated with the NBD. PLP-1 was shown to monitor the product of $\sec 9$, a membrane-bound SNARE protein essential to the transport of vesicles. Allelic differences between anastomosing germlings at either $\sec 9$ or $p l p-1$ result in conformational changes in PLP-1, which then oligomerizes with PLP-2 to promote the rapid induction of programmed cell death in an as-yet unknown pathway (Heller et al., 2018).

Cp76171 appears to lack the functional capacity of a molecular switch, making it unclear how this links to VI. It is tempting to speculate that the upregulation of this gene in VI pairings increases either signal strength or sensitivity if a similar functional switch has been triggered elsewhere. Such an event could happen if this cluster was found to be upregulated during vic2 
associated incompatibility, which has not been studied at the metabolomic level. However, this hypothesis lacks support from the transcriptomic analysis of vic3 incompatibility, as there were no genes upregulated in the "day 3" VI transcriptomes with strong homology to plp-1.

Another hypothesis of interest to this study is perhaps simpler: $C p 76171$ modifies membrane constituents. This hypothesis lacks direct empirical evidence, however $C p 76171$ is predicted to function as an iPLA2, a class of enzyme which could modify membrane constituents to produce lysolipids such as the putative LPCs detected in this study.

Table 4. Putative proteins within predicted curvupallide gene cluster in C. parasitica

\begin{tabular}{|c|c|c|c|c|c|c|c|}
\hline $\begin{array}{l}C p \text { protein } \\
\text { ID }\end{array}$ & $\begin{array}{l}\text { Homolog } \\
\text { ID }\end{array}$ & $\begin{array}{l}\text { Size } \\
\text { (aa) }\end{array}$ & $\begin{array}{l}\text { BLASTp } C . \\
\text { pallescens }\end{array}$ & $\begin{array}{l}\text { ID } \\
\%\end{array}$ & $\begin{array}{c}\text { \% } \\
\text { Cov }\end{array}$ & C. parasitica conserved domain predictions & $\begin{array}{l}\text { Domain e- } \\
\text { value }\end{array}$ \\
\hline 252003 & cpaA & 4050 & BAZ95823.1 & 62 & 88.8 & $\begin{array}{c}\text { PKS-NRPS (AT, DH, MT, KR, ACP, NRPS, } \\
\text { TE) }\end{array}$ & 0 \\
\hline 287530 & сраB & 567 & BAZ95824.1 & 71.2 & 95.1 & FAD/FMN containing dehydrogenase & $4.58 \mathrm{E}-13$ \\
\hline 355276 & cpaC & 530 & BAZ95825.1 & 71.1 & 87 & Cytochrome P450 & $1.03 \mathrm{E}-31$ \\
\hline 327767 & cpaD & 513 & BAZ95826.1 & 53.4 & 37.6 & GAL4-like ZN(II)Cys6 DNA-binding domain & $8.42 \mathrm{E}-08$ \\
\hline 321284 & cpaE & 408 & BAZ95827.1 & 54 & 74 & None predicted & NA \\
\hline 350192 & cpaF & 594 & BAZ95828.1 & 60.6 & 94.1 & Alcohol oxidase (FAD/FMN dehydrogenase) & $1.25 \mathrm{E}-09$ \\
\hline 355307 & cpaG & 408 & BAZ95829.1 & 75.2 & 102 & NAD-binding oxidoreductase & $1.81 \mathrm{E}-17$ \\
\hline 355303 & сраH & 165 & BAZ95830.1 & 46.7 & 83 & DUF 3237 & $1.86 \mathrm{E}-20$ \\
\hline 355270 & cpaI & 572 & BAZ95831.1 & 75.7 & 79.7 & Drug resistance, transport, MFS pump & $2.87 \mathrm{E}-88$ \\
\hline 355290 & cpaJ & 296 & BAZ95832.1 & 63 & 93.2 & Oxidoreductase, Short chain reductase & $1.91 \mathrm{E}-24$ \\
\hline 274011 & сраK & 399 & BAZ95833.1 & 67.1 & 99.7 & O-methyl transferase & $3.39 \mathrm{E}-19$ \\
\hline 337606 & cpaL & 578 & BAZ95834.1 & 65 & 84.4 & FAD/FMN binding dehydrogenase & $8.17 \mathrm{E}-12$ \\
\hline 355284 & $\mathrm{cpaO}$ & 420 & BAZ95821.1 & 75.9 & 96 & FAD-dependent oxidoreductase & $4.45 \mathrm{E}-15$ \\
\hline 355279 & cpaP & 322 & BAZ95822.1 & 73.5 & 90.4 & Oxidoreductase, Fe-dependent & $9.76 \mathrm{E}-62$ \\
\hline 76171 & NA & 666 & NA & NA & NA & $\begin{array}{c}\text { Patatin-like phospholipase, Tetracopeptide } \\
\text { Repeat }\end{array}$ & $5.59 \mathrm{E}-48$ \\
\hline
\end{tabular}

Why were there no curvupallide signals significant to barraging cultures? If known curvupallides were produced, it is likely that the extraction and UPLC-HRMS protocols used in this study would have led to their detection, as curvupallides are known to be soluble in ethyl acetate and ionize well (Abraham et al., 1995). There are many reasons why hypothetical 
curvupallide-associated signals are not associated with VI metabolomes: the proposed gene cluster could be producing a new variant of curvupallide which was among the unidentified signals in this study; curvupallides could be transformed into another product during VI; or there could be post-transcriptional inhibition of curvupallide production. The transformation hypothesis is especially appealing given the precedent of functional modifications to putative decumbenones during VI by the addition of the dioic acid moiety. Further experimentation is required to support any of these hypotheses.

\subsection{SKYRINS AND OTHER BISANTHRAQUINONES}

\subsubsection{Skyrins and Rugulosins are Potent Bioactive Molecules Produced by C. parasitica}

Considering the genetic potential for natural product biosynthesis in C. parasitica (Table 1), studies exploring this devastating pathogen's natural product diversity are few. In the 1950s researchers discovered the origins of rich orange and red colours were in large part to the presence of various forms of "dimerized" anthraquinones, (sometimes called bisanthraquinones), including skyrins and rugulosins (Shibata et al., 1955). Production of anthraquinones is commonly detected across many fungal taxa, and some have shown potent fungicidal, herbicidal, antiviral, insecticidal and carcinogenic bioactivities, making them promising resources for future therapeutic development (Fouillaud et al., 2016; Gessler et al., 2013).

Skyrin is a symmetric homodimer of the much-studied anthraquinone 'emodin', a potent antioxidant with numerous bioactivities against human cancer cell lines (Srinivas et al., 2007). Skyrin, iridoskyrin, rubroskyrin and erythroskyrin were first characterized from cultures of Penicillium islandicum in 1954 (Howard et al., 1954) and shortly after, skyrin and the related bisanthraquinone rugulosin were identified from C. parasitica (Shibata et al., 1955). Skyrins, like emodin, have shown remarkable levels of biological activity in various systems. Potential 
roles that skyrin may play (if any) in the $C$. parasitica plant invasion process are unclear:

although toxic to some plant cells in high concentrations, skyrin and rugulosin appear not to play a role in the tissue invasion through the bark of American chestnut trees (McCarroll et al., 1985). Some forms of skyrin show activity as anti-bacterials (Howard and Raistrick 1953), as DNA and RNA binders inhibiting RNA transcription (though not viral RNA polymerase activity) (Yanagi et al., 2011), and as antioxidants, absorbing free radicals and singlet oxygen (Vargas et al., 2008). The toxicity of some skyrins towards cancer cells has led to a recent resurgence of interest in this class of compounds (Jahn et al., 2017).

Table 5. Experimentally detected (putative) bisanthraquinone retention times, $m / z$ and UV absorbance maxima. None were significantly more abundant during vic3 VI over the 8 day time course.

\begin{tabular}{|c|c|c|c|c|c|c|}
\hline Peak annotation & Formula & $\begin{array}{l}\text { Predicted } \\
{[\mathrm{M}+\mathrm{H}]+}\end{array}$ & $\begin{array}{c}\text { Observed } \\
{[\mathrm{M}+\mathrm{H}]+}\end{array}$ & $\begin{array}{c}\Delta \\
\text { PPM }\end{array}$ & Peak RT & UV maxima (nm) \\
\hline Skyrin & $\mathrm{C} 30 \mathrm{H} 18 \mathrm{O} 10$ & 539.09785 & 539.09843 & -1.07 & 5.6 & $225,255,295,455$ \\
\hline Oxyskyrin & $\mathrm{C} 30 \mathrm{H} 18 \mathrm{O} 11$ & 555.09283 & 555.09322 & 0.71 & 4.94 & $220,260,300,455$ \\
\hline Rugulosin A & $\mathrm{C} 3 \mathrm{OH} 22 \mathrm{O} 10$ & 543.12910 & 543.12858 & 0.96 & 5.07 & 250,390 \\
\hline $\begin{array}{l}\text { Rugulosin B / } \\
\text { deoxyluteoskyrin }\end{array}$ & $\mathrm{C} 30 \mathrm{H} 22 \mathrm{O} 11$ & 559.12383 & 559.12384 & 0.03 & $4.56,4.82$ & 210,390 \\
\hline $\begin{array}{l}\text { Rugulosin C / } \\
\text { luteoskyrin }\end{array}$ & $\mathrm{C} 3 \mathrm{OH} 22 \mathrm{O} 12$ & 575.11883 & 575.11926 & 0.76 & 4.4 & NA \\
\hline Emodin & $\mathrm{C} 15 \mathrm{H} 10 \mathrm{O} 5$ & 271.06083 & 271.06016 & -2.45 & 4.25 & NA \\
\hline
\end{tabular}

Signatures from the HRMS data matched the predicted masses of skyrin, oxyskyrin and rugulosin A, all previously detected from C. parasitica (Shibata, 1973; Shibata et al., 1955), as well as $\mathrm{m} / \mathrm{z}$ match to other putative rugulosins or skyrin analogs not previously reported from $C$. parasitica (Table 5): multiple peaks with the mass of rugulosin B / deoxyluteoskyrin appear in the metabolomes. The exact structures of most rugulosin and skyrin-associated features detected in this study are unclear, as many mass signatures and UV absorbance patterns are shared between compounds, such as rugulosin B sharing the same $\mathrm{m} / \mathrm{z}$ as deoxyluteoskyrin, and luteoskyrin sharing $\mathrm{m} / \mathrm{z}$ with rubroskyrin. Unfortunately, many of these compounds do not have 
published UV signatures. One compound eluting at RT 5.6min with $m / z 539.08933([\mathrm{M}+\mathrm{H}]+)$ shares the exact $m / z(<5 \mathrm{ppm})$ and published UV absorbance signature of skyrin (Fig. 8)(Jahn et al., 2017; Shibata et al., 1957). This feature did not show statistical significance to the VI treatment when univariate analysis included all days from the time course, but when data was processed from each day separately, it was found to be marginally significant to VI on day 6 only (averaged $p$-value $=0.0215$, averaged LFC $=6.17$ ). Given the marginal level of significance restricted to one time point, it is unclear whether this signature is reliably associated with VI processes.

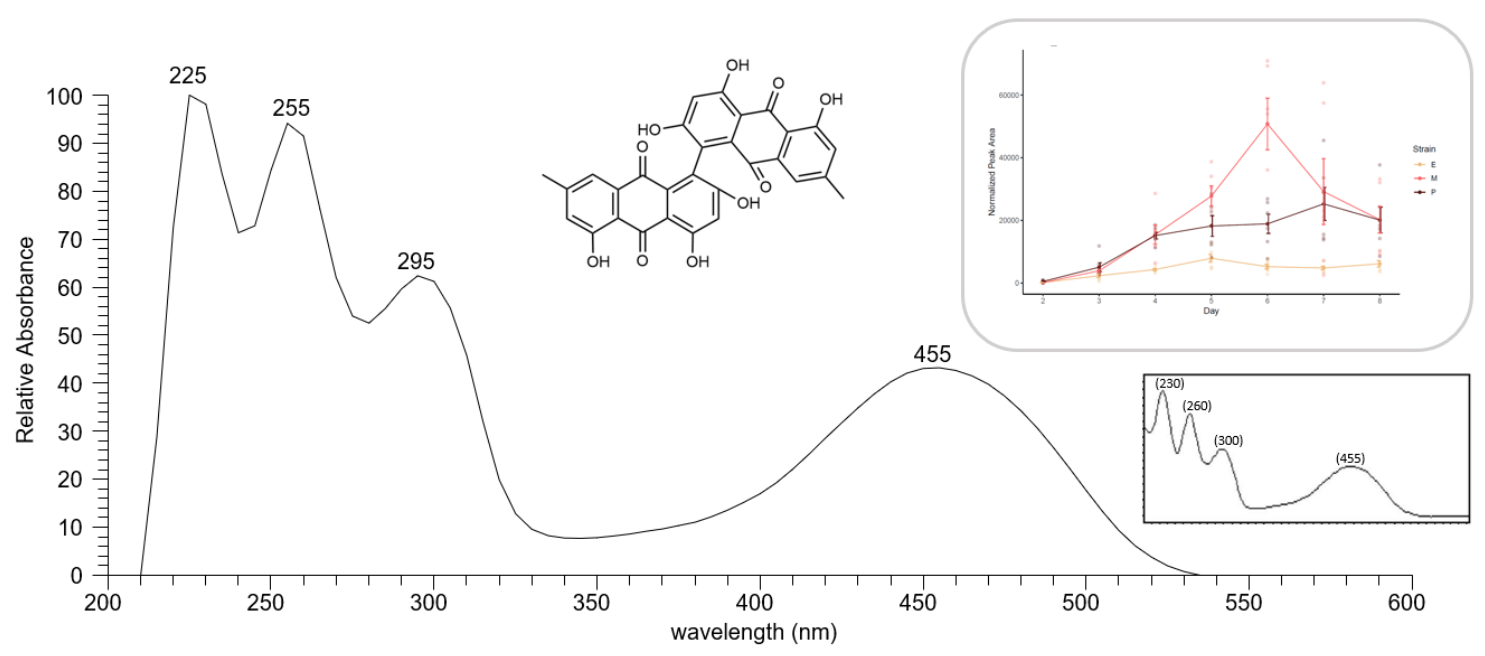

Figure 10. Experimentally derived UV absorbance signature of putative skyrin, corresponding to variable RT5.6_539.08933. Upper inset graph represents time signature of putative skyrin in all treatments (VI in red, P74-3 in brown and EP155 in yellow). Lower inset graph is a published UV absorbance signature of skyrin, adapted from Jahn et al. (2017) for comparison.

\subsubsection{Two predicted BGCs show homology to emodin/skyrin BGC in A. nidulans}

Skyrins and relatives are most likely built from the anthraquinone emodin, itself encoded by a non-reducing polyketide synthase (NR-PKS). Nine NR-PKSs were predicted by antiSMASH as being scaffold proteins in C. parasitica BGCs, and of these two showed levels of homology over $60 \%$ with greater than $90 \%$ coverage at the amino acid level to an NR-PKS 
shown via genetic knockout to be involved in the biosynthesis of emodin, an intermediate in the biosynthetic pathway for monodictyphenone and skyrin in A. nidulans (Bok et al., 2009). Both of the C. parasitica $\mathrm{BGCs}$ have product template (PT) domains considered crucial for the controlled cyclization of highly reactive poly- $\beta$-keto intermediates (Crawford et al., 2009). Closer examination of the predicted tailoring proteins in each of the two C. parasitica BGCs develops a picture of cluster-level homology (Table 6).

Table 6. Putative proteins within two predicted biosynthetic gene clusters surrounding PKS1 and PKS10 in $C$. parasitica showing blastp homology to monodictyphenone cluster from $A$. nidulans

\begin{tabular}{|c|c|c|c|c|c|}
\hline \multirow[b]{2}{*}{$\begin{array}{l}\text { Homolog } \\
\text { name }\end{array}$} & \multicolumn{2}{|c|}{ Putative PKS1 BGC } & \multicolumn{2}{|c|}{ Putative PKS10 BGC } & \multirow[b]{2}{*}{ Published Description } \\
\hline & $\begin{array}{c}\text { Cp Protein } \\
\text { ID }\end{array}$ & $\begin{array}{c}\% \text { ID / } \\
\% \text { coverage }\end{array}$ & $\begin{array}{c}\text { Cp Protein } \\
\text { ID }\end{array}$ & $\begin{array}{c}\% \text { ID / } \\
\% \text { coverage }\end{array}$ & \\
\hline$m d p A$ & 261933 & $48.1 / 76.1$ & 25889 & $41.1 / 90.7$ & $\begin{array}{l}\text { Transcriptional } \\
\text { coactivator }\end{array}$ \\
\hline$m d g D$ & -- & -- & -- & -- & $\begin{array}{l}\text { FAD-dependent mono- } \\
\text { oxygenase }\end{array}$ \\
\hline$m p d E$ & 261797 & $65 / 54.8$ & 262336 & $62.5 / 78.4$ & Regulatory protein \\
\hline$\underline{m d p F}$ & 356900 & $75.1 / 95.8$ & 323049 & $68.6 / 92.7$ & $\begin{array}{l}\text { Atrochrysone carboxyl } \\
\text { ACP thioesterase }\end{array}$ \\
\hline$\underline{m d p G}$ & 261577 & $63.8 / 92.2$ & 292843 & $66.3 / 93$ & NR-PKS \\
\hline$\underline{m d p H}$ & 73658 & $59 / 87.6$ & 356961 & $66.4 / 89.3$ & Anthrone oxygenase \\
\hline$m d g K$ & 292619 & $58.7 / 98.5$ & -- & -- & Mono-oxygenase \\
\hline$m d g L$ & 346955 & $46.2 / 84.8$ & -- & -- & Questin oxidase \\
\hline claM* $^{*}$ & -- & -- & 279251 & $40.1 / 81.3$ & Mono-oxygenase \\
\hline \multicolumn{6}{|c|}{ Blastp best hit, not in any predicted BGC } \\
\hline$m d g B$ & 336245 & $59.3 / 72.2$ & & & $\begin{array}{l}\text { Scytalone dehydratase- } \\
\text { like protein }\end{array}$ \\
\hline$m d g C$ & 255659 & $62.2 / 82.7$ & & & $\begin{array}{l}\text { Short chain } \\
\text { dehydrogenase }\end{array}$ \\
\hline$m d p J$ & 358538 & $39.5 / 30.5$ & & & Glutathione transferase \\
\hline
\end{tabular}

Underlined genes are considered crucial for the production of emodin.

* claM is a mono-oxygenase shown to dimerize anthraquinones, described from biosynthesis of the bisanthraquinone cladofulvin from Cladosporium fulvum. The C. parasitica BGC containing PKS10 has a homolog to this gene while that of PKS1 does not.

Neither putative BGC shows complete homology to the A. nidulans cluster, however all relevant genes to produce emodin are predicted to have homologs in both gene clusters. There are likely multiple biosynthetic routes towards production of emodin, as well as the potential for 
coordination between multiple BGCs to create diverse anthraquinone products. A predicted protein of interest is $C p 279251$, which shows modest homology to $c l a M$, a mono-oxygenase recently shown to dimerize anthraquinones to produce the bisanthraquinone cladofulvin in Cladosporium fulvum (Griffiths et al., 2016). The dimerization of emodin in the production of skyrin was not investigated by Bok et al. (2009) in their analysis of monodictyphenone production. In C. parasitica, both candidate skyrin BGCs have genes predicted to encode metallo-beta lactamases as well as short-chain dehydrogenases and o-methyl transferases (data not shown), suggesting the production of alternate products from those detected in A. nidulans, possibly including oxyskyrin and rugulosin. However, given the lack of both signal abundance for putative skyrin-associated molecules in metabolomes of VI cultures, as well as differential expression data supporting upregulation of either C. parasitica BCGs hypothesized to make skyrin, the biosynthetic origins of skyrin-related molecules in C. parasitica requires future experimentation to clarify. 


\subsection{Conclusions}

This study confirms vic3 VI phenotypes show significant differences in secondary metabolite production. Characterization of the most abundantly detected differences has enabled an exploratory glimpse into broad-scale VI processes at the metabolomic level, and implicates polyketide biosynthesis, mating-type pheromone metabolism and membrane constituent modification (likely involving lipid signaling). Hypotheses surrounding calbistrins and farnesyls-oxide analogs point to the heavily regulated mevalonate pathway, critical to growth and signaling processes in all eukaryotic life, as an important aspect in barraging fungal cultures. The early appearance of calbistrin-associated signals, possibly controlling the mevalonate pathway, is followed by the accumulation of farnesyl analogs, likely downstream products of the same pathway. Macroscopic observations of co-inoculations of EP155 and P74-3 at different distances underline the complexity of conspecific interactions (unpublished): when co-inoculated in close proximity ( $<10 \mathrm{~mm}$ apart), hyphae are more likely to fuse briefly (and then die back) before the incompatible cultures mount an acute barrage reaction as evident by a line of demarcation, and pigmentation. On the other hand, when strains are inoculated at opposite ends of a $10 \mathrm{~cm}$ petri plate, the colony margins tend to arrest growth short of full contact and are less likely to fuse cells. This suggests multiple layers of communication operate between colonies during development, possibly effected by diffusible small molecules. This idea aligns with recent findings of pre-fusion signaling among $N$. crassa germlings in which putative receptor genes for uncharacterized long-distance signals were associated with compatible 'kind' strain identification at a distance (Heller et al., 2016).

Close examination of the seven predicted BGCs with over five differentially expressed genes during vic3 VI suggests there are small molecules produced which were not annotated here 
(Table 1), which may be among the less abundant signals we were unable to purify (Fig. 2).

Characterizing all significant signals detected during VI was beyond the scope of this study using existing technology and reference databases. Additionally, the experimental design by necessity excluded some types of signal detection: small, highly polar molecules were likely not extracted in the ethyl acetate, nor were their ions characterized using the reverse phase column and gradient system used here. Secondly, UPLC-HRMS parameters employed in this study made exclusive use of positive-mode ion detection, limiting the types of molecules characterized (for example, lipids tend to be readily detected in negative mode). Targeted $\mathrm{MS}^{\mathrm{n}}$ fragmentation protocols were not automatable given the technology available, restricting the possibility of using large-scale molecular networking tools such as GNPS to automate the creation and comparison of pseudomolecular ion groups based on common fragment $\mathrm{m} / \mathrm{z}$ and abundance patterns (M. Wang et al., 2016). Furthermore, attempts to use GNPS and other open online databases mentioned in this study were often frustrated by the lack of $\mathrm{MS}^{2}$ and structural data available specifically for fungal secondary metabolites. Thankfully, tools and databases of these types are improving rapidly, allowing further mining of rich data sets such as those generated in this study to allow for new discoveries and testable hypotheses in the future.

One hypothesis which came from the transcriptomic analysis of vic3 VI was that 'toxins' may be upregulated and play a role either in triggering apoptosis in incompatible heterokaryons, or in maintaining the 'line of demarcation' between the colonies. This toxicity would require surrounding cells to undergo extensive stress responses and detoxification processes - also hypothetically supported in the transcriptomes. Ultimately this study neither confirms nor disagrees with this hypothesis, as many of the BGCs upon which the hypothesis was crafted have not yet been annotated, and some metabolomic signals remain uncharacterized. Rather, the 
metabolomic data supports the production of secondary metabolite classes which might be related to controlling hyphal growth, proposes mating pheromones are modified and potentially take on an altered role during VI, and implicates lipid modification and signaling. Major signals characterized here were the most abundantly produced ones, and may represent 'global' or colony-wide processes associated with barrage, rather than fine-scale signals occurring in the few cells which are undergoing PCD at any given time. If there is a toxic release during VI (and here we might expand the concept of 'toxins' to include growth inhibitors such as statins), it seems unlikely these products would be produced in heavy abundance. Rather, small amounts of toxic elements might be enough to spark a larger-scale and likely complex signal cascade which redirects growth and energy for the surrounding cells, perhaps leading to conidiogenesis and antioxidant production, and other processes.

Observations and hypotheses generated here can be furthered in at least three ways: by expanding a 'catalog' of molecules associated with VI processes, such as by including VI caused by polymorphisms at any of the other five vic loci known from C. parasitica (Biella et al., 2002)(Table 1); by investigating the function of VI-associated secondary metabolites via metabolomes between barraging strains with genetic knockouts in key biosynthetic genes; and by targeted bioactivity assays of the characterized molecules, such as in GPCR ligand binding or antibiotic assays. Bioactivity elucidation can explore the possibility that VI-associated molecules have multiple roles, and could represent 'exaptations' of innate immune system functions (Paoletti et al., 2009). These types of studies may well lead to breakthroughs in understanding filamentous fungal PCD, non-self recognition signal pathways, and provide future targets for antifungal compound research. 


\section{Appendices}

\section{Appendix A: Time course visualizations}

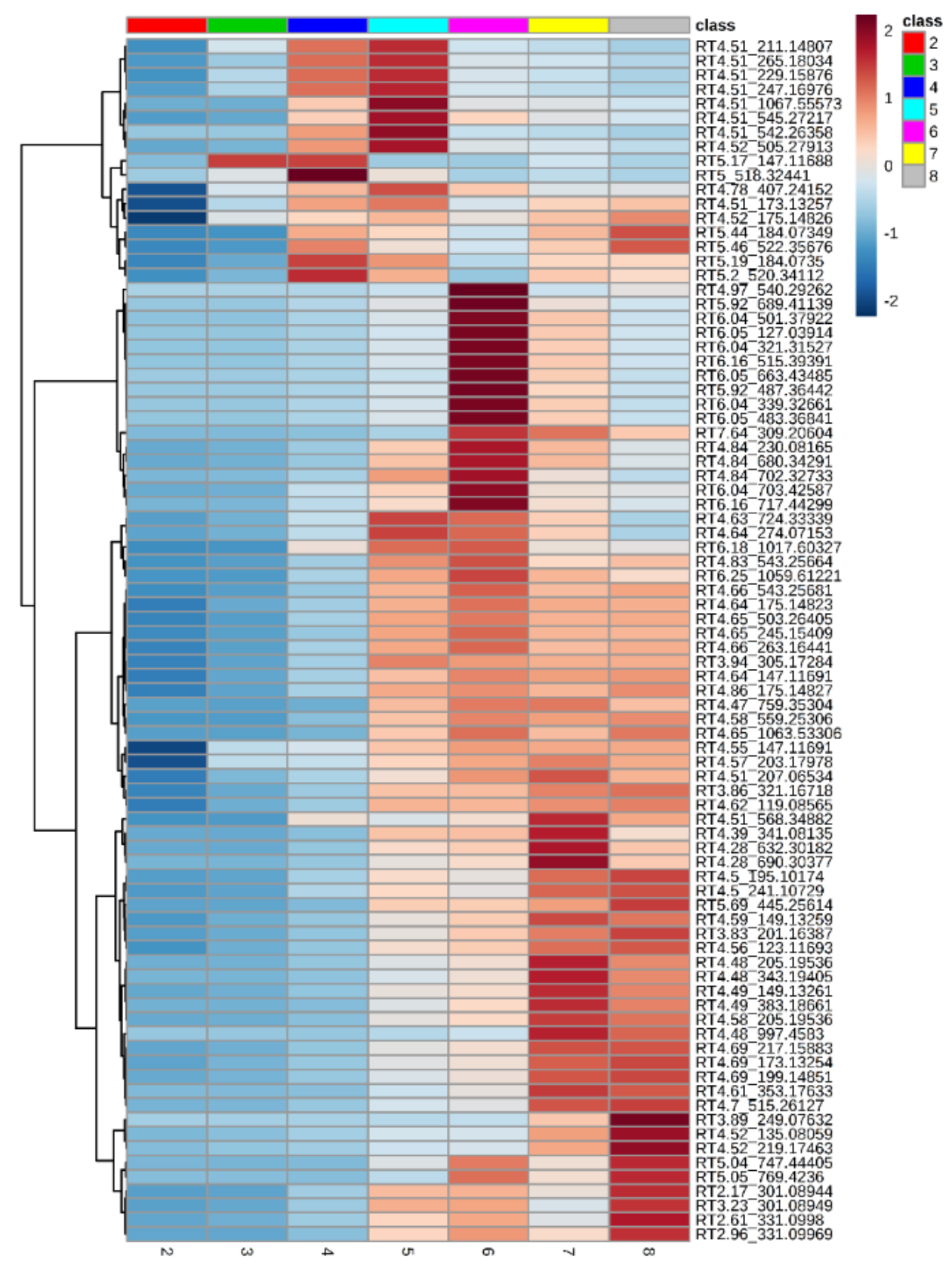

Figure S1. Heatmap visualization of feature detection over days 2 to 8 for all features significant to VI samples (agar + mycelium, $p$-values $<0.05$ from univariate analysis). Variables are scaled in the 'pareto' method and clustered using the Ward clustering algorithm (rows), whereas samples are averaged by day ( $\mathrm{n}=6$, columns). Sample nomenclature lists the retention time (after "RT"), followed by the observed exact mass/charge ratio (after the underscore). Red colours indicate higher normalized, scaled peak area values. Heatmap created using MetaboAnalyst (Xia et al., 2016). 

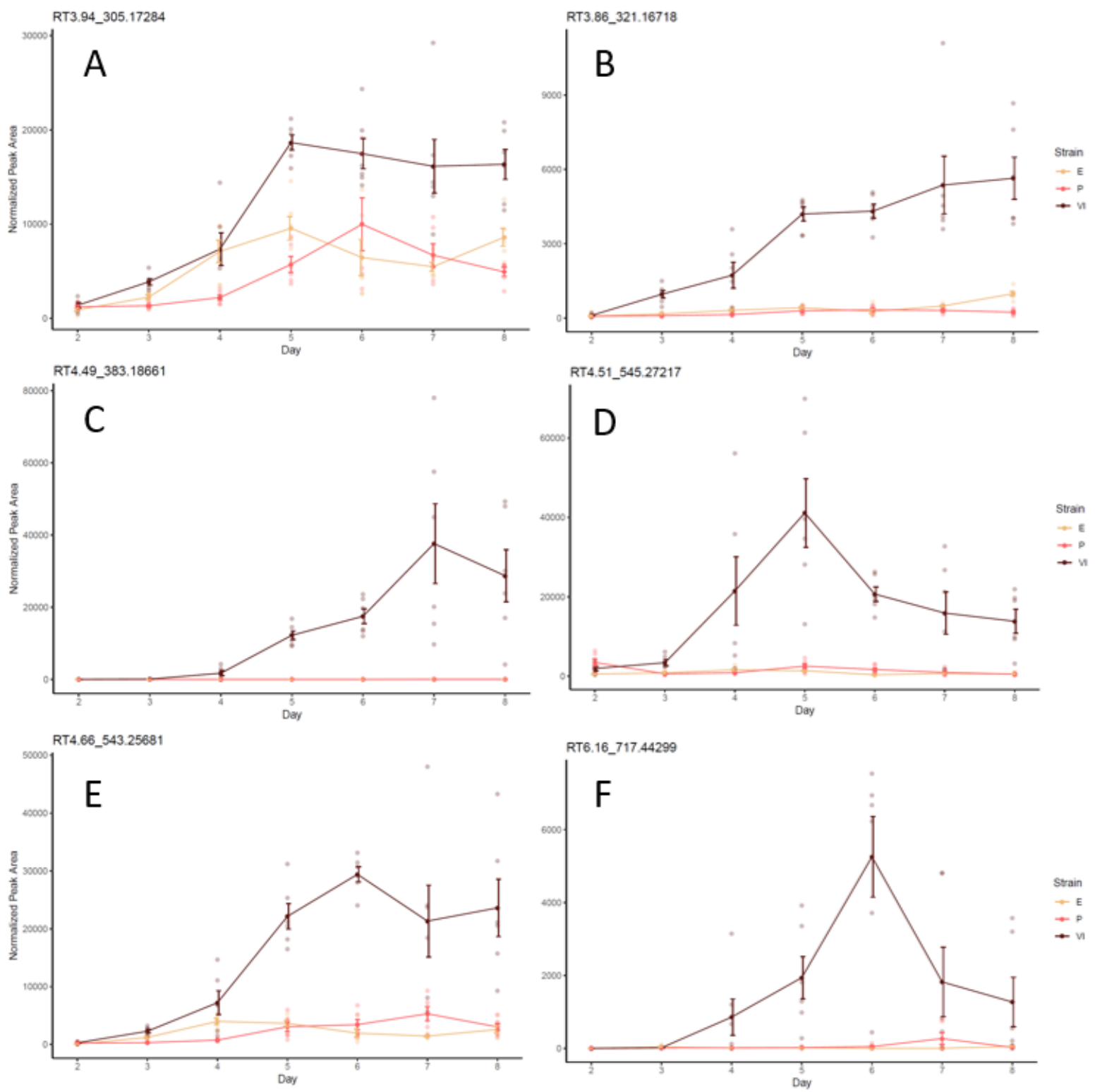

Figure S2. Six examples of line graphs showing fluctuations in normalized feature peak areas over the time course of the project for all three treatments. Strain "E" = EP155, "P" = P74-3, "VI" = a mix of the two strains. A: decumbenone B-associated signals. B: oxidized decumbenone-associated signals. C: farnesyl s-oxide (3). D: calbistrin P (1). E: calbistrin O (2) F: lipid disaccharide (23C) (11). Data visualized is from agar and mycelial extractions summed for each culture. Sample nomenclature lists the retention time (after "RT"), followed by the exact mass/charge ratio (after the underscore), to five decimal points. Lines connect means between independent biological replicates $(n=6)$. Error bars $=$ SE. 


\section{Appendix B: NMR tables}

Table S1. NMR $\left(\mathrm{CD}_{3} \mathrm{OD}, 500 \mathrm{MHz}\right)$ Data for Calbistrin $\mathrm{O}$ and $\mathrm{P}$ compared to published data describing calbistrin A (Brill et al., 1993 - coupling constants not published)

\begin{tabular}{|c|c|c|c|c|c|c|c|c|c|}
\hline \multirow[b]{2}{*}{ Position } & \multicolumn{3}{|c|}{ Calbistrin $\mathbf{P}$} & \multicolumn{3}{|c|}{ Calbistrin 0} & \multicolumn{3}{|c|}{ Calbistrin A } \\
\hline & $\delta \mathrm{H}$ (mult., $\mathrm{J}$ in $\mathrm{Hz}$ ) & $\delta C$ & Type & $\delta \mathrm{H}$ (mult., $\mathrm{J}$ in $\mathrm{Hz}$ ) & $\delta C$ & Type & H (mult.) & $\delta C$ & Type \\
\hline 1 & $5.26(\mathrm{br} \mathrm{s})$ & 73.9 & $\mathrm{CH}$ & $5.26(\mathrm{br} \mathrm{s})$ & 73.8 & $\mathrm{CH}$ & $6.02(\mathrm{~m})$ & 71.1 & $\mathrm{CH}$ \\
\hline $2 a$ & $1.9(\mathrm{~m})$ & 40.7 & $\mathrm{CH}_{2}$ & $1.93(\mathrm{~m})$ & 40.6 & $\mathrm{CH}_{2}$ & $2.19(\mathrm{~m})$ & 36.2 & $\mathrm{CH}_{2}$ \\
\hline $2 b$ & $1.18(t, 13.2)$ & & & $1.17(\mathrm{t}, 12.7)$ & & & $1.34(\mathrm{br} \mathrm{dd})$ & & \\
\hline 3 & $1.84(\mathrm{~m})$ & 28.4 & $\mathrm{CH}$ & $1.84(\mathrm{~m})$ & 28.8 & $\mathrm{CH}$ & $2.5(\mathrm{~m})$ & 28.2 & $\mathrm{CH}$ \\
\hline $4 a$ & $1.9(\mathrm{~m})$ & 42.75 & $\mathrm{CH}_{2}$ & $1.89(\mathrm{~m})$ & 42.88 & $\mathrm{CH}_{2}$ & $5.74(\mathrm{br} \mathrm{s})$ & 136.7 & $\mathrm{CH}$ \\
\hline $4 b$ & $0.81(q, 12.0)$ & & & $0.81(q, 12.1)$ & & & & & \\
\hline 5 & $2.47(\mathrm{td}, 11.8,2.0)$ & 33.61 & $\mathrm{CH}$ & $2.47(\mathrm{~m})$ & 33.6 & $\mathrm{CH}$ & -- & 131.6 & C \\
\hline 6 & $5.42(\mathrm{dd}, 10.1,1.8)$ & 131 & $\mathrm{CH}$ & $5.43(\mathrm{dd}, 10.1,2.6)$ & 130.9 & $\mathrm{CH}$ & $6.00(d)$ & 129.7 & $\mathrm{CH}$ \\
\hline 7 & $5.35(\mathrm{dd}, 10.1,2.45)$ & 134.8 & $\mathrm{CH}$ & $5.64(\mathrm{dd}, 10.1,2.72)$ & 134.8 & $\mathrm{CH}$ & $5.64(d)$ & 131.6 & $\mathrm{CH}$ \\
\hline 8 & -- & 74.9 & $\mathrm{C}$ & -- & 74.9 & $\mathrm{C}$ & -- & 78.7 & $\mathrm{C}$ \\
\hline 9 & -- & 57.7 & C & -- & 57.8 & $\mathrm{C}$ & -- & 54.8 & C \\
\hline 10 & $2.05(\mathrm{~m})$ & 46.6 & $\mathrm{CH}$ & $2.03(\mathrm{~m})$ & 46.5 & $\mathrm{CH}$ & $2.89(\mathrm{~m})$ & 41.1 & $\mathrm{CH}$ \\
\hline 11 & -- & 215.8 & $\mathrm{C}$ & -- & 213.9 & $\mathrm{C}$ & -- & 210.9 & $\mathrm{C}$ \\
\hline $12 a$ & $3.03(\mathrm{dt}, 18.2,6.8)$ & 45.59 & $\mathrm{CH}_{2}$ & $2.86(\mathrm{dd}, 14.5,8.1)$ & 48.2 & $\mathrm{CH}_{2}$ & 2.8 (none) & 48 & $\mathrm{CH}_{2}$ \\
\hline $12 b$ & $2.74(\mathrm{dt}, 18.3,3.6)$ & & & $2.4(\mathrm{dd}, 14.5,4.39)$ & & & 2.39 (none) & & \\
\hline 13 & $3.77(\mathrm{~m})$ & 58.32 & $\mathrm{CH}_{2}$ & $5.22(\mathrm{~m})$ & 92.7 & $\mathrm{CH}$ & $5.21(d)$ & 92.5 & $\mathrm{CH}$ \\
\hline 14 & $0.9(d, 6.52)$ & 22.27 & $\mathrm{CH}_{3}$ & $0.9(\mathrm{dd}, 6.72,8.88)$ & 22.27 & $\mathrm{CH}_{3}$ & $1.04(d)$ & 21.3 & $\mathrm{CH}_{3}$ \\
\hline 15 & 1.07 (s) & 27.8 & $\mathrm{CH}_{3}$ & $1.08(d, 7.67)$ & 27.7 & $\mathrm{CH}_{3}$ & $1.24(\mathrm{~s})$ & 23.5 & $\mathrm{CH}_{3}$ \\
\hline 16 & $1.42(\mathrm{~s})$ & 13.56 & $\mathrm{CH}_{3}$ & $1.41(\mathrm{~s})$ & 16.97 & $\mathrm{CH}_{3}$ & $1.33(\mathrm{~s})$ & 18.4 & $\mathrm{CH}_{3}$ \\
\hline $1^{\prime}$ & -- & 176.9 & $\mathrm{C}$ & -- & 176.7 & $C$ & -- & 176.6 & $\mathrm{C}$ \\
\hline $2^{\prime}$ & -- & 79.54 & $\mathrm{C}$ & -- & 79.5 & C & $2.52(\mathrm{~m})$ & 45.7 & $\mathrm{CH}$ \\
\hline $3^{\prime}$ & $3.67(d, 3.7)$ & 79.08 & $\mathrm{CH}$ & $3.66(d, 3.41)$ & 79.1 & $\mathrm{CH}$ & 4.07 (d) & 81.1 & $\mathrm{CH}$ \\
\hline $4^{\prime}$ & $1.96(\mathrm{~m})$ & 35.4 & $\mathrm{CH}$ & $1.96(\mathrm{~m})$ & 35.4 & $\mathrm{CH}$ & -- & 141.2 & $\mathrm{C}$ \\
\hline \multirow[t]{2}{*}{$5^{\prime}$} & $2.05(\mathrm{~m})$ & 35.9 & $\mathrm{CH}_{2}$ & $2.06(\mathrm{~m})$ & 35.9 & $\mathrm{CH}_{2}$ & $6.13(d)$ & 129.8 & $\mathrm{CH}$ \\
\hline & \multicolumn{3}{|c|}{$2.67(\mathrm{ddd}, 14.3,6.0,2.6)$} & $2.67(\mathrm{~m})$ & & & & & \\
\hline $6^{\prime}$ & $\begin{array}{l}6.12 \text { (ddd, 14.7, 7.6, } \\
6.5)\end{array}$ & 143.3 & $\mathrm{CH}$ & $6.15(\mathrm{~m})$ & 144.71 & $\mathrm{CH}$ & $6.74(d)$ & 128.5 & $\mathrm{CH}$ \\
\hline $7^{\prime}$ & $6.21(\mathrm{dd}, 15.2,11.04)$ & 131.3 & $\mathrm{CH}$ & $6.23(\mathrm{~m})$ & 131.2 & $\mathrm{CH}$ & $6.41(d)$ & 137.9 & $\mathrm{CH}$ \\
\hline $8^{\prime}$ & $7.15(\mathrm{dd}, 14.95,10.7)$ & 144.6 & $\mathrm{CH}$ & $7.23(\mathrm{dd}, 15.3,10.4)$ & 146.27 & $\mathrm{CH}$ & -- & 145.5 & $\mathrm{C}$ \\
\hline $9^{\prime}$ & $5.80(d, 15.3)$ & 123.5 & $\mathrm{CH}$ & $5.78(d, 15.3)$ & 121.19 & $\mathrm{CH}$ & $6.30(d)$ & 129.8 & $\mathrm{CH}$ \\
\hline $10^{\prime}$ & -- & 173 & $\mathrm{C}$ & -- & 171.8 & $\mathrm{C}$ & 7.7 (dd) & 141.9 & $\mathrm{CH}$ \\
\hline $11^{\prime}$ & $1.34(\mathrm{~s})$ & 22.9 & $\mathrm{CH}_{3}$ & $1.34(\mathrm{~s})$ & 22.8 & $\mathrm{CH}_{3}$ & $5.89(d)$ & 122 & $\mathrm{CH}$ \\
\hline $12^{\prime}$ & $0.97(d, 6.88)$ & 18.6 & $\mathrm{CH}_{3}$ & $0.97 \mathrm{dd}(6.96,8.34)$ & 18.7 & $\mathrm{CH}_{3}$ & -- & 171 & $\mathrm{C}$ \\
\hline $13^{\prime}$ & & & & & & & $0.89(d)$ & 14.9 & $\mathrm{CH}_{3}$ \\
\hline $14^{\prime}$ & & & & & & & $1.77(\mathrm{~s})$ & 11.4 & $\mathrm{CH}_{3}$ \\
\hline $15^{\prime}$ & & & & & & & $2.04(s)$ & 13.1 & $\mathrm{CH}_{3}$ \\
\hline
\end{tabular}

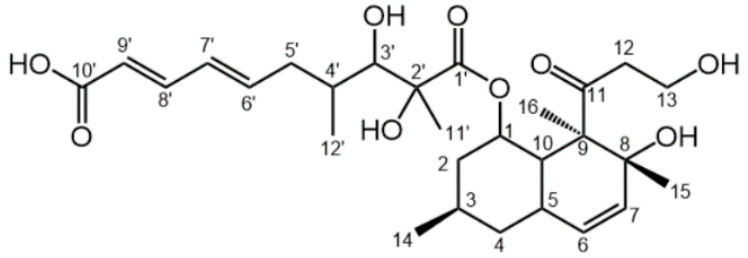
calbistrin $\mathrm{P}$

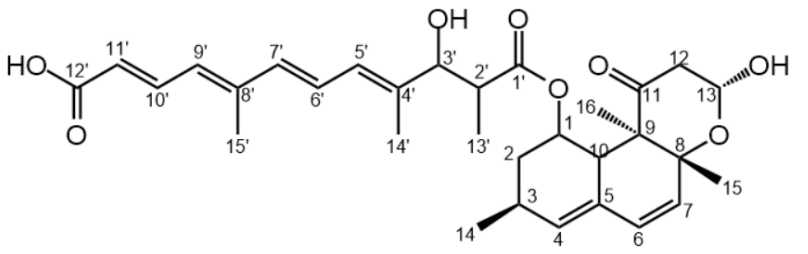

calbistrin A 
Table S2. NMR $\left(\mathrm{CD}_{3} \mathrm{OD}, 600 \mathrm{MHz}\right)$ Data for farnesyl s-oxide analog (2)

\begin{tabular}{rlrl}
\hline$\#$ & $\boldsymbol{\delta H}$ (mult., J in Hz) & $\boldsymbol{\delta} \mathbf{C}$ & Type \\
\hline 1 & $3.77(1 \mathrm{H}, \mathrm{dd}, 13.3,7.6)$ & 51.8 & $\mathrm{CH}_{2}$ \\
& $3.65(1 \mathrm{H}, \mathrm{dd}, 13.3,8.4)$ & & \\
2 & $5.37(1 \mathrm{H}, \mathrm{t}, 7.8)$ & 113.1 & $\mathrm{CH}$ \\
3 & -- & 146.5 & $\mathrm{C}$ \\
4 & $1.77(3 \mathrm{H}, \mathrm{s})$ & 17 & $\mathrm{CH}_{3}$ \\
5 & $2.19(2 \mathrm{H}, \mathrm{m})$ & 40.5 & $\mathrm{CH}_{2}$ \\
6 & $2.19(2 \mathrm{H}, \mathrm{m})$ & 26.8 & $\mathrm{CH}_{2}$ \\
7 & $5.34(1 \mathrm{H}, \mathrm{t}, 6.3)$ & 126.6 & $\mathrm{CH}$ \\
8 & -- & 138.8 & $\mathrm{C}$ \\
9 & $1.59(3 \mathrm{H}, \mathrm{s})$ & 11.1 & $\mathrm{CH}_{3}$ \\
& & & \\
10 & $3.88(1 \mathrm{H}, \mathrm{t}, 6.9)$ & 79 & $\mathrm{CH}$ \\
11 & $1.20(1 \mathrm{H}, \mathrm{m})$ & 36.3 & $\mathrm{CH}_{2}$ \\
& $1.05(1 \mathrm{H}, \mathrm{m})$, & & \\
12 & $1.51(2 \mathrm{H}, \mathrm{m})$ & 33.6 & $\mathrm{CH}_{2}$ \\
13 & $1.51(1 \mathrm{H}, \mathrm{m})$ & 29.2 & $\mathrm{CH}$ \\
14 & $0.88(3 \mathrm{H}, \mathrm{s})$ & 23 & $\mathrm{CH}_{3}$ \\
15 & $0.9(3 \mathrm{H}, \mathrm{s})$ & 23.1 & $\mathrm{CH}_{3}$ \\
1 & $3.38(1 \mathrm{H}, \mathrm{dd}, 13.5,3.8)$ & 56.6 & $\mathrm{CH}_{2}$ \\
& $2.98(1 \mathrm{H}, \mathrm{dd}, 13.4,7.9)$ & & \\
2 & $4.32(1 \mathrm{H}, \mathrm{dd}, 7.7,3.6)$ & 68.2 & $\mathrm{CH}$ \\
3 & -- & 178.4 & $\mathrm{CO}^{2}$ \\
\hline
\end{tabular}

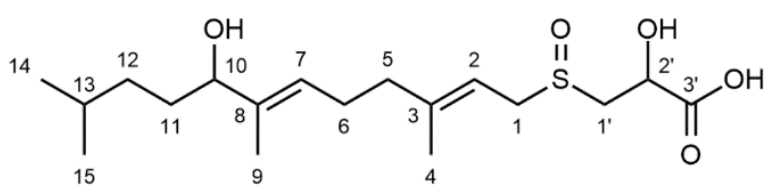




\section{Appendix C: $\mathrm{MS}^{2}$ fragmentation patterns}
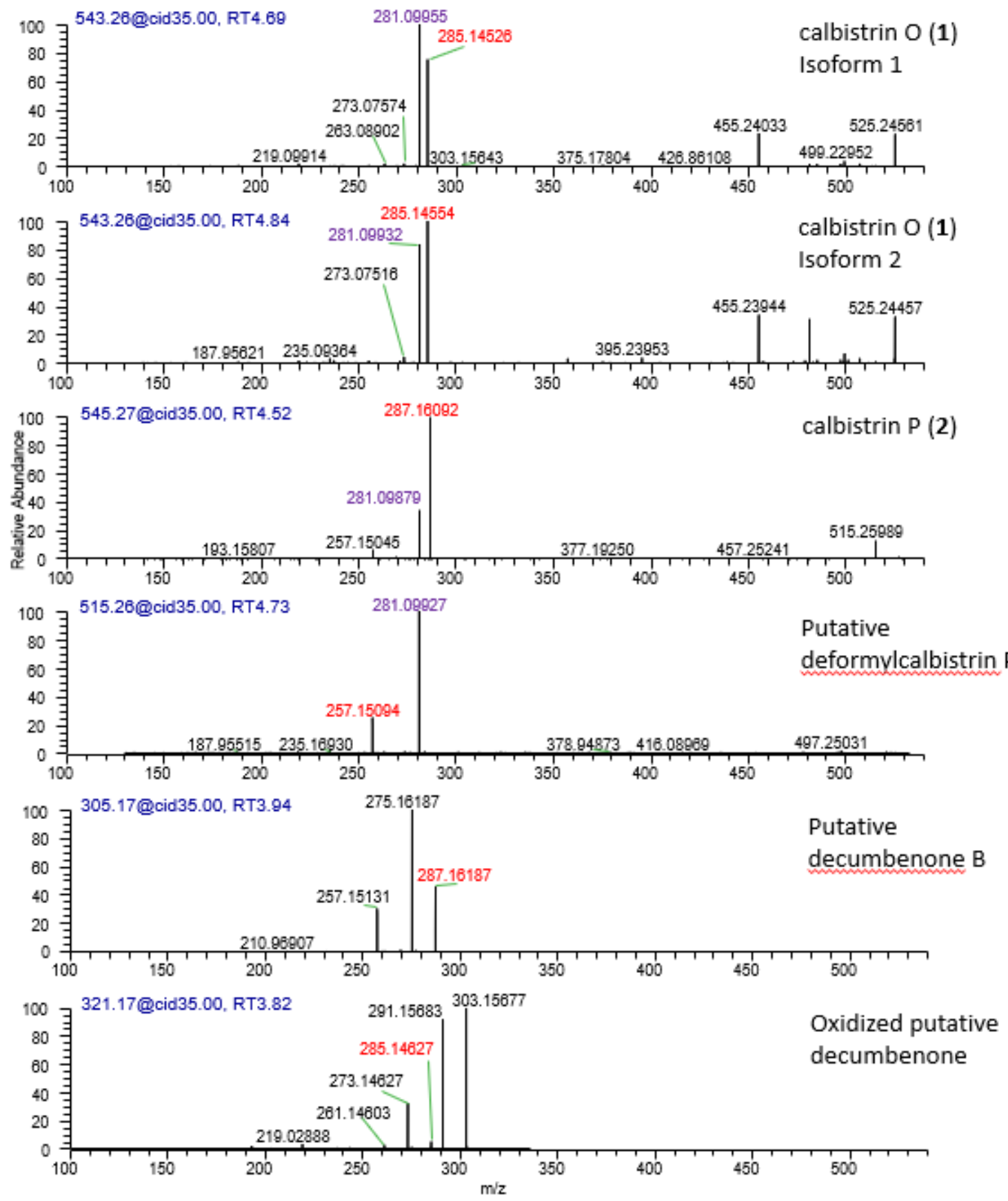

Figure S3. MSMS fragmentation spectra for calbistrin P (1) (two putative isoforms), calbistrin O (2), and putative deformylcalbistrin $\mathrm{P}$ as well as decumbenone associated signals. All parent ions are $[\mathrm{M}+\mathrm{Na}]+$. Red $m / z$ represent decalin-associated moieties in calbistrins (and matching $m / z$ in putative decumbenones, within 5ppm). Fragments with nominal $\mathrm{m} / z=281$ (in purple) match within 5ppm of exact mass of dioic acid moiety (predicted $[\mathrm{M}+\mathrm{Na}]+=281.09956)$. 


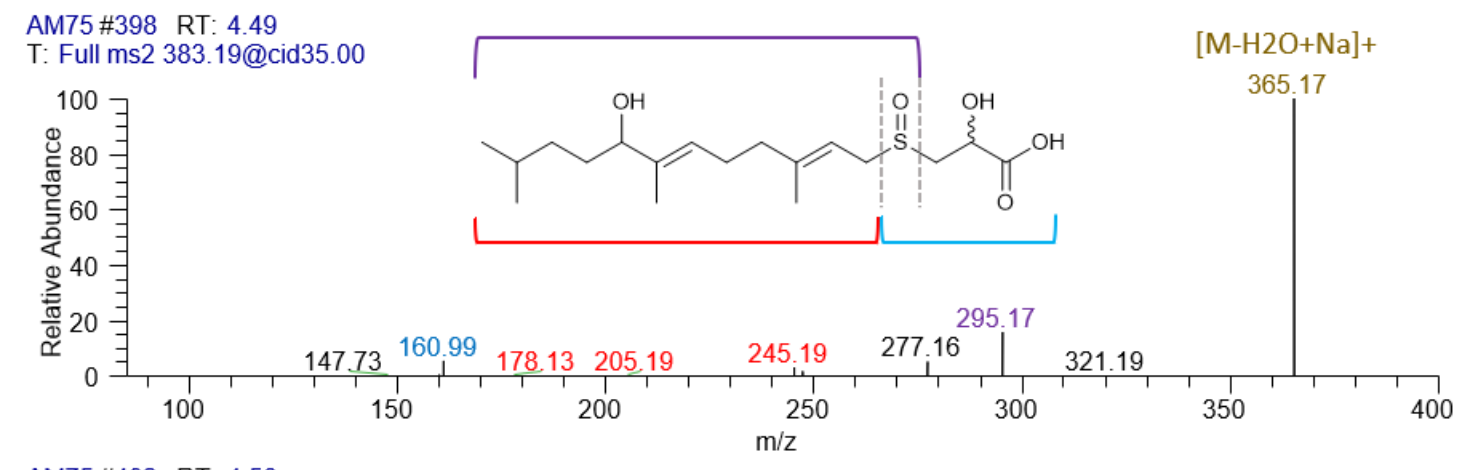

AM75 \#402 RT: 4.56

T: Full ms2 353.18@cid35.00]

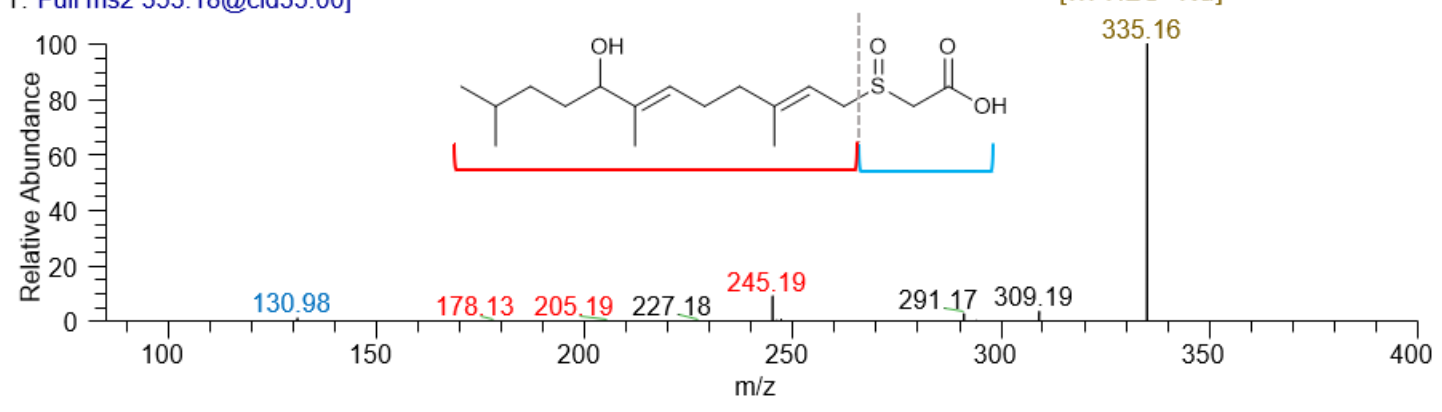

Figure S4. MSMS fragmentation spectra for farnesyl-S-oxide analog described in this paper (upper), and putative secondary analog with exact mass 353.17633. Predicted fragmentation patterns are inset in each scan. Dashed lines hypothesize fragmentation sites. Colours match $\mathrm{m} / \mathrm{z}$ to predicted fragments.
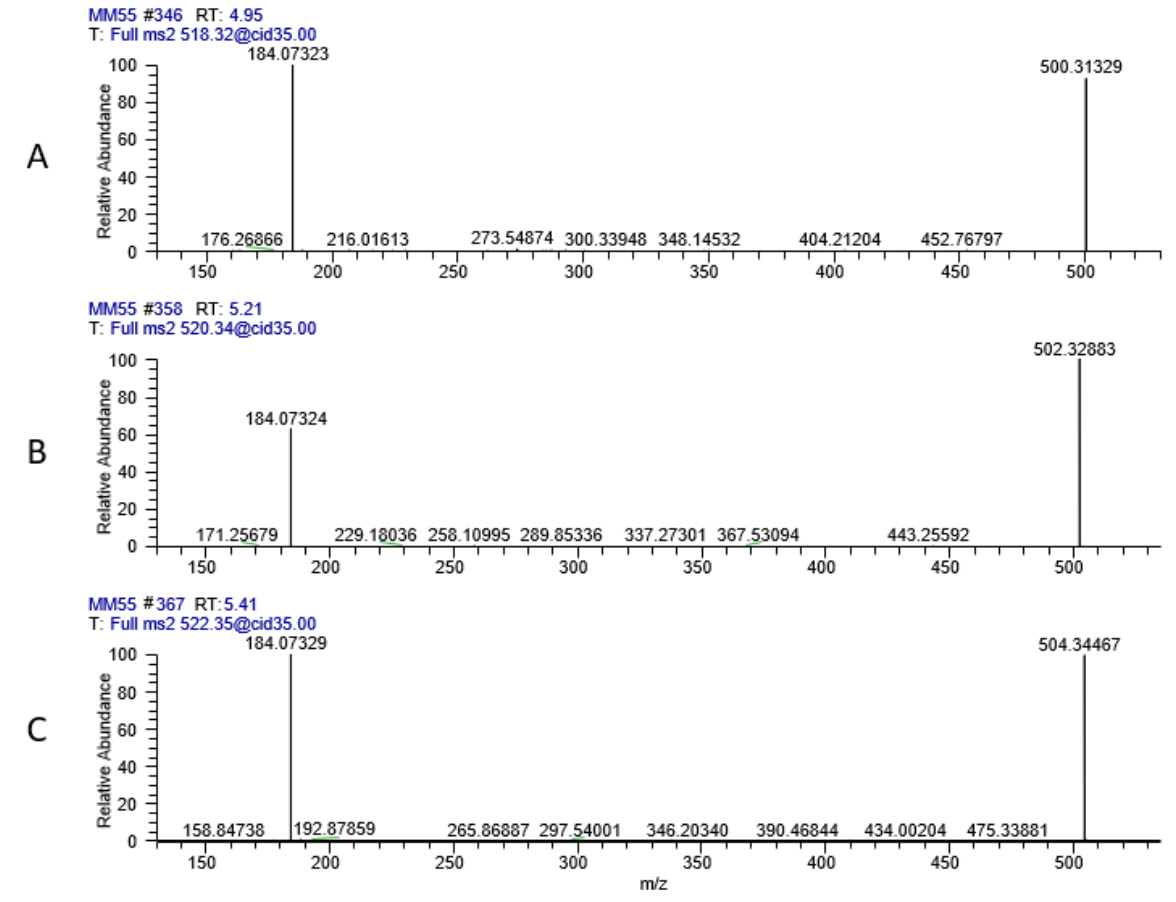

Figure S5. MSMS fragmentation spectra of putative lysophosphatidylcholines. A: LPC (18:3) B: LPC (18:2) C: LPC (18:1). Spectra are minimal and show characteristic fragmentation of the phosphatidylcholine head group at $m / z \sim 184.0732$. 


\section{Appendix D: Multivariate analyses}
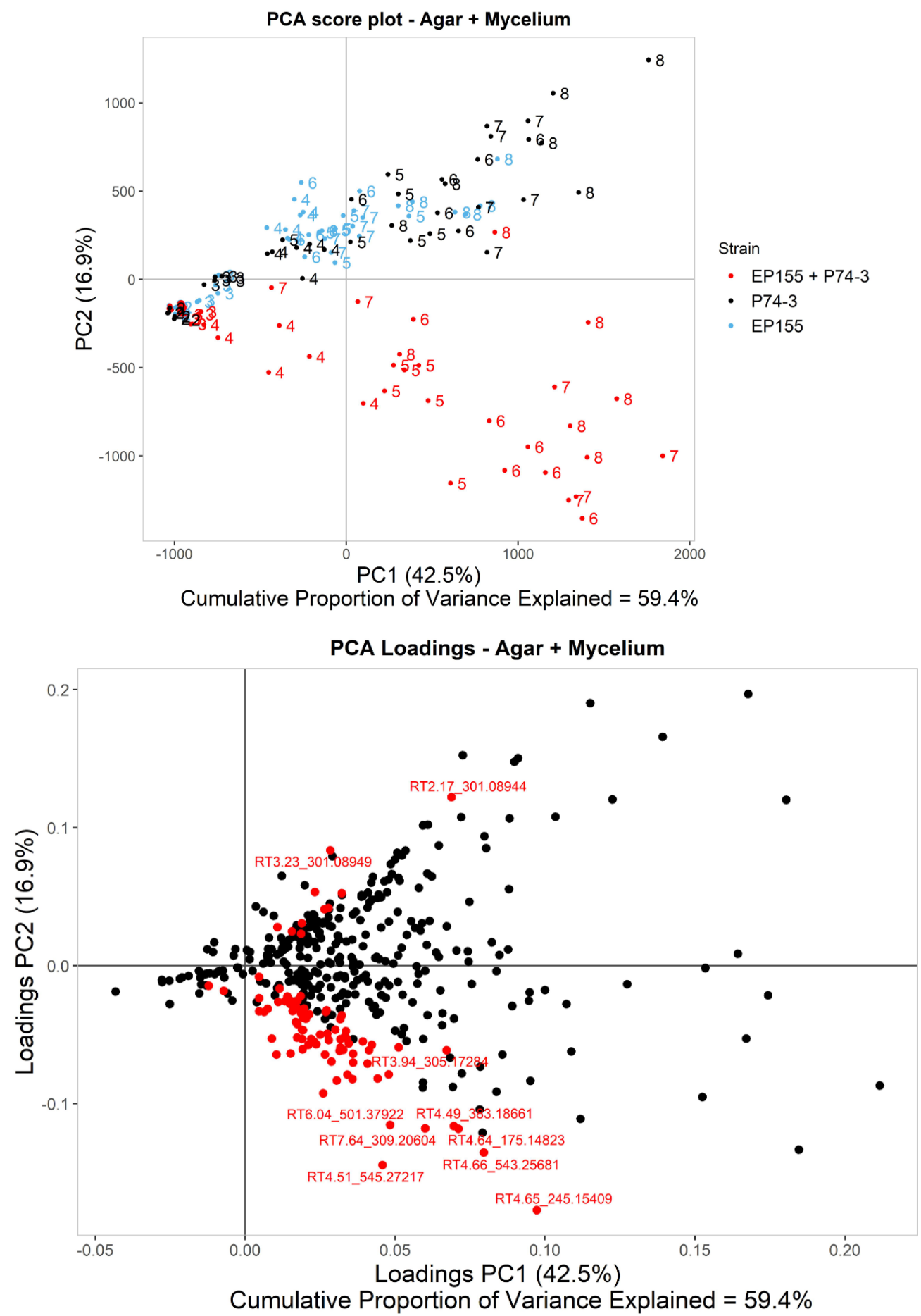

Figure S6. Principal component analysis (PCA) for PC1 vs. PC2 of data from agar and mycelium samples summed together (per plate). Numbers beside dots on score plot indicate day on which sample was harvested after inoculation. Red dots on loading plot indicate features deemed significant to VI samples from univariate analysis (full list in Figure S1). All data scaled using pareto method. 

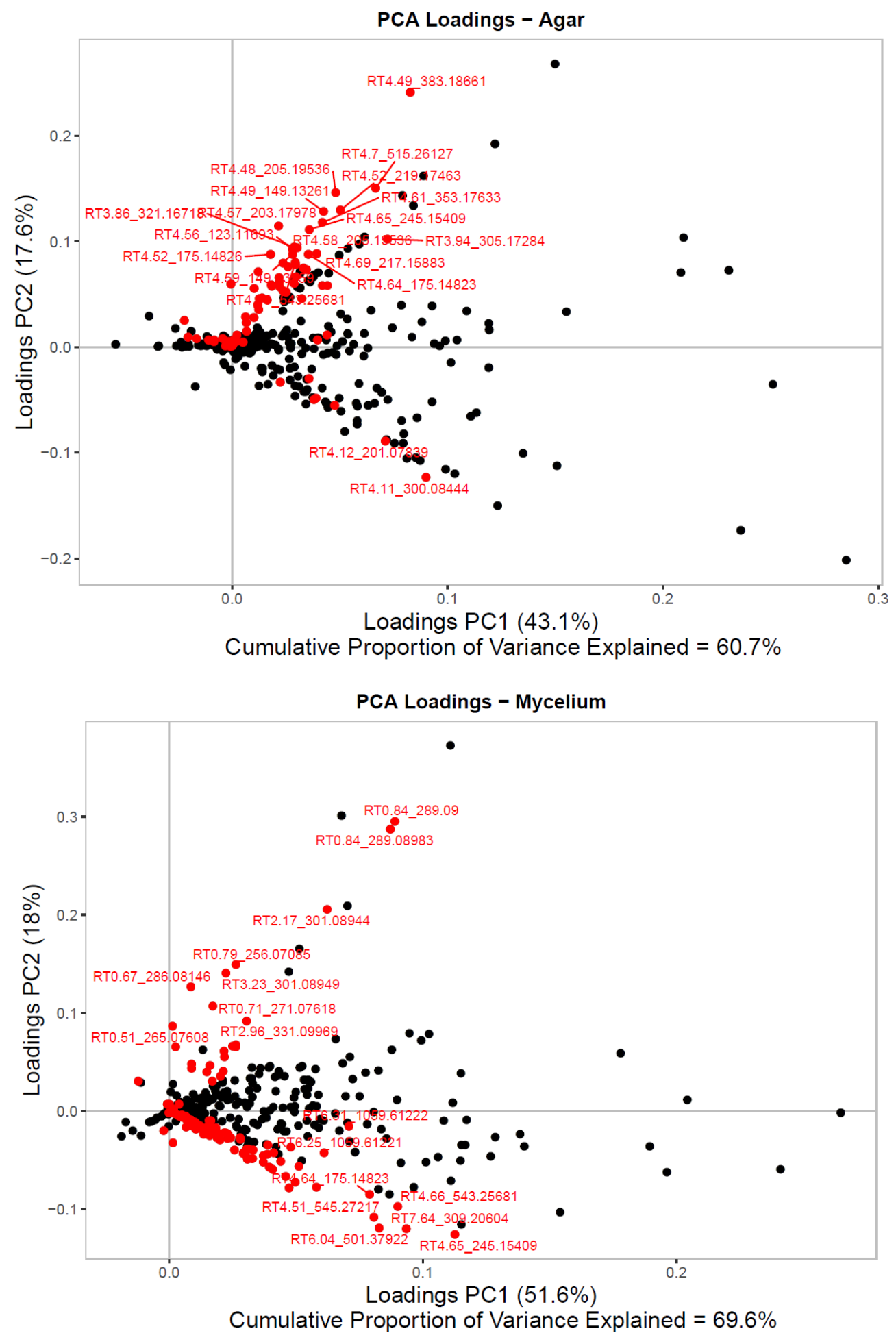

Figure S7. Principal component analysis (PCA) loadings for PC1 vs. PC2. Upper plot models data from agar extractions. Lower plot is from mycelium extractions. Red dots indicate features deemed significant from univariate analysis. All data scaled using pareto method. 


\section{Appendix E: NMR data}

Subappendix E.1: Calbistrin O data

$\underline{\text { H-NMR }}$

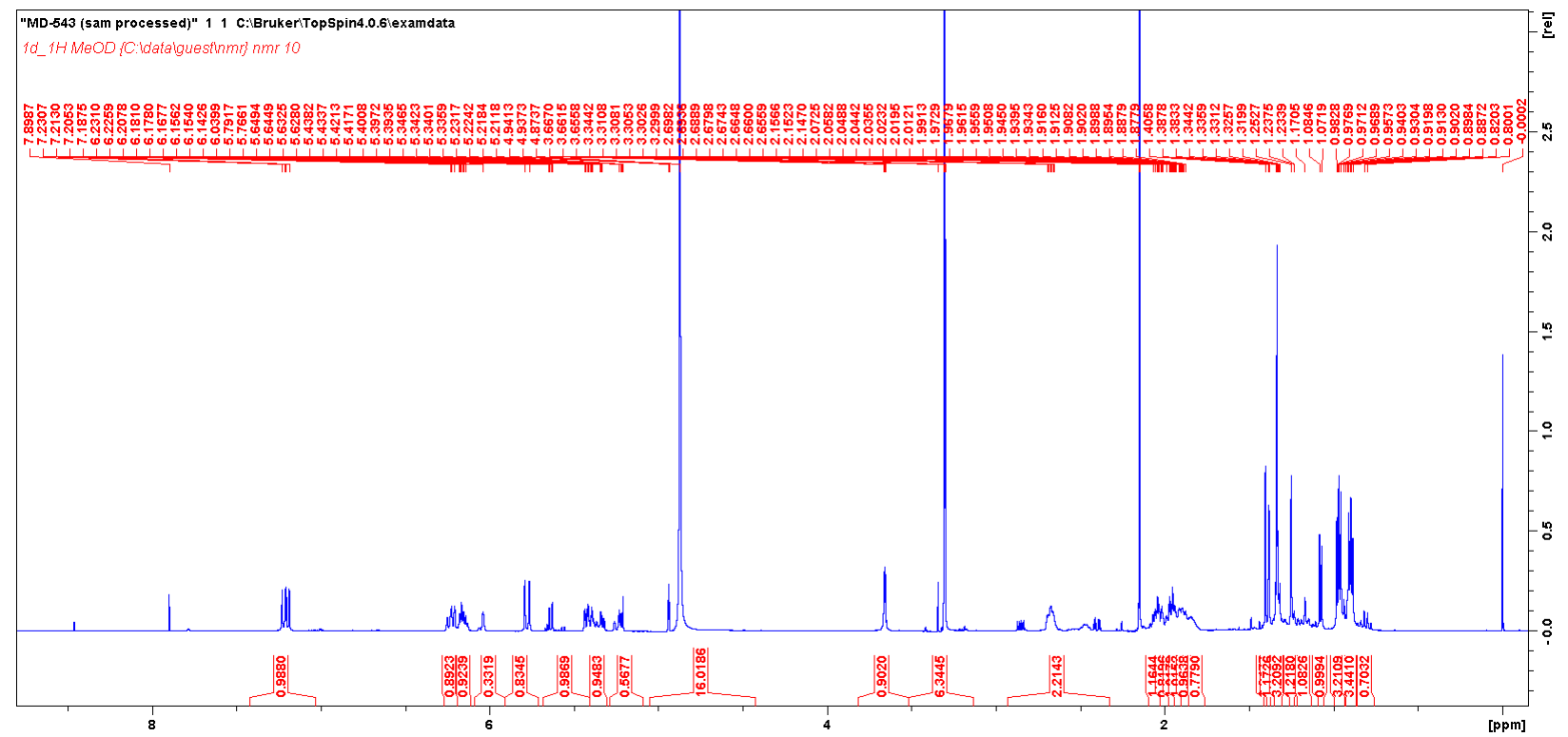

C-NMR

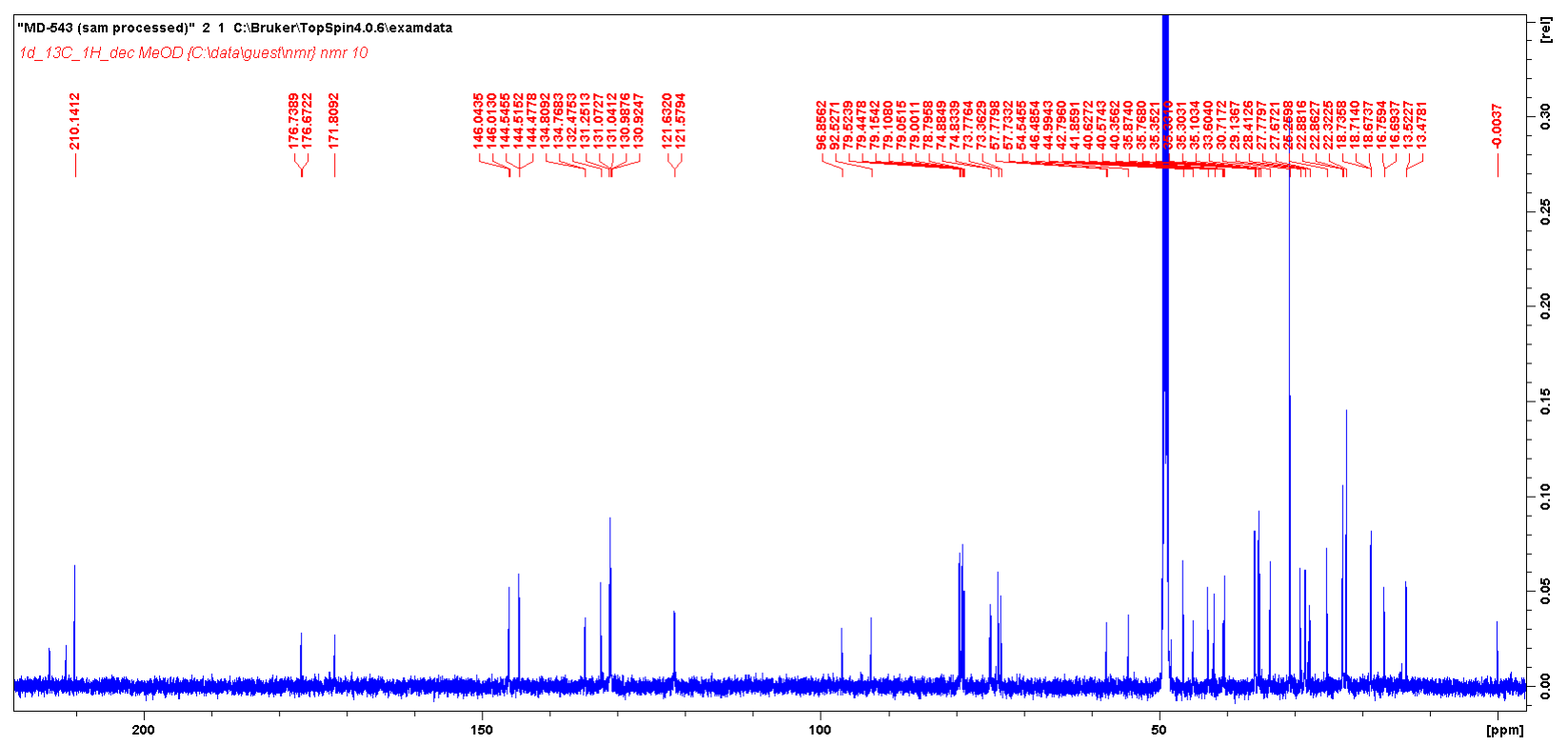




\section{DEPT}
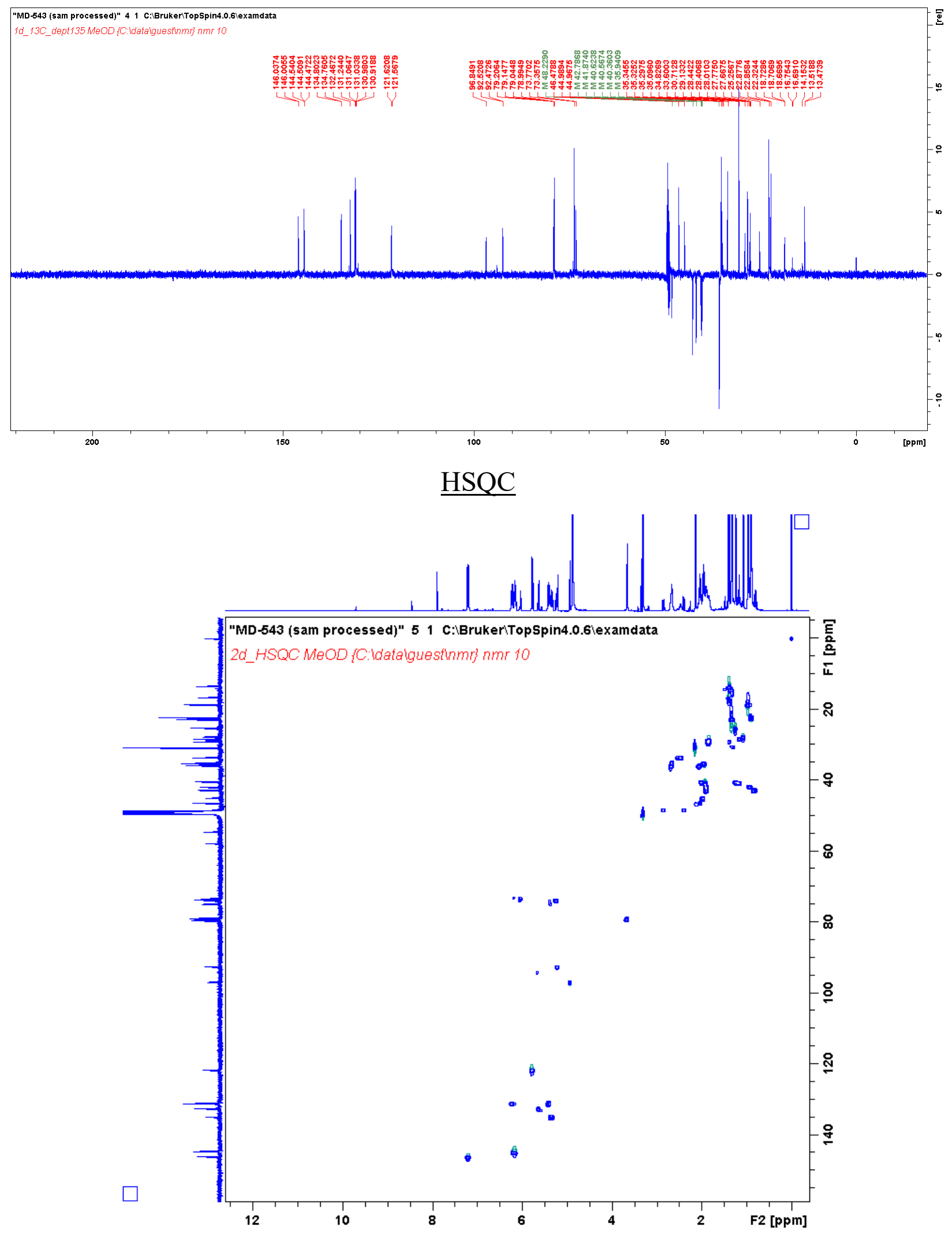


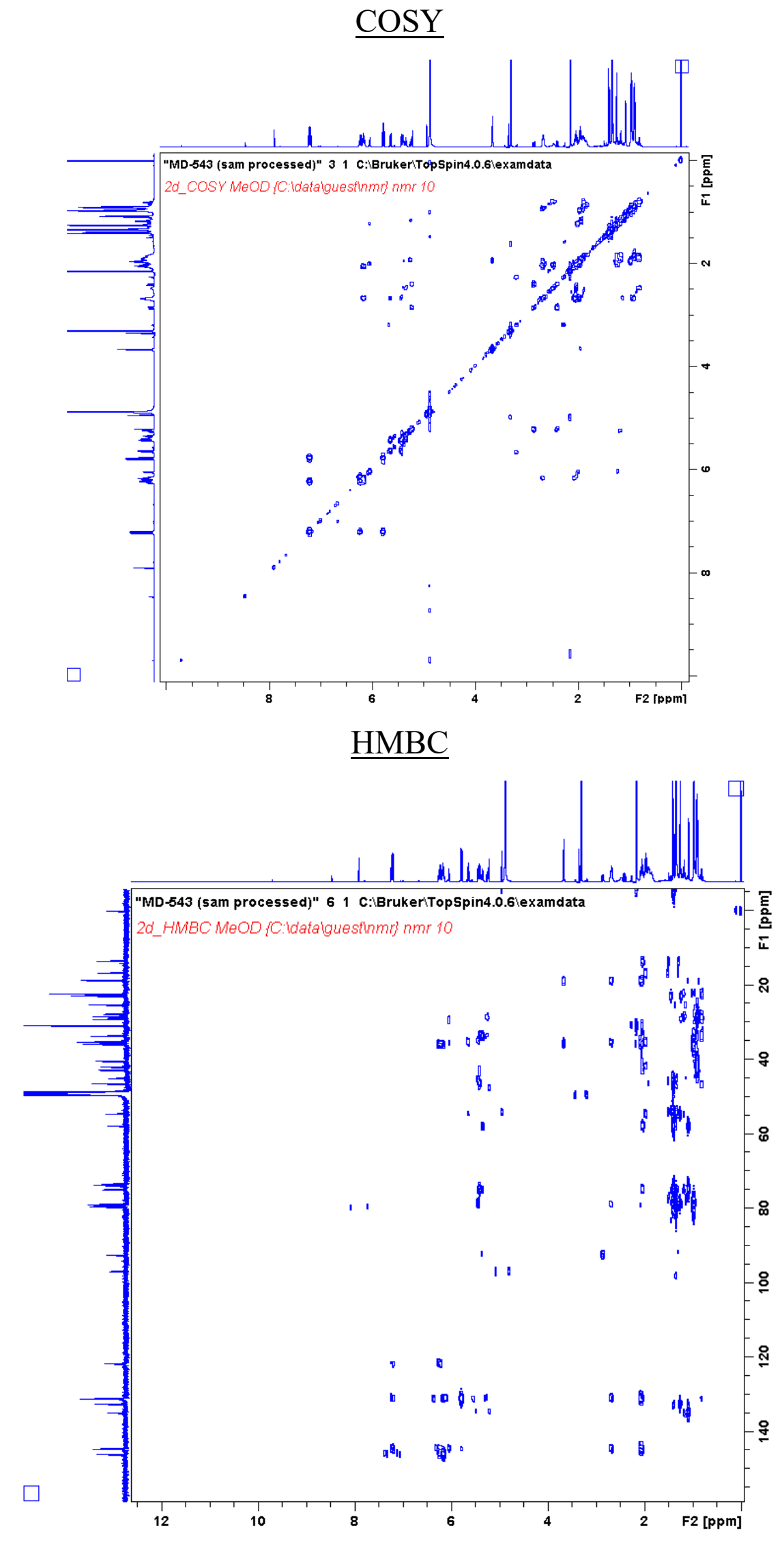




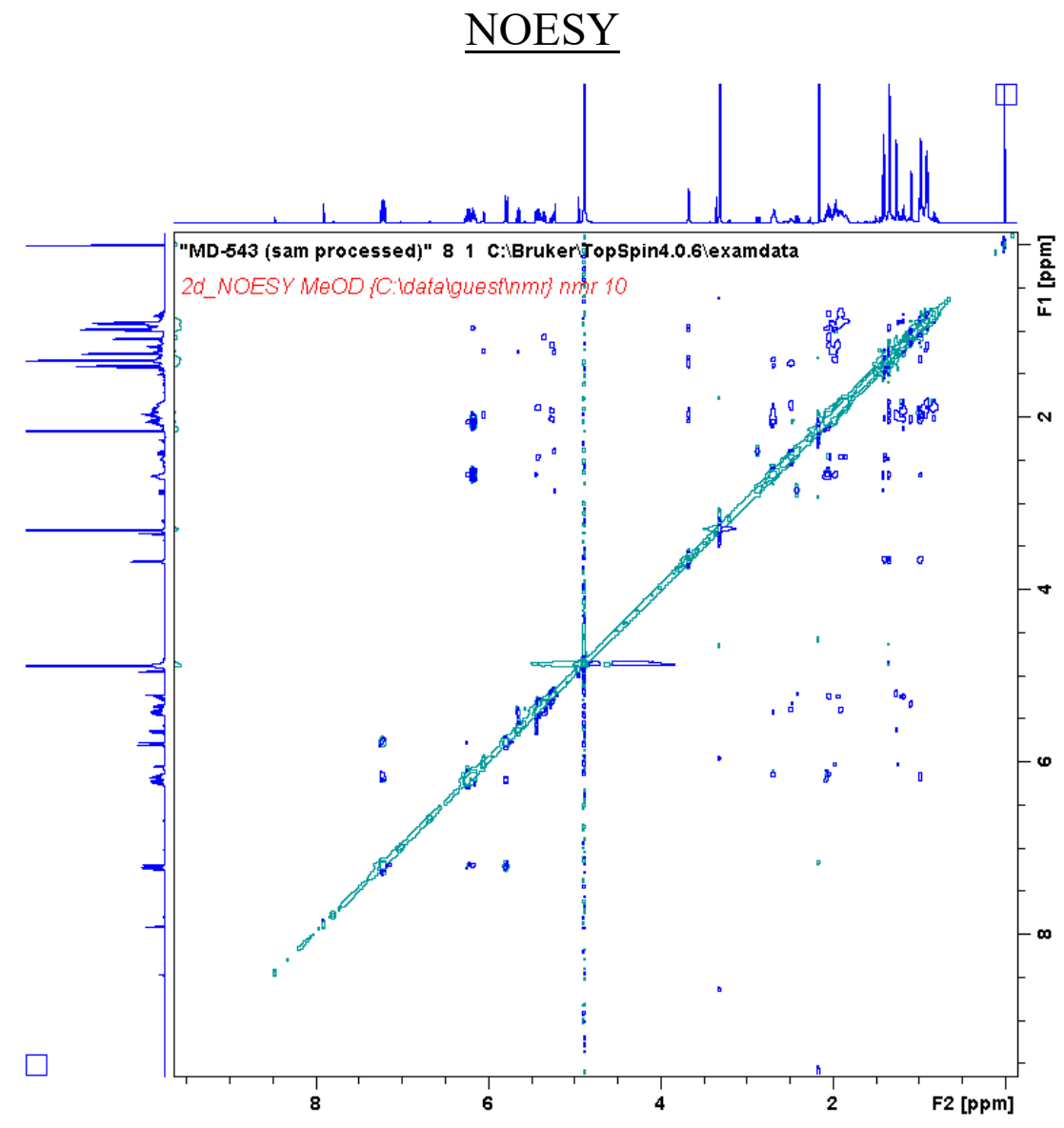


Subappendix E.2: Calbistrin P data

\section{H-NMR}

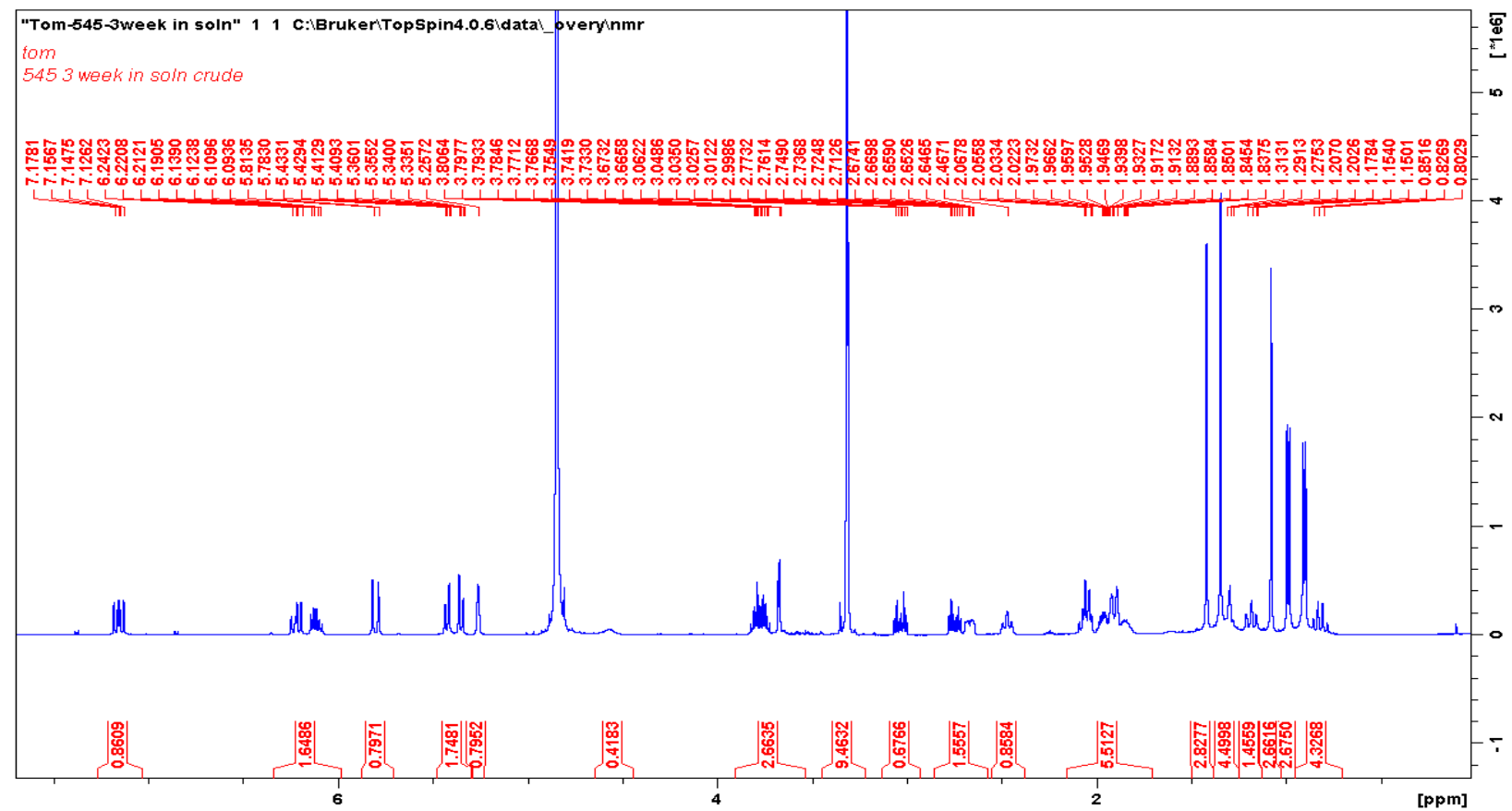

C-NMR

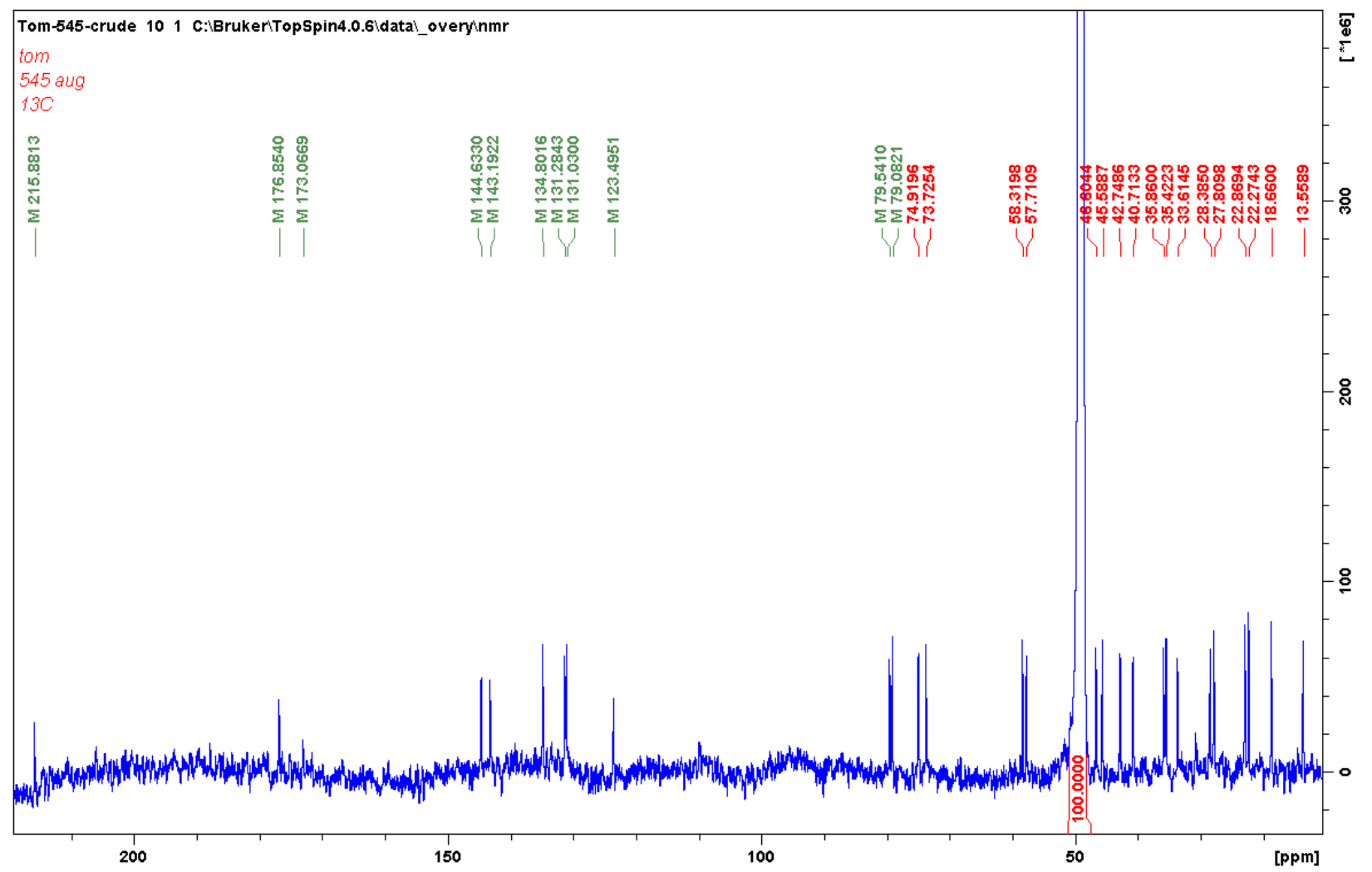




\section{DEPT}
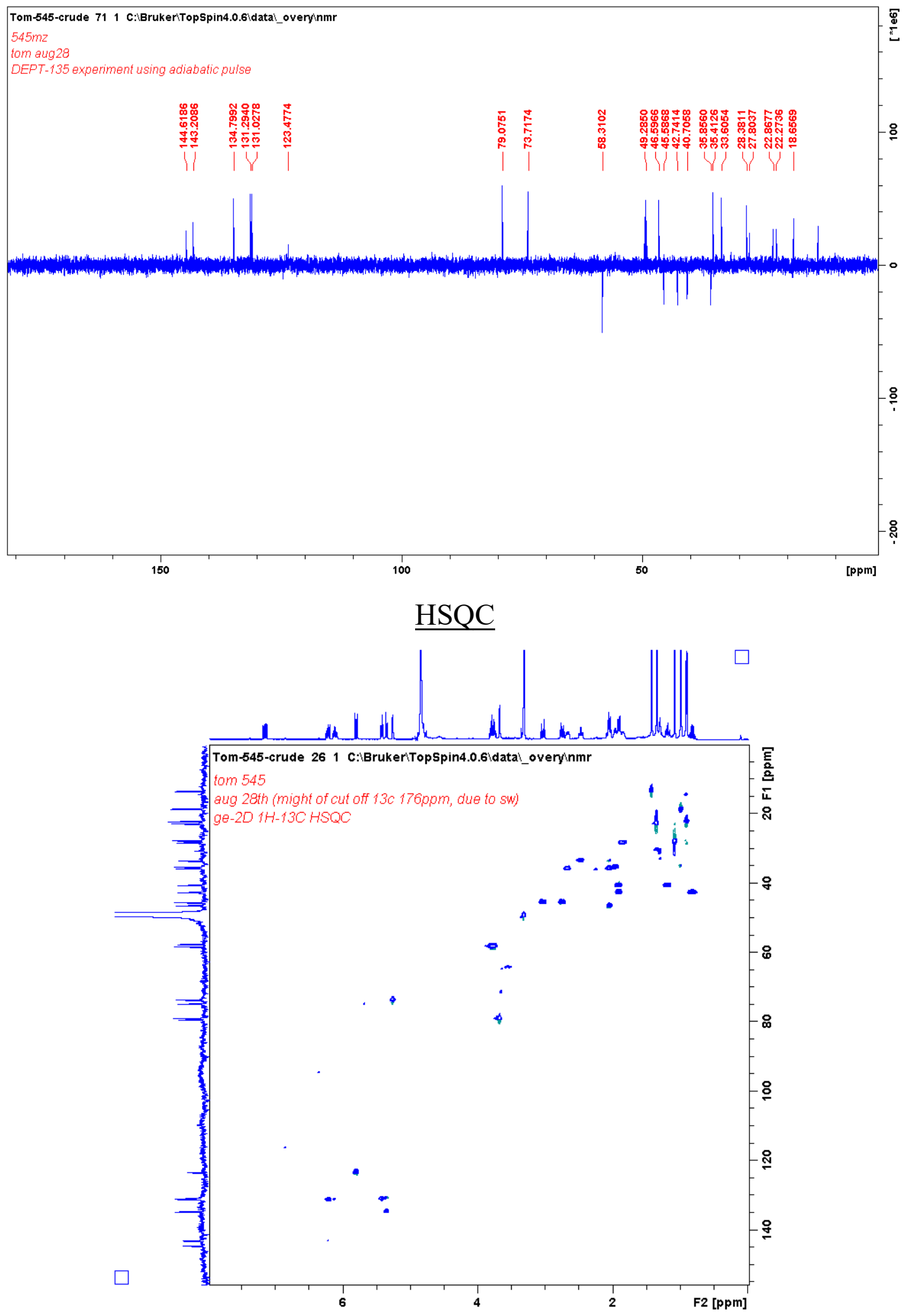


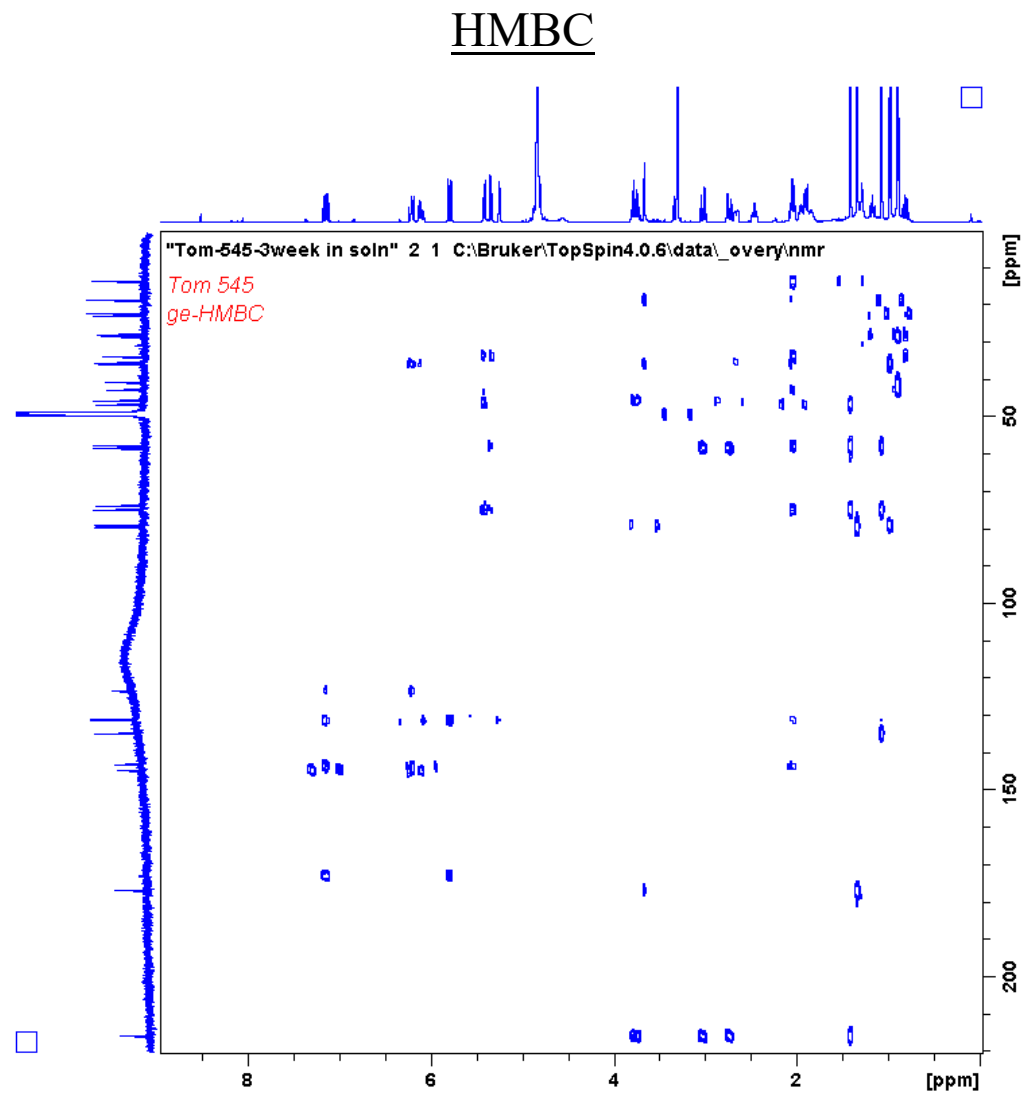


Subappendix E.3: Farnesyl S-oxide (3) data

\section{$\underline{\text { H-NMR }}$}

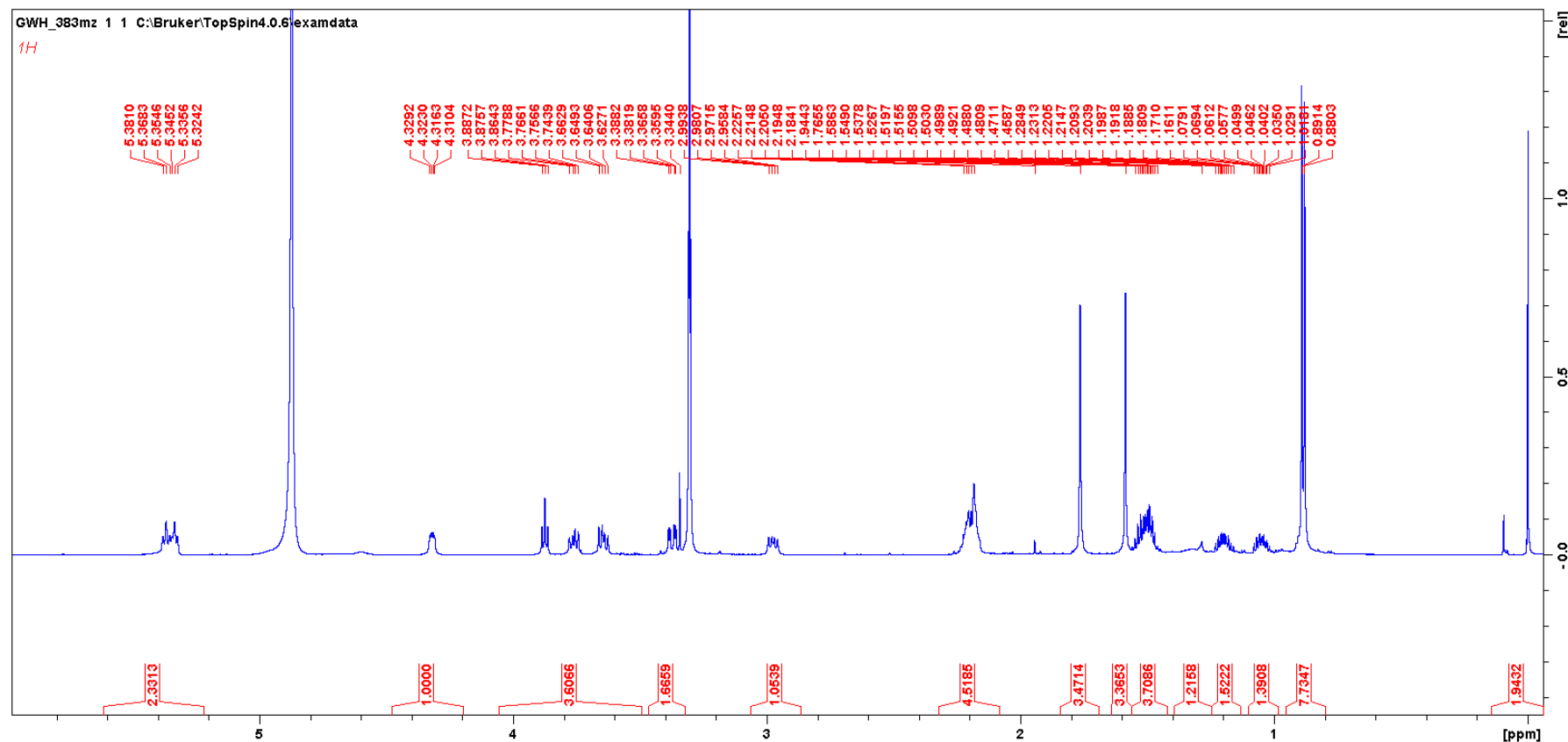

\section{C-NMR}

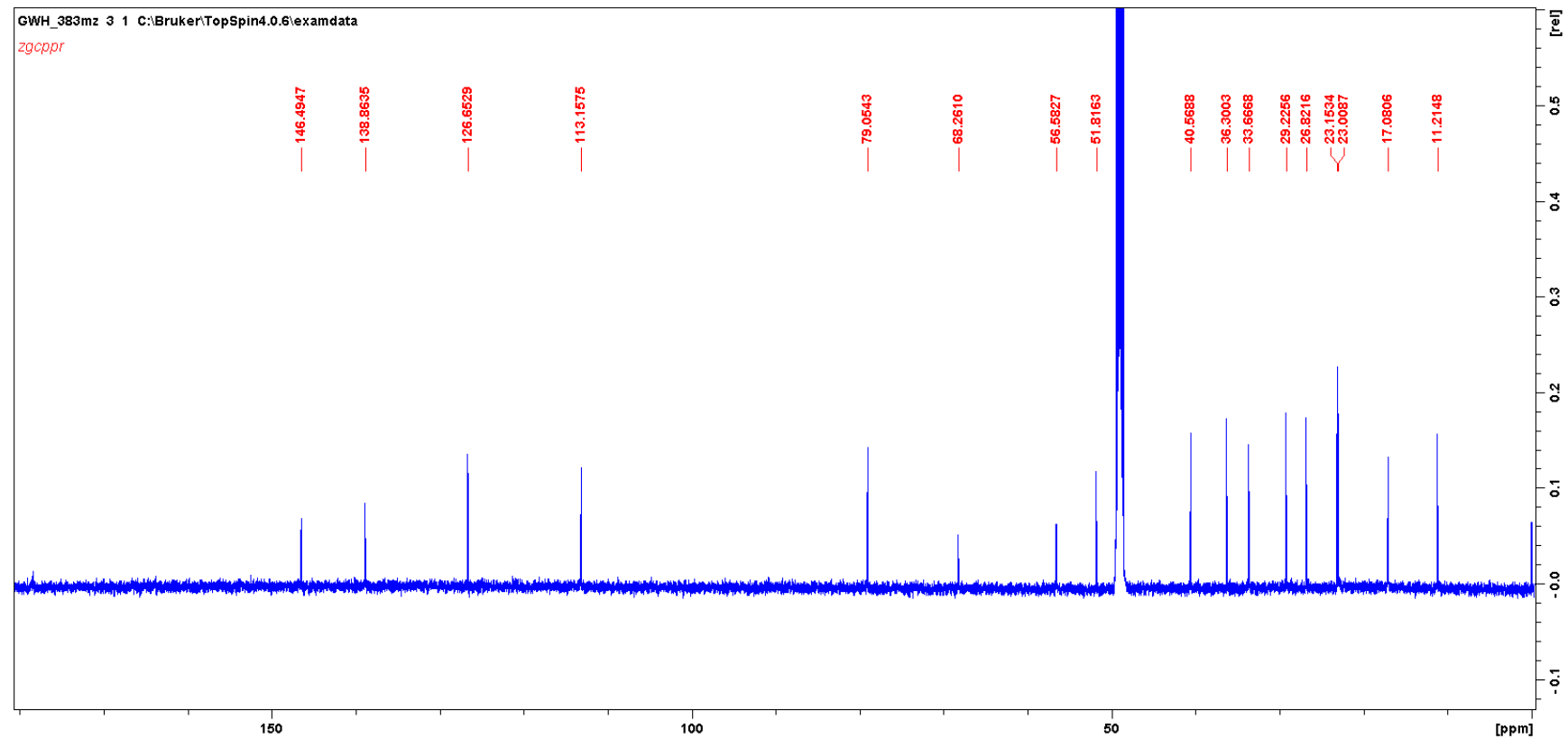




\section{DEPT}
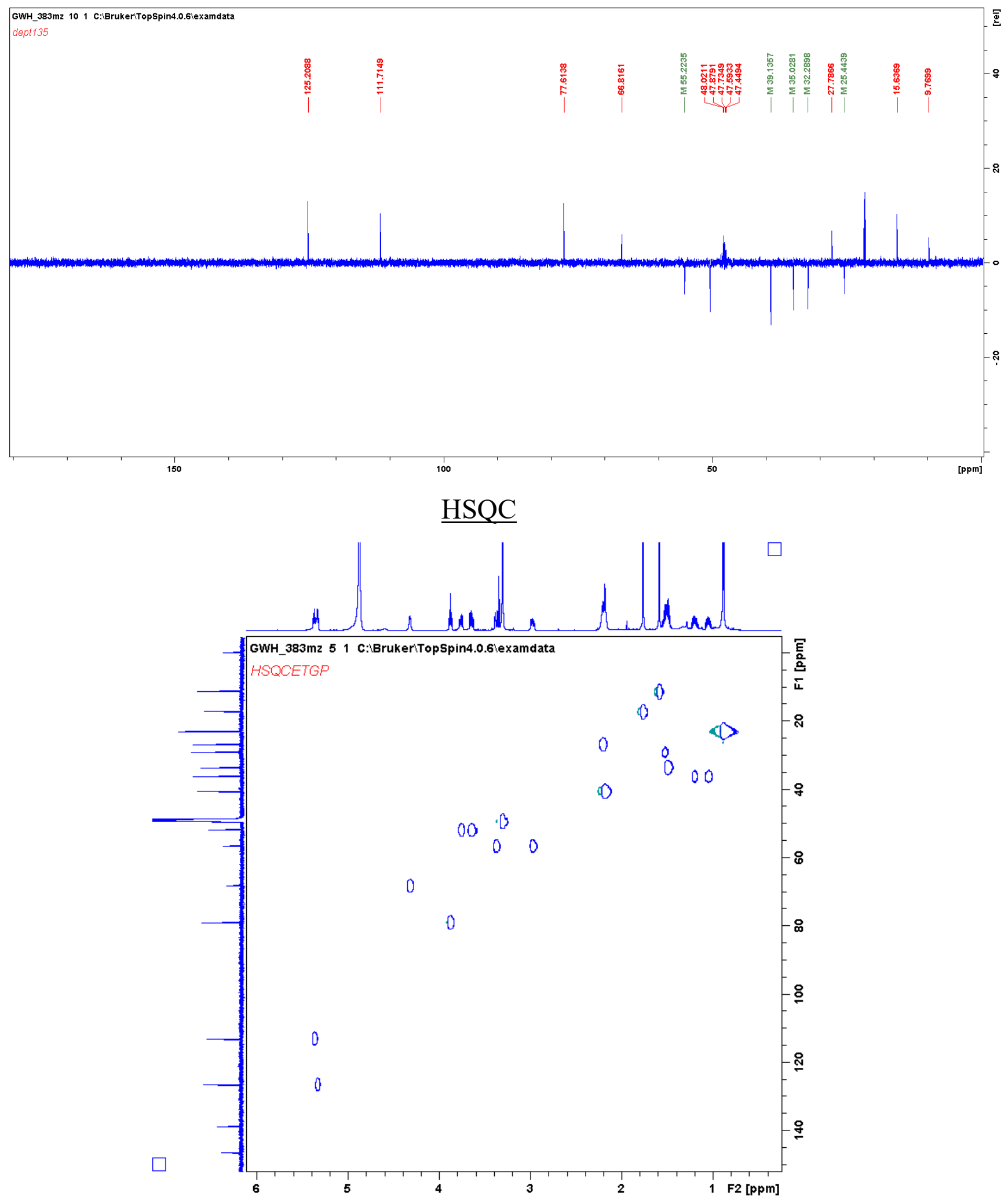


\section{COSY}
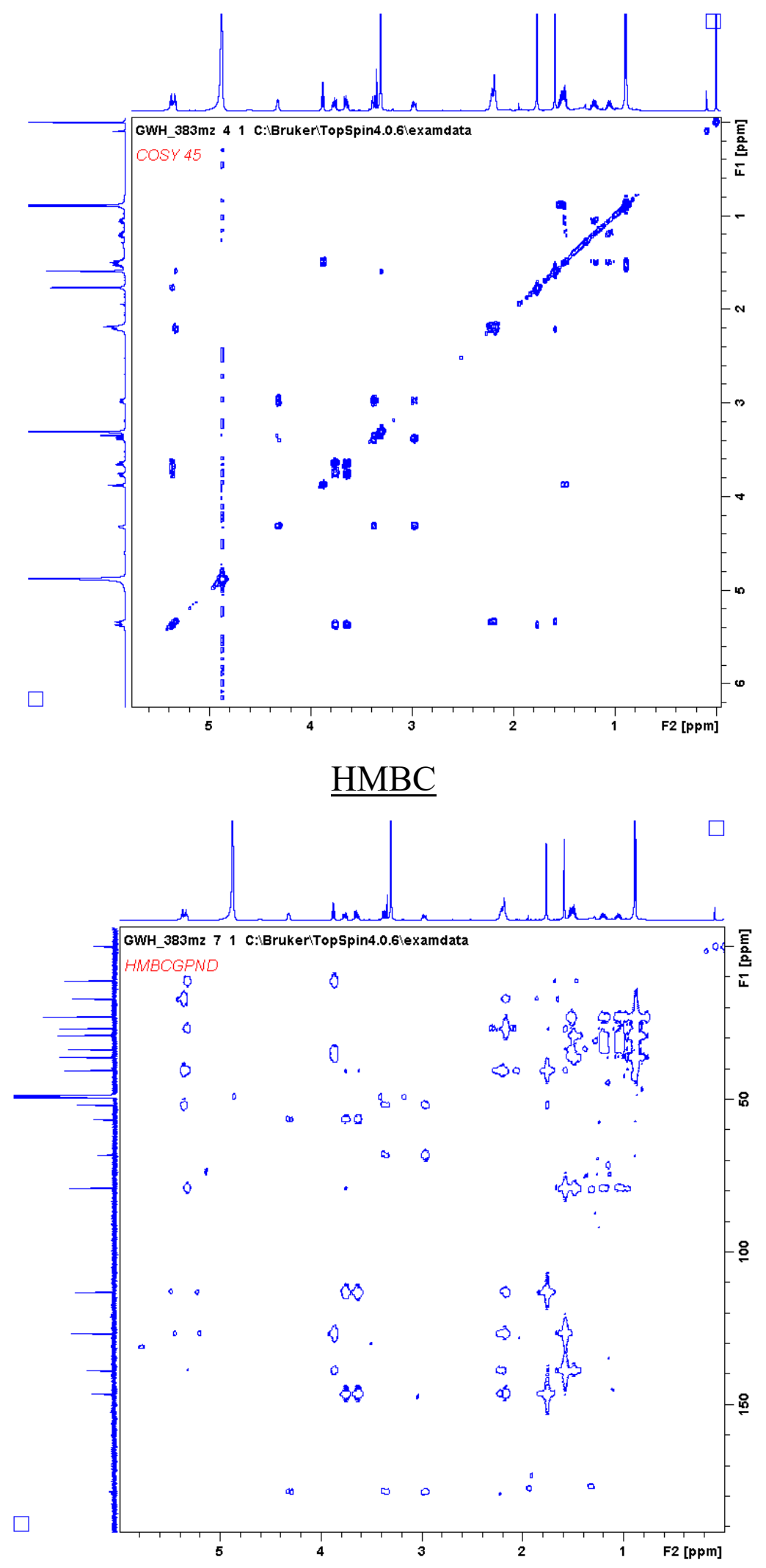


\section{TOCSY}

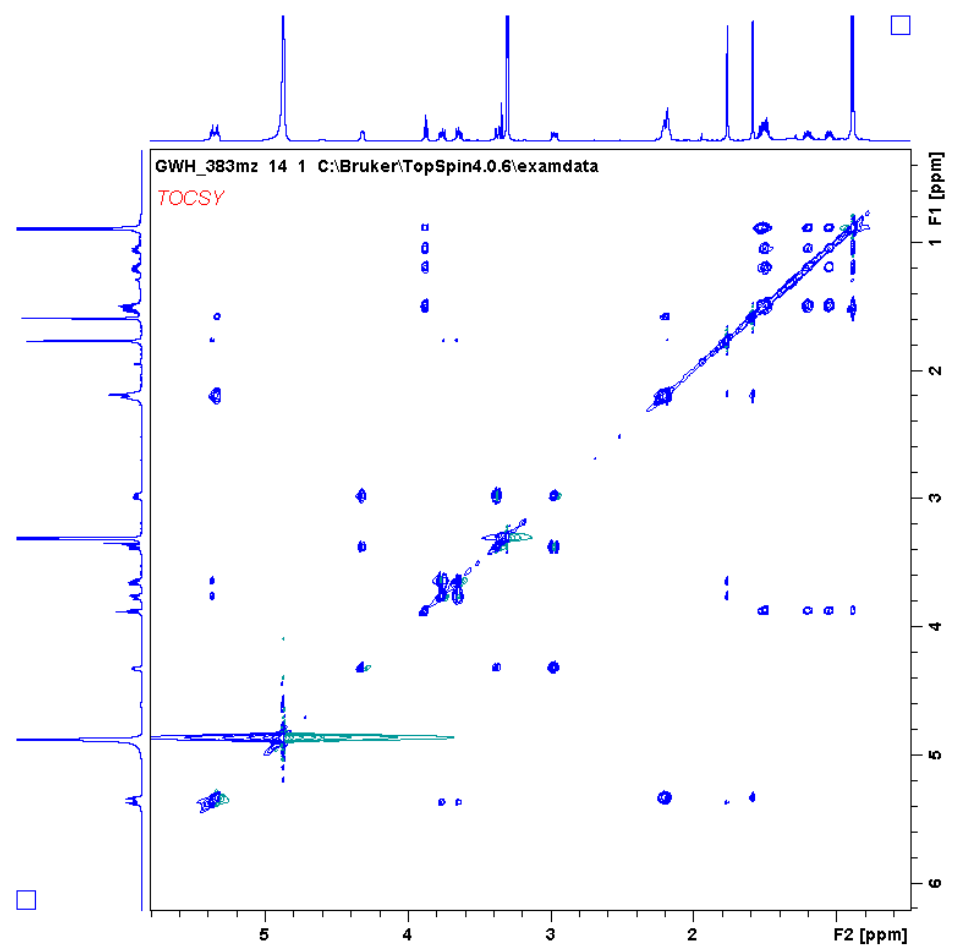




\section{Appendix F: R code for Pearson correlation script}

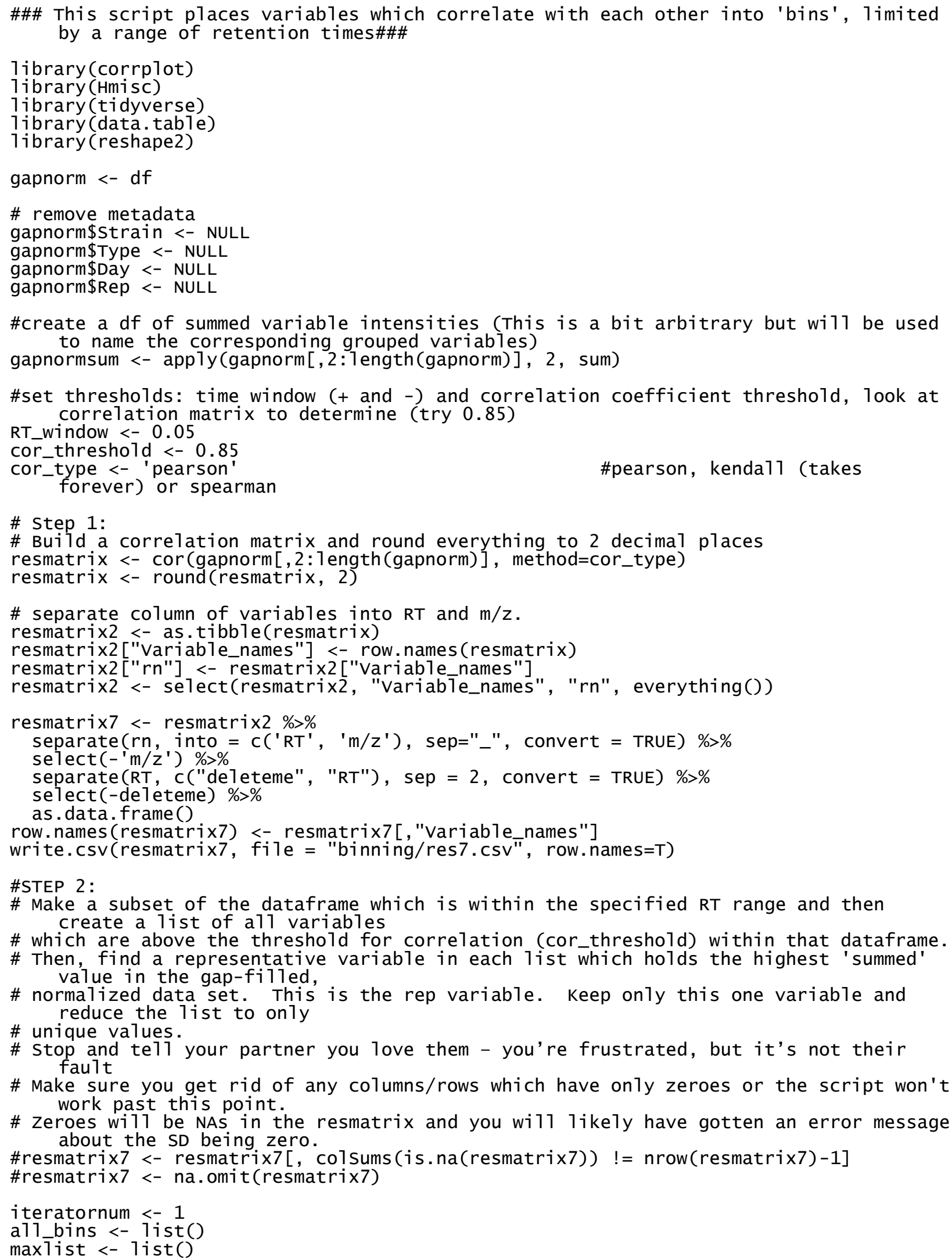




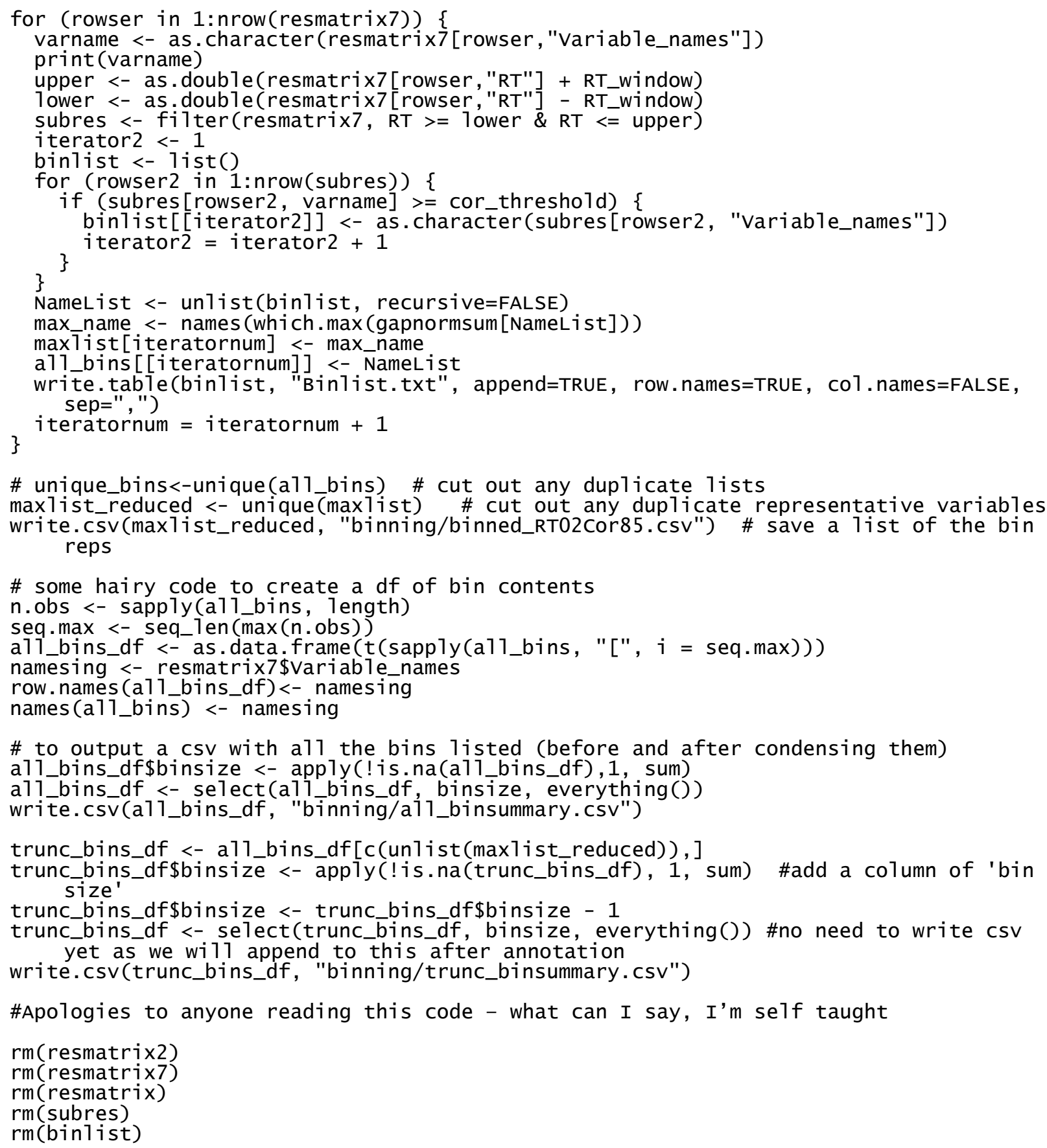




\section{Bibliography}

Abraham, W. R., Meyer, H., \& Abate, D. (1995). Curvupallides, a new class of alkaloids from the fungus Curvularia pallescens. Tetrahedron, 51(17), 4947-4952. https://doi.org/10.1016/00404020(95)98692-B

Alberts, A. W., Chen, J., Kuron, G., Hunt, V., Huff, J., Hoffman, C., ... Springer, J. (1980). Mevinolin: a highly potent competitive inhibitor of hydroxymethylglutaryl-coenzyme A reductase and a cholesterol-lowering agent. Proceedings of the National Academy of Sciences, 77(7), 3957-3961. https://doi.org/10.1073/PNAS.77.7.3957

Anagnostakis, S. L. (1986). Diversity of Vegetative Compatibility Groups of Cryphonectria parasitica in Connecticut and Europe. Plant Disease, 70(6), 536. https://doi.org/10.1094/PD-70-536

Balguerie, A., Reis, S. Dos, Ritter, C., Chaignepain, S., Coulary-Salin, B., Forge, V., ... Saupe, S. J. (2003). Domain organization and structure-function relationship of the HET-s prion protein of Podospora anserina. The EMBO Journal, 22(9), 2071-2081. https://doi.org/10.1093/emboj/cdg213

Bardwell, L., Cook, J. G., Inouye, C. J., \& Thorner, J. (1994). Signal Propagation and Regulation in the Mating Pheromone Response Pathway of the Yeast Saccharomyces cerevisiae. Developmental Biology, 166(2), 363-379. https://doi.org/10.1006/DBIO.1994.1323

Belov, A. (2018). Transcriptome analysis of programmed cell death associated with allorecognition in chestnut blight fungus Cryphonectria parasitica (Doctoral dissertation) (Carleton University, Ottawa). https://doi.org/https://doi.org/10.22215/etd/2018-12631

Bidard, F., Clavé, C., \& Saupe, S. J. (2013). The Transcriptional Response to Nonself in the Fungus Podospora anserina. G3\&amp;\#58; Genes $\mid$ Genomes $\mid$ Genetics. https://doi.org/10.1534/g3.113.006262

Biella, S., Myron, L. S., Aist, J. R., Cortesi, P., \& Milgroom, M. G. (2002). Programmed cell death correlates with virus transmission in a filamentous fungus. Proceedings of the Royal Society of London B Biological Sciences, 269(1506), 2269-2276. https://doi.org/10.1098/rspb.2002.2148

Bistis, G. N. (1981). Chemotropic Interactions Between Trichogynes and Conidia of Opposite MatingType in Neurospora Crassa. Mycologia, 73(5), 959-975.

https://doi.org/10.1080/00275514.1981.12021425

Bistis, G. N. (1983). Evidence for diffusible, mating-type-specific trichogyne attractants inNeurospora crassa. Experimental Mycology, 7(3), 292-295. https://doi.org/10.1016/0147-5975(83)90051-8

Blin, K., Shaw, S., Steinke, K., Villebro, R., Ziemert, N., Lee, S. Y., ... Weber, T. (2019). antiSMASH 5.0: updates to the secondary metabolite genome mining pipeline. Nucleic Acids Research. https://doi.org/10.1093/nar/gkz310

Bok, J. W., Chiang, Y.-M., Szewczyk, E., Reyes-Dominguez, Y., Davidson, A. D., Sanchez, J. F., ... Keller, N. P. (2009). Chromatin-level regulation of biosynthetic gene clusters. Nature Chemical Biology, 5(7), 462-464. https://doi.org/10.1038/nchembio.177

Brill, G. M., Chen, R. H., Rasmussen, R. R., Whittern, D. N., \& Mcalpine, J. B. (1993). Calbistrins, novel antifungal agents produced by Penicillium restrictum. II. Isolation and elucidation of structure. The Journal of Antibiotics, 46(1), 39-47. https://doi.org/10.7164/antibiotics.46.39

Chevanne, D., Bastiaans, E., Debets, A., Saupe, S. J., Clavé, C., \& Paoletti, M. (2009). Identification of the het-r vegetative incompatibility gene of Podospora anserina as a member of the fast evolving HNWD gene family. Current Genetics, 55(1), 93-102. https://doi.org/10.1007/s00294-008-0227-5 
Choi, G. H., Dawe, A. L., Churbanov, A., Smith, M. L., Milgroom, M. G., \& Nuss, D. L. (2012). Molecular characterization of vegetative incompatibility genes that restrict hypovirus transmission in the chestnut blight fungus Cryphonectria parasitica. Genetics, 190(1), 113-127. https://doi.org/10.1534/genetics.111.13398

Colín-González, A. L., Santana, R. A., Silva-Islas, C. A., Chánez-Cárdenas, M. E., Santamaría, A., \& Maldonado, P. D. (2012). The Antioxidant Mechanisms Underlying the Aged Garlic Extract- and SAllylcysteine-Induced Protection. Oxidative Medicine and Cellular Longevity, 2012, 1-16. https://doi.org/10.1155/2012/907162

Cortesi, P., \& Milgroom, M. G. (1998). Genetics of vegetative incompatibility in cryphonectria parasitica. Applied and Environmental Microbiology, 64(8), 2988-2994. Retrieved from http://www.ncbi.nlm.nih.gov/pubmed/9687462

Crawford, J. M., Korman, T. P., Labonte, J. W., Vagstad, A. L., Hill, E. A., Kamari-Bidkorpeh, O., ... Townsend, C. A. (2009). Structural basis for biosynthetic programming of fungal aromatic polyketide cyclization. Nature, 461(7267), 1139-1143. https://doi.org/10.1038/nature08475

Debets, A. J. M., \& Griffiths, A. J. F. (1998). Polymorphism of het-genes prevents resource plundering in Neurospora crassa. Mycological Research, 102(11), 1343-1349. https://doi.org/10.1017/S095375629800639X

Debets, F., Yang, X., \& Griffiths, A. J. F. (1994). Vegetative incompatibility in Neurospora: Its effect on horizontal transfer of mitochondrial plasmids and senescence in natural populations. Current Genetics, 26(2), 113-119. https://doi.org/10.1007/BF00313797

Drissner, D., Kunze, G., Callewaert, N., Gehrig, P., Tamasloukht, M., Boller, T., ... Bucher, M. (2007). Lyso-phosphatidylcholine is a signal in the arbuscular mycorrhizal symbiosis. Science (New York, N.Y.), 318(5848), 265-268. https://doi.org/10.1126/science.1146487

Dührkop, K., Fleischauer, M., Ludwig, M., Aksenov, A. A., Melnik, A. V., Meusel, M., ... Böcker, S. (2019). SIRIUS 4: a rapid tool for turning tandem mass spectra into metabolite structure information. Nature Methods, 16(4), 299-302. https://doi.org/10.1038/s41592-019-0344-8

Endo, A. (1988). Chemistry, biochemistry, and pharmacology of HMG-CoA reductase inhibitors. Klinische Wochenschrift, 66(10), 421-427. https://doi.org/10.1007/BF01745510

Endo, Akira. (1979). Monacolin K, a new hypocholesterolemic agent produced by a Monascus species. The Journal of Antibiotics, 32(8), 852-854. https://doi.org/10.7164/antibiotics.32.852

Endo, Akira. (2008). A gift from nature: the birth of the statins. Nature Medicine, 14(10), 1050-1052. https://doi.org/10.1038/nm1008-1050

Endo, Akira, Kuroda, M., \& Tanzawa, K. (1976). Competitive inhibition of 3-hydroxy-3-methylglutaryl coenzyme a reductase by ML-236A and ML-236B fungal metabolites, having hypocholesterolemic activity. FEBS Letters, 72(2), 323-326. https://doi.org/10.1016/0014-5793(76)80996-9

Espagne, E., Balhadère, P., Penin, Marie-Louise Barreau, C., \& Turcq, B. (2002). HET-E and HET-D Belong to a New Subfamily of WD40 Proteins Involved in Vegetative Incompatibility Specificity in the Fungus Podospora anserina. Genetics, 161(1), 71-81.

Fouillaud, M., Venkatachalam, M., Girard-Valenciennes, E., Caro, Y., Dufossé, L., Fouillaud, M., ... Dufossé, L. (2016). Anthraquinones and Derivatives from Marine-Derived Fungi: Structural Diversity and Selected Biological Activities. Marine Drugs, 14(4), 64.

https://doi.org/10.3390/md14040064 
Fujii, Y., Asahara, M., Ichinoe, M., \& Nakajima, H. (2002). Fungal melanin inhibitor and related compounds from Penicillium decumbens. Phytochemistry, 60(7), 703-708. https://doi.org/10.1016/S0031-9422(02)00196-6

Gaude, E., Chignola, F., Spiliotopoulos, D., Spitaleri, A., Garcìa-manteiga, J. M., Mari, S., \& Musco, G. (2013). muma , An R Package for Metabolomics Univariate and Multivariate Statistical Analysis. Curr Metabolomics, 1(2), 180-189. https://doi.org/10.2174/2213235X11301020005

Gessler, N. N., Egorova, A. S., \& Belozerskaya, T. A. (2013). Fungal anthraquinones. Applied Biochemistry and Microbiology, 49(2), 85-99. https://doi.org/10.1134/S000368381302004X

Glass, N L, Grotelueschen, J., \& Metzenberg, R. L. (1990). Neurospora crassa A mating-type region. Proceedings of the National Academy of Sciences, 87(13).

Glass, N Louise, Jacobson, D. J., \& Shiu, P. K. T. (2000). The Genetics of Hyphal Fusion and Vegetative Incompatibility in Filamentous Ascomycete Fungi. Annual Review of Genetics, 34(1), 165-186. https://doi.org/10.1146/annurev.genet.34.1.165

Goldstein, J. L., \& Brown, M. S. (1990). Regulation of the mevalonate pathway. Nature, 343(6257), 425430. https://doi.org/10.1038/343425a0

González-Menéndez, V., Crespo, G., de Pedro, N., Diaz, C., Martín, J., Serrano, R., ... Genilloud, O. (2018). Fungal endophytes from arid areas of Andalusia: high potential sources for antifungal and antitumoral agents. Scientific Reports, 8(1), 9729. https://doi.org/10.1038/s41598-018-28192-5

Griffiths, S., Mesarich, C. H., Saccomanno, B., Vaisberg, A., De Wit, P. J. G. M., Cox, R., \& Collemare, J. (2016). Elucidation of cladofulvin biosynthesis reveals a cytochrome P450 monooxygenase required for anthraquinone dimerization. Proceedings of the National Academy of Sciences of the United States of America, 113(25), 6851-6856. https://doi.org/10.1073/pnas.1603528113

Grijseels, S., Pohl, C., Nielsen, J. C., Wasil, Z., Nygård, Y., Nielsen, J., ... Frandsen, R. J. N. (2018). Identification of the decumbenone biosynthetic gene cluster in Penicillium decumbens and the importance for production of calbistrin. Fungal Biology and Biotechnology, 5(1), 1-17. https://doi.org/10.1186/s40694-018-0063-4

Gunde-Cimerman, N., \& Cimerman, A. (1995). Pleurotus Fruiting Bodies Contain the Inhibitor of 3Hydroxy-3-Methylglutaryl-Coenzyme A Reductase — Lovastatin. Experimental Mycology, 19(1), 16. https://doi.org/10.1006/EMYC.1995.1001

Heller, J., Clavé, C., Gladieux, P., Saupe, S. J., \& Glass, N. L. (2018). NLR surveillance of essential SEC9 SNARE proteins induces programmed cell death upon allorecognition in filamentous fungi.

Proceedings of the National Academy of Sciences of the United States of America, 115(10), E2292E2301. https://doi.org/10.1073/pnas.1719705115

Heller, J., Zhao, J., Rosenfield, G., Kowbel, D. J., Gladieux, P., \& Glass, N. L. (2016). Characterization of Greenbeard Genes Involved in Long-Distance Kind Discrimination in a Microbial Eukaryote. PLOS Biology, 14(4), e1002431. https://doi.org/10.1371/journal.pbio.1002431

Helms, G. L., Horn, W. S., Jones, E. T., Linemeyer, D. L., Dombrowski, A. W., Koupal, L., ... Rozdilsky, W. (1992). Patent No. CA2063230A1.

Hewage, R. T., Aree, T., Mahidol, C., Ruchirawat, S., \& Kittakoop, P. (2014). One strain-many compounds (OSMAC) method for production of polyketides, azaphilones, and an isochromanone using the endophytic fungus Dothideomycete sp. Phytochemistry, 108, 87-94. https://doi.org/10.1016/j.phytochem.2014.09.013 
Horn, W. S., Bierilo, K. K., Bills, G. F., Dombrowski, A. W., Helms, G. L., Jones, E. T., ... Wilson, K. E. (1993). Characterization of the light- and base-mediated instability of calbistrin A. Journal of Natural Products, 56(10), 1779-1785. https://doi.org/10.1021/np50100a018

Hornby, J. M., Jensen, E. C., Lisec, A. D., Tasto, J. J., Jahnke, B., Shoemaker, R., ... Nickerson, K. W. (2001). Quorum sensing in the dimorphic fungus Candida albicans is mediated by farnesol. Applied and Environmental Microbiology, 67(7), 2982-2992. https://doi.org/10.1128/AEM.67.7.29822992.2001

Howard, B. H., \& Raistrick, H. (1954). Studies in the biochemistry of micro-organisms. 91. The colouring matters of Penicillium islandicum Sopp. Part 3. Skyrin and flavoskyrin. Biochemical Journal, 56(1), 56-65. https://doi.org/10.1042/bj0560056

Hrycyna, C. A., Sapperstein, S. K., Clarke, S., \& Michaelis, S. (1991). The Saccharomyces cerevisiae STE14 gene encodes a methyltransferase that mediates C-terminal methylation of a-factor and RAS proteins. The EMBO Journal, 10(7), 1699-1709. https://doi.org/10.1002/j.14602075.1991.tb07694.x

Hutchison, E., Brown, S., Tian, C., \& Glass, N. L. (2009). Transcriptional profiling and functional analysis of heterokaryon incompatibility in Neurospora crassa reveals that reactive oxygen species, but not metacaspases, are associated with programmed cell death. Microbiology, 155(12), 39573970. https://doi.org/10.1099/mic.0.032284-0

Jackson, M., Karwowski, J. P., Humphrey, P. E., Kohl, W. L., Barlow, G. J., \& Tanaka, S. K. (1993). Calbistrins, novel antifungal agents produced by Penicillium retrictum. The Journal of Antibiotics, 34-38.

Jahn, L., Schafhauser, T., Wibberg, D., Rückert, C., Winkler, A., Kulik, A., ... Wohlleben, W. (2017). Linking secondary metabolites to biosynthesis genes in the fungal endophyte Cyanodermella asteris: The anti-cancer bisanthraquinone skyrin. Journal of Biotechnology, 257(December 2016), 233-239. https://doi.org/10.1016/j.jbiotec.2017.06.410

Jones, S. K., \& Bennett, R. J. (2011). Fungal mating pheromones: Choreographing the dating game. Fungal Genetics and Biology, 48(7), 668-676. https://doi.org/10.1016/J.FGB.2011.04.001

Kaneko, I., Dementhon, K., Xiang, Q., \& Glass, N. L. (2006). Nonallelic interactions between het-c and a polymorphic locus, pin-c, are essential for nonself recognition and programmed cell death in Neurospora crassa. Genetics, 172(3), 1545-1555. https://doi.org/10.1534/genetics.105.051490

Kennedy, J., Auclair, K., Kendrew, S. G., Park, C., Vederas, J. C., \& Hutchinson, C. R. (1999). Modulation of polyketide synthase activity by accessory proteins during lovastatin biosynthesis. Science (New York, N.Y.), 284(5418), 1368-1372. https://doi.org/10.1126/science.284.5418.1368

Kothe, E. (2008). Sexual attraction: On the role of fungal pheromone/receptor systems (A review). Acta Microbiologica et Immunologica Hungarica, 55(2), 125-143. https://doi.org/10.1556/AMicr.55.2008.2.5

Kuhlman, L. (1978). The devastation of the American Chestnut by Blight. In W. L. MacDonald, F. Cech, J. Luchok, \& C. Smith (Eds.), Proceedings of the American Chestnut Symposium (pp. 1-3). West Virginia University Press.

Kumamoto, C. A. (2008). Molecular mechanisms of mechanosensing and their roles in fungal contact sensing. Nature Reviews Microbiology, 6(9), 667-673. https://doi.org/10.1038/nrmicro1960

Lai, Z., Tsugawa, H., Wohlgemuth, G., Mehta, S., Mueller, M., Zheng, Y., ... Fiehn, O. (2018). Identifying metabolites by integrating metabolome databases with mass spectrometry 
cheminformatics. Nature Methods, 15(1), 53-56. https://doi.org/10.1038/nmeth.4512

Lamacchia, M., Dyrka, W., Breton, A., Saupe, S. J., \& Paoletti, M. (2016). Overlapping Podospora anserina transcriptional responses to bacterial and fungal non self indicate a multilayered innate immune response. Frontiers in Microbiology. https://doi.org/10.3389/fmicb.2016.00471

Lauber, K., Bohn, E., Kröber, S. M., Xiao, Y., Blumenthal, S. G., Lindemann, R. K., ... Wesselborg, S. (2003). Apoptotic cells induce migration of phagocytes via caspase-3-mediated release of a lipid attraction signal. Cell, 113(6), 717-730. Retrieved from http://www.ncbi.nlm.nih.gov/pubmed/12809603

Leipe, D. D., Koonin, E. V., \& Aravind, L. (2004). STAND, a class of P-loop NTPases including animal and plant regulators of programmed cell death: Multiple, complex domain architectures, unusual phyletic patterns, and evolution by horizontal gene transfer. Journal of Molecular Biology, 343(1), 1-28. https://doi.org/10.1016/j.jmb.2004.08.023

Lorenz, R. T., \& Parks, L. W. (1990). Effects of lovastatin (mevinolin) on sterol levels and on activity of azoles in Saccharomyces cerevisiae. Antimicrobial Agents and Chemotherapy, 34(9), 1660-1665. https://doi.org/10.1128/aac.34.9.1660

Macreadie, I. G., Johnson, G., Schlosser, T., \& Macreadie, P. I. (2006). Growth inhibition of Candida species and Aspergillus fumigatus by statins. FEMS Microbiology Letters, 262(1), 9-13. https://doi.org/10.1111/j.1574-6968.2006.00370.x

Maheshwari, R. (2005). Nuclear behavior in fungal hyphae. FEMS Microbiology Letters, 249(1), 7-14. https://doi.org/10.1016/j.femsle.2005.06.031

McCarroll, D. R., \& Thor, E. (1985). Do “toxins" affect pathogenesis by Endothia parasitica? Physiological Plant Pathology, 26(3), 357-366. https://doi.org/10.1016/0048-4059(85)90010-4

Medzhitov, R., \& Janeway, C. a. (2002). Decoding the patterns of self and nonself by the innate immune system. Science (New York, N.Y.), 296(5566), 298-300. https://doi.org/10.1126/science.1068883

Micali, C. O., \& Smith, M. L. (2003). On the independence of barrage formation and heterokaryon incompatibility in Neurospora crassa. Fungal Genetics and Biology, 38(2), 209-219. https://doi.org/10.1016/S1087-1845(02)00533-9

Miyakawa, T., Nishihara, M., Tsuchiya, E., \& Fukui, S. (1982). Role of metabolism of the mating pheromone in sexual differentiation of the heterobasidiomycete Rhodosporidium toruloides. Journal of Bacteriology, 151(3), 1184-1194. Retrieved from http://www.ncbi.nlm.nih.gov/pubmed/7050081

Narvaez-Vasquez, J., Florin-Christensen, J., \& Ryan, C. A. (1999). Positional specificity of a phospholipase A activity induced by wounding, systemin, and oligosaccharide elicitors in tomato leaves. The Plant Cell, 11(11), 2249-2260. https://doi.org/10.1105/tpc.11.11.2249

Nuss, D. L. (2005). Hypovirulence: Mycoviruses at the fungal-plant interface. Nature Reviews Microbiology, 3(8), 632-642. https://doi.org/10.1038/nrmicro1206

Paoletti, M., \& Clavé, C. (2007). The fungus-specific HET domain mediates programmed cell death in Podosnora anserina. Eukaryotic Cell, 6(11), 2001-2008. https://doi.org/10.1128/EC.00129-07

Paoletti, Mathieu, \& Saupe, S. J. (2009). Fungal incompatibility: Evolutionary origin in pathogen defense? BioEssays, 31(11), 1201-1210. https://doi.org/10.1002/bies.200900085

Petersen, L. M., Hoeck, C., Frisvad, J. C., Gotfredsen, C. H., \& Larsen, T. O. (2014). Dereplication guided discovery of secondary metabolites of mixed biosynthetic origin from Aspergillus aculeatus. 
Molecules (Basel, Switzerland), 19(8), 10898-10921. https://doi.org/10.3390/molecules190810898

Philley, M. L., \& Staben, C. (1994). Functional analyses of the Neurospora crassa MT a-1 mating type polypeptide. Genetics, 137(3).

Polke, M., Leonhardt, I., Kurzai, O., \& Jacobsen, I. D. (2018). Farnesol signalling in Candida albicans more than just communication. Critical Reviews in Microbiology, 44(2), 230-243. https://doi.org/10.1080/1040841X.2017.1337711

Ripp, S. L., Overby, L. H., Philpot, R. M., \& Elfarra, A. A. (1997). Oxidation of Cysteine S-Conjugates by Rabbit Liver Microsomes and cDNA-Expressed Flavin-Containing Mono-oxygenases: Studies with S-(1,2-Dichlorovinyl)-cysteine. Molecular Pharmacology, 51(3), 507 LP - 515. Retrieved from http://molpharm.aspetjournals.org/content/51/3/507.abstract

Roper, M., Simonin, A., Hickey, P. C., Leeder, A., \& Glass, N. L. (2013). Nuclear dynamics in a fungal chimera. Proceedings of the National Academy of Sciences, 110(32), 12875-12880. https://doi.org/10.1073/pnas.1220842110

Sapperstein, S., Berkower, C., \& Michaelis, S. (1994). Nucleotide sequence of the yeast STE14 gene, which encodes farnesylcysteine carboxyl methyltransferase, and demonstration of its essential role in a-factor export. Molecular and Cellular Biology, 14(2), 1438-1449. https://doi.org/10.1128/mcb.14.2.1438

Saupe, S., Descamps, C., Turcq, B., \& Bégueret, J. (1994). Inactivation of the Podospora anserina vegetative incompatibility locus het-c, whose product resembles a glycolipid transfer protein, drastically impairs ascospore production. Proceedings of the National Academy of Sciences of the United States of America, 91(13), 5927-5931. https://doi.org/10.1073/pnas.91.13.5927

Saupe, S J. (2000). Molecular genetics of heterokaryon incompatibility in filamentous ascomycetes. Microbiology and Molecular Biology Reviews : MMBR, 64(3), 489-502. https://doi.org/10.1128/mmbr.64.3.489-502.2000

Saupe, Sven J., Kuldau, G. A., Smith, M. L., \& Glass, N. L. (1996). The Product of the het-C Heterokaryon Incompatibility Gene of Neurospora crassa Has Characteristics of a Glycine-Rich Cell Wall Protein. Genetics, 143(4).

Schafer, W. R., \& Rine, J. (1992). Protein Prenylation: Genes, Enzymes, Targets, and Functions. Annual Review of Genetics, 26(1), 209-237. https://doi.org/10.1146/annurev.ge.26.120192.001233

Semighini, C. P., Hornby, J. M., Dumitru, R., Nickerson, K. W., \& Harris, S. D. (2006). Farnesol-induced apoptosis in Aspergillus nidulans reveals a possible mechanism for antagonistic interactions between fungi. Molecular Microbiology, 59(3), 753-764. https://doi.org/10.1111/j.13652958.2005.04976.x

Shibata, S. (1973). Some recent studies on the metabolites of fungi and lichens. Pure and Applied Chemistry, 33(1), 109-128. https://doi.org/10.1351/pac197333010109

Shibata, Shoji, Murakami, T., Tanaka, O., Chihara, G., Kitagawa, I., Sumimoto, M., \& Kaneko, C. (1955). The Respective Identities of Endothianin and Radicalisin with Skyrin and Rugulosin : and the Structure of Skyrin. Pharmaceutical Bulletin, 3(2), 160-161.

https://doi.org/10.1248/cpb1953.3.160

Shibata, Shoji, Takido, M., Ohta, A., \& Kurosu, T. (1957). Metabolic Products of Fungi. XIII. The Structure of Oxyskyrin. Pharmaceutical Bulletin, 5(6), 573-575.

https://doi.org/10.1248/cpb1953.5.573 
Shiu, P. K. T., \& Glass, N. L. (1999). Molecular Characterization of tol, a Mediator of Mating-TypeAssociated Vegetative Incompatibility in Neurospora crassa. Genetics, 151(2), 545-555.

Simonin, A., Palma-Guerrero, J., Fricker, M., \& Louise Glass, N. (2012). Physiological significance of network organization in fungi. Eukaryotic Cell, 11(11), 1345-1352.

https://doi.org/10.1128/EC.00213-12

Smith, M. L., Micali, O. C., Hubbard, S. P., Mir-Rashed, N., Jacobson, D. J., \& Glass, N. L. (2000). Vegetative incompatibility in the het- 6 region of Neuospora crassa is mediated by two linked genes. Genetics.

Smith, Myron L., \& Lafontaine, D. L. (2013). The Fungal Sense of Non-self. In Neurospora: Genomics and Molecular Biology (pp. 9-21). Horizon Scientific Press.

Somia, N. V, Schmitt, M. J., Vetter, D. E., Van Antwerp, D., Heinemann, S. F., \& Verma, I. M. (1999). LFG: an anti-apoptotic gene that provides protection from Fas-mediated cell death. Proceedings of the National Academy of Sciences of the United States of America, 96(22), 12667-12672. https://doi.org/10.1073/pnas.96.22.12667

Spencer, J. F. T., Gorin, P. A. J., \& Tulloch, A. P. (1970). Torulopsis bombicola sp. n. Antonie van Leeuwenhoek, 36(1), 129-133. https://doi.org/10.1007/BF02069014

Srinivas, G., Babykutty, S., Sathiadevan, P. P., \& Srinivas, P. (2007). Molecular mechanism of emodin action: Transition from laxative ingredient to an antitumor agent. Medicinal Research Reviews, 27(5), 591-608. https://doi.org/10.1002/med.20095

Stauder, C. M., Nuss, D. L., Zhang, D.-X., Double, M. L., MacDonald, W. L., Metheny, A. M., \& Kasson, M. T. (2019). Enhanced hypovirus transmission by engineered super donor strains of the chestnut blight fungus, Cryphonectria parasitica, into a natural population of strains exhibiting diverse vegetative compatibility genotypes. Virology, 528, 1-6. https://doi.org/10.1016/j.virol.2018.12.007

Stewart, M., Capon, R. J., Lacey, E., Tennant, S., \& Gill, J. H. (2005). Calbistrin E and two other new metabolites from an Australian isolate of Penicillium striatisporum. Journal of Natural Products, 68(4), 581-584. https://doi.org/10.1021/np049614y

Stotzler, D., Kiltz, H. -H, \& Duntze, W. (1976). Primary Structure of $\alpha$-Factor Peptides from Saccharomyces cerevisiae. European Journal of Biochemistry, 69(2), 397-400. https://doi.org/10.1111/j.1432-1033.1976.tb10923.x

Sullivan, M. J., Petty, N. K., \& Beatson, S. A. (2011). Easyfig: a genome comparison visualizer. Bioinformatics (Oxford, England), 27(7), 1009-1010. https://doi.org/10.1093/bioinformatics/btr039

Tulloch, A. P., Hill, A., \& Spencer, J. F. T. (1968). Structure and reactions of lactonic and acidic sophorosides of 17-hydroxyoctadecanoic acid. Canadian Journal of Chemistry, 46(21), 3337-3351. https://doi.org/10.1139/v68-551

Van Bogaert, I. N. A., Holvoet, K., Roelants, S. L. K. W., Li, B., Lin, Y. C., Van de Peer, Y., \& Soetaert, W. (2013). The biosynthetic gene cluster for sophorolipids: A biotechnological interesting biosurfactant produced by Starmerella bombicola. Molecular Microbiology, 88(3), 501-509. https://doi.org/10.1111/mmi.12200

Van Den Bosch, H. (1980). Intracellular phospholipases A. Biochimica et Biophysica Acta (BBA) Biomembranes, 604(2), 191-246. https://doi.org/10.1016/0005-2736(80)90574-X

Vargas, F., Rivas, C., Zoltan, T., López, V., Ortega, J., Izzo, C., ... Rosales, L. (2008). Antioxidant and 
scavenging activity of skyrin on free radical and some reactive oxygen species. 3(1), 7-14.

Retrieved from www.saber.ula.ve/avancesenquimica

Viehweger, K., Dordschbal, B., Roos, W., Lein, W., \& Roos, W. (2002). Elicitor-Activated

Phospholipase $\mathrm{A}_{2}$ Generates Lysophosphatidylcholines That Mobilize the Vacuolar $\mathrm{H}^{+}$Pool for $\mathrm{pH}$ Signaling via the Activation of $\mathrm{Na}^{+}$-Dependent Proton Fluxes. The Plant Cell, 14(7), 1509-1525. https://doi.org/10.1105/tpc.002329

Walsh, C. T. (2004). Polyketide and nonribosomal peptide antibiotics: modularity and versatility. Science (New York, N.Y.), 303(5665), 1805-1810. https://doi.org/10.1126/science.1094318

Wang, L., Radu, C. G., Yang, L. V, Bentolila, L. A., Riedinger, M., \& Witte, O. N. (2005).

Lysophosphatidylcholine-induced surface redistribution regulates signaling of the murine $\mathrm{G}$ proteincoupled receptor G2A. Molecular Biology of the Cell, 16(5), 2234-2247.

https://doi.org/10.1091/mbc.e04-12-1044

Wang, M., Carver, J. J., Phelan, V. V, Sanchez, L. M., Garg, N., Peng, Y., ... Bandeira, N. (2016). Sharing and community curation of mass spectrometry data with Global Natural Products Social Molecular Networking. Nature Biotechnology, 34(8), 828-837. https://doi.org/10.1038/nbt.3597

Wijesekera, K., Mahidol, C., Ruchirawat, S., \& Kittakoop, P. (2017). Metabolite diversification by cultivation of the endophytic fungus Dothideomycete sp. in halogen containing media: Cultivation of terrestrial fungus in seawater. Bioorganic and Medicinal Chemistry, 25(11), 2868-2877. https://doi.org/10.1016/j.bmc.2017.03.040

Xia, J., \& Wishart, D. S. (2016). Using MetaboAnalyst 3.0 for Comprehensive Metabolomics Data Analysis. Current Protocols in Bioinformatics, 55(1), 14.10.1-14.10.91. https://doi.org/10.1002/cpbi.11

Xue, C., Hsueh, Y.-P., \& Heitman, J. (2008). Magnificent seven: roles of G protein-coupled receptors in extracellular sensing in fungi. FEMS Microbiology Reviews, 32(6), 1010-1032. https://doi.org/10.1111/j.1574-6976.2008.00131.x

Yanagi, Y., Nakata, M., \& Suzuki, N. (2011). Selective Inhibition of Viral RNA Transcription by Skyrin. Journal of Pesticide Science, 1(2), 107-114. https://doi.org/10.1584/jpestics.1.107

Yokoyama, M., Hirayama, Y., Yamamoto, T., Kishimoto, S., Tsunematsu, Y., \& Watanabe, K. (2017). Integration of Chemical, Genetic, and Bioinformatic Approaches Delineates Fungal PolyketidePeptide Hybrid Biosynthesis. Organic Letters, 19(8), 2002-2005.

https://doi.org/10.1021/acs.orglett.7b00559

Zhang, D.-X., Spiering, M. J., Dawe, A. L., Nuss, D. L., Jacobson, D. J., \& Glass, N. L. (2014). Vegetative incompatibility loci with dedicated roles in allorecognition restrict mycovirus transmission in chestnut blight fungus. Genetics, 197(2), 701-714. https://doi.org/10.1534/genetics.114.164574

Zhang, D. X., Spiering, M. J., Dawe, A. L., \& Nuss, D. L. (2014). Vegetative incompatibility loci with dedicated roles in allorecognition restrict mycovirus transmission in chestnut blight fungus. Genetics, 197(2), 701-714. https://doi.org/10.1534/genetics.114.164574

Zhang, L., Baasiri, R. A., \& Van Alfen, N. K. (1998). Viral repression of fungal pheromone precursor gene expression. Molecular and Cellular Biology, 18(2), 953-959.

https://doi.org/10.1128/mcb.18.2.953

Zhang, L., Churchill, A. C., Kazmierczak, P., Kim, D. H., \& Van Alfen, N. K. (1993). Hypovirulenceassociated traits induced by a mycovirus of Cryphonectria parasitica are mimicked by targeted 
inactivation of a host gene. Molecular and Cellular Biology, 13(12), 7782-7792.

https://doi.org/10.1128/mcb.13.12.7782

Zhuravleva, O. I., Afiyatullov, S. S., Vishchuk, O. S., Denisenko, V. A., Slinkina, N. N., \& Smetanina, O. F. (2012). Decumbenone C, a new cytotoxic decaline derivative from the marine fungus Aspergillus sulphureus KMM 4640. Archives of Pharmacal Research, 35(10), 1757-1762.

https://doi.org/10.1007/s12272-012-1007-9 